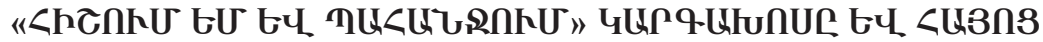

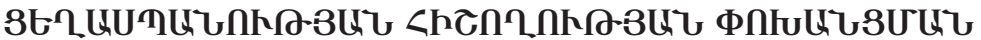

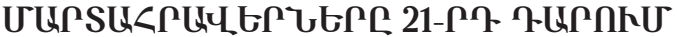

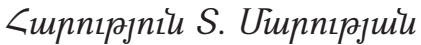

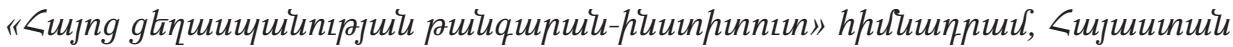

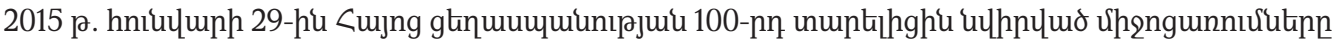

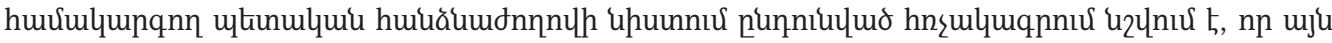

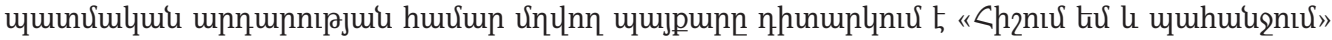

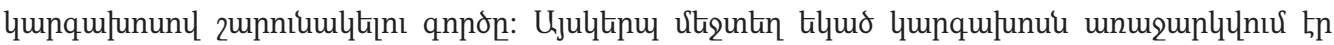

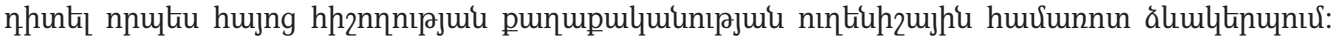

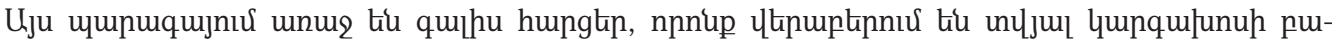

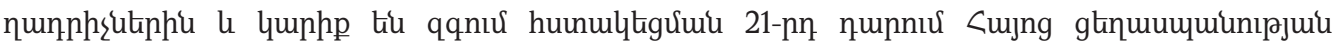

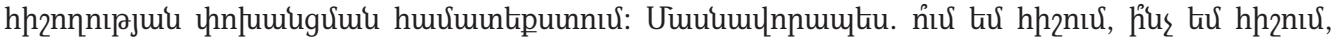

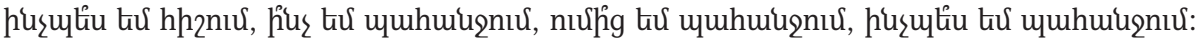

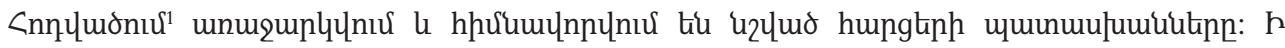

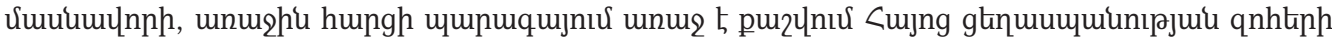

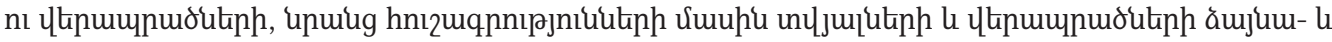

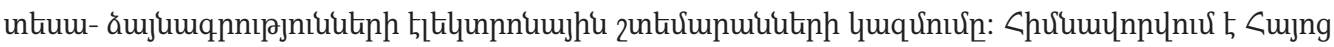

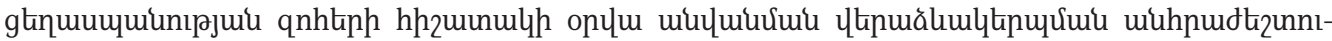

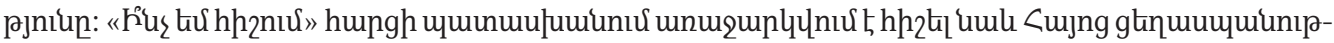

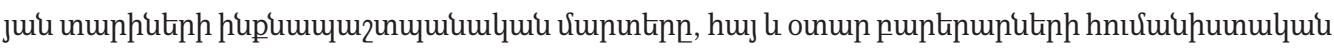

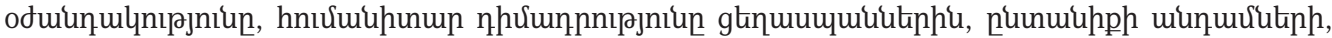

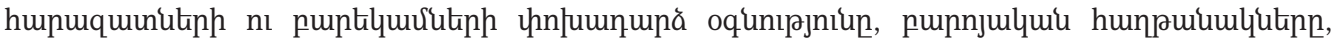

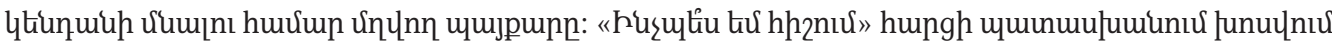

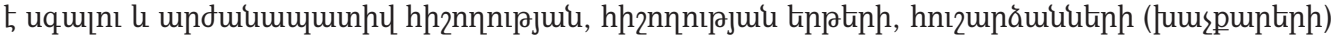

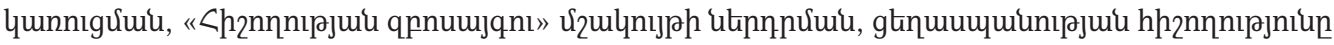

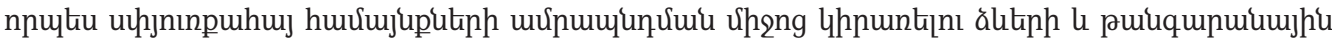

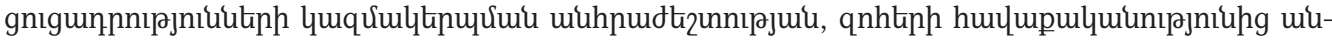

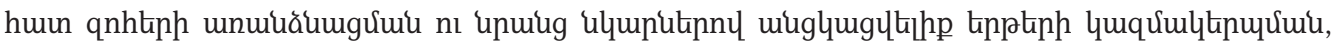

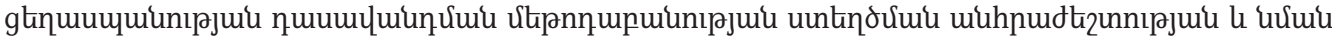
ujl Juinhputiph Uumuhu:

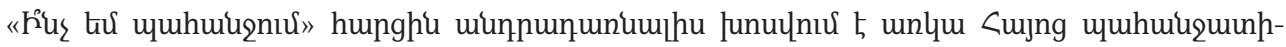

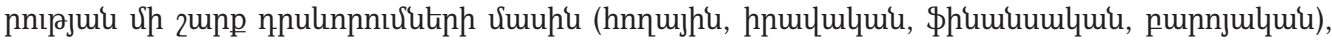

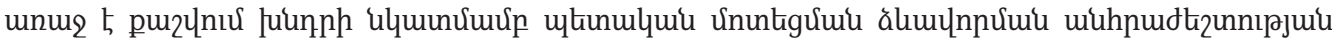

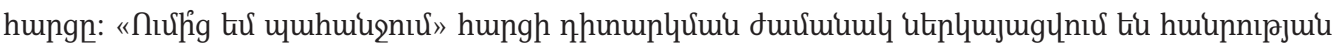

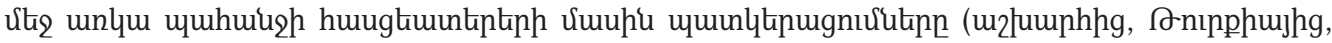

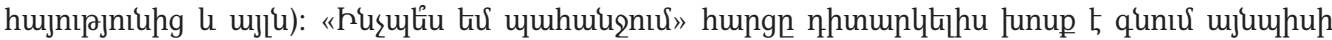

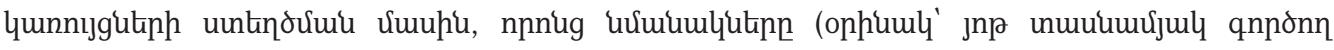

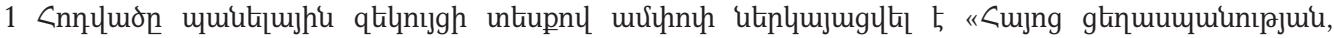

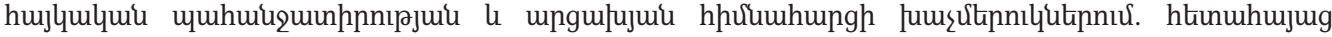

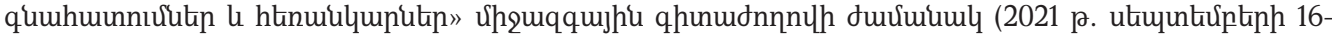
18, Gplumu, <8קh hpưumpuu, $<<$ qUU): 


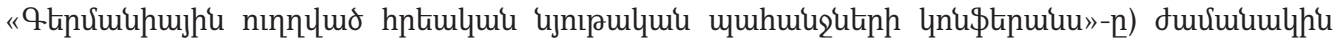

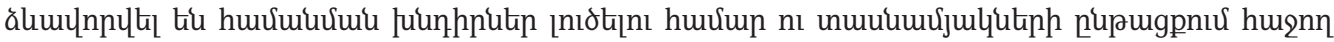

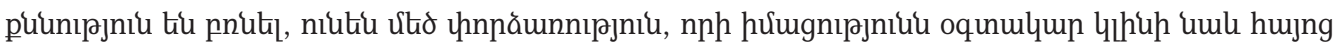
huvuup:

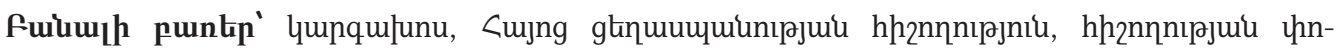

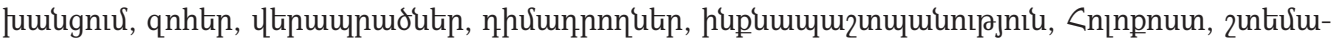
nuiu, Łnџnıрјniu:

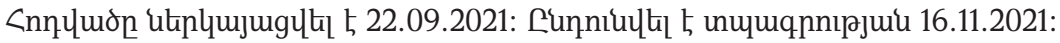

The article was submitted on 22.09.2021 and accepted for publication on 16.11.2021.

Статья поступила 22.09.2021 и была принята к публикации 16.11.2021.

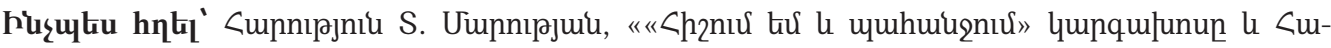

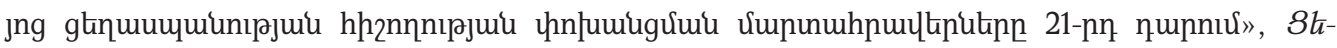

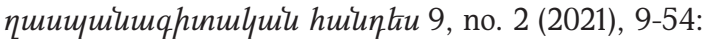

How to cite: Harutyun T. Marutyan, "The Motto 'I Remember and Demand' and the Challenges of Transmission of the Armenian Genocide Memory in the 21 $1^{\text {st }}$ Century,"

TS'eghaspanagitakan handes 9, no. 2 (2021): 9-54.

Как ссылаться: Арутюн Т. Марутян, “Девиз “Помню и требую” и вызовы 21-го века, связанные с передачей памяти о Геноциде армян,” Тсехаспанагитакан андес 9, по. 2 (2021): 9-54.

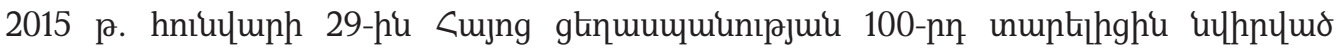

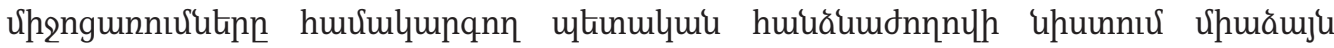

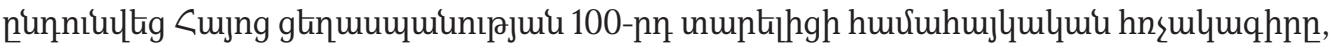

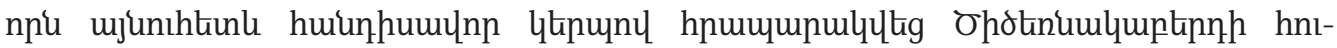

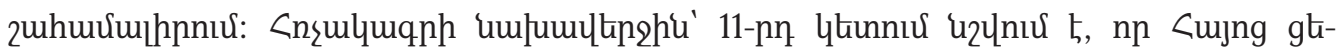

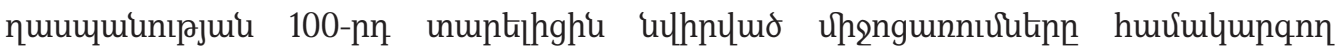

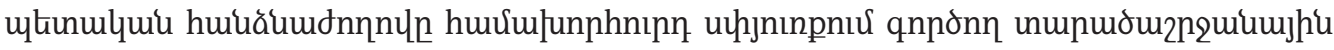

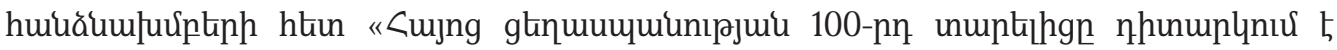

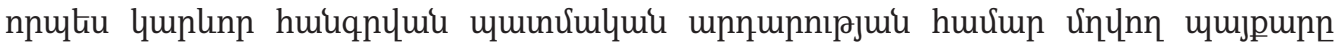

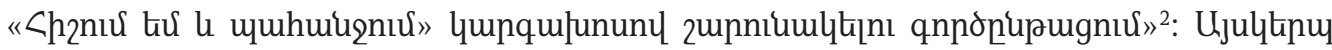

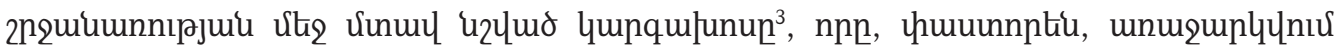

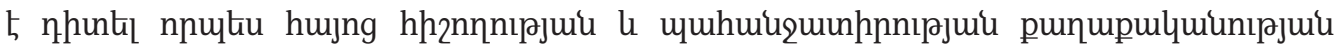

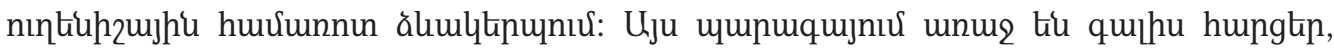

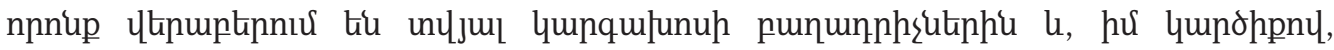

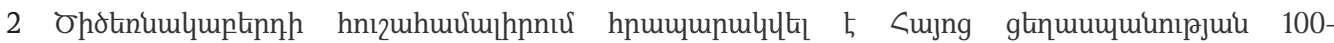

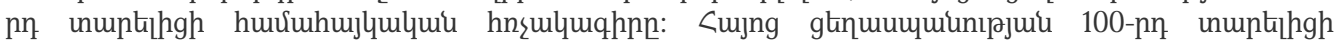
huúuhujlquluiu hnধulumqhn, http://www.president.am/hy/press-release/item/2015/01/29/PresidentSerzh-Sargsyan-visit-Tsitsernakaberd-Genocide/, nhunцli 5 t 20.09.2021:

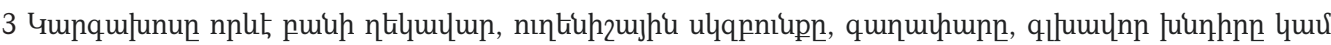

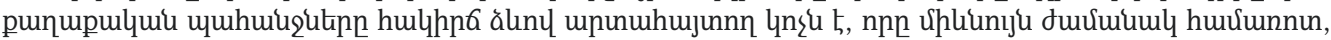

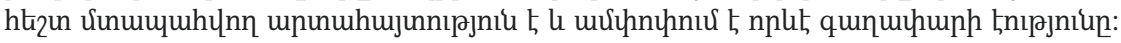




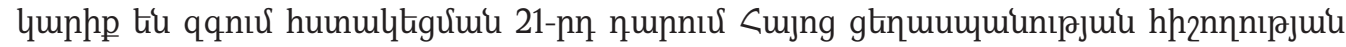

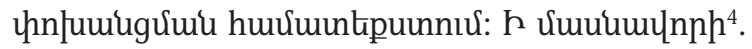

- nou tư hhrniu,

- híuz kư hhrnuर,

- husultiu tư hrznứ,

- hír tư uquhuugnứu,

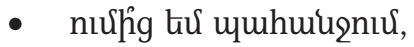

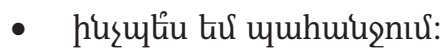

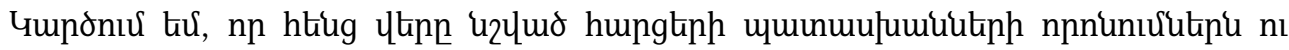

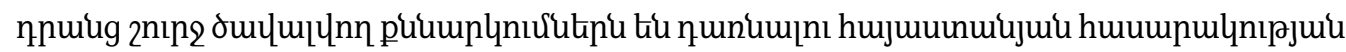

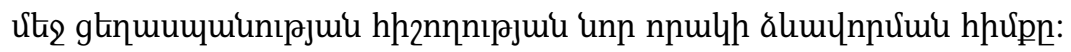

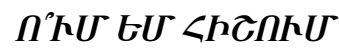

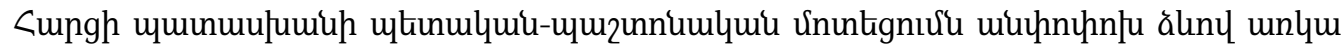

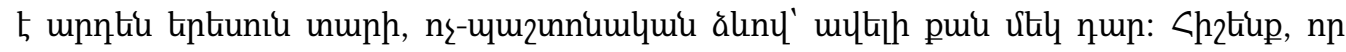

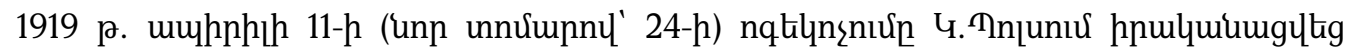

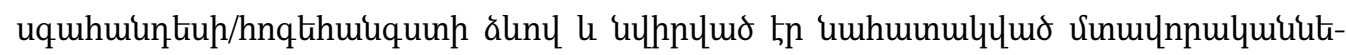

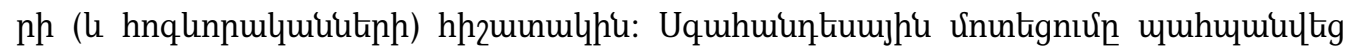

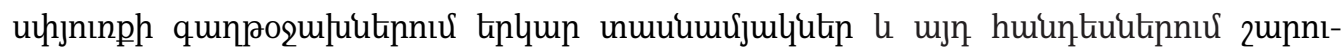

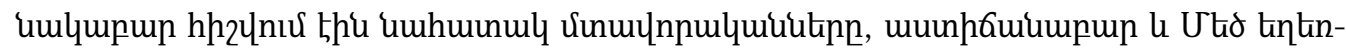

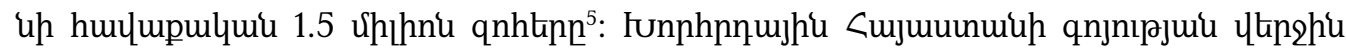

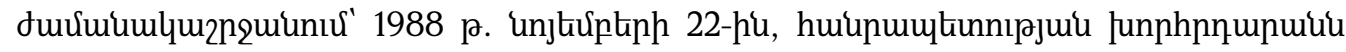

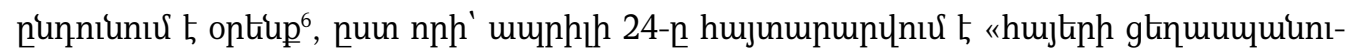

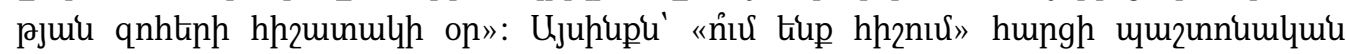

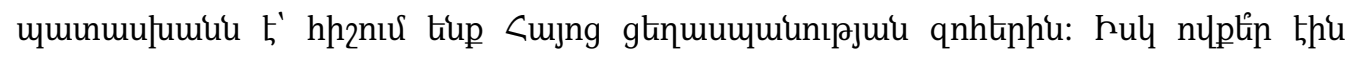

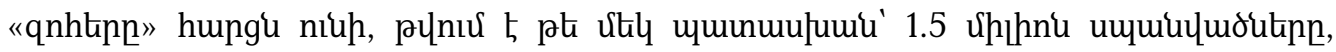

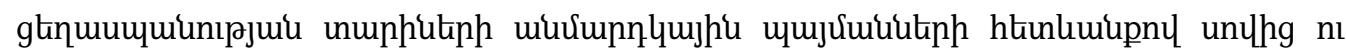

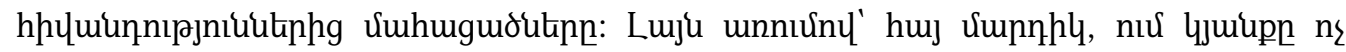

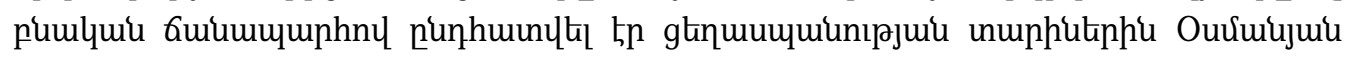

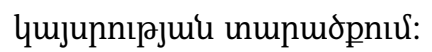

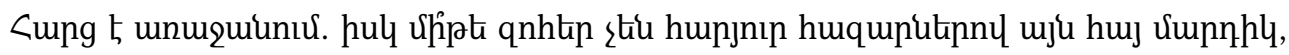

4 Lungunnưuu Uumuhu unt'u umu' Harutyun Marutyan, "The Armenian Genocide and the Jewish Holocaust: Trauma and Its Influence on Identity Changes of Survivors and Their Descendants," in Armenian and Jewish Experience between Expulsion and Destruction, eds. Sarah M. Ross and Regina Randhofer (Berlin: De Gruyter Oldenbourg, 2021), 187, doi: 10.1515/9783110695403-010

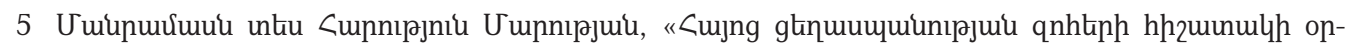

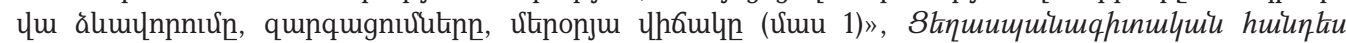

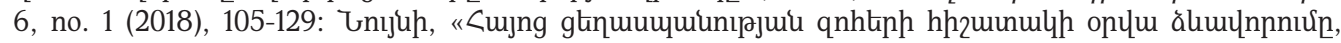

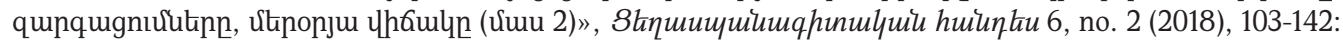

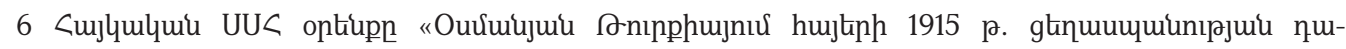

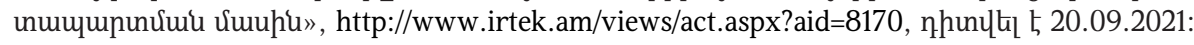




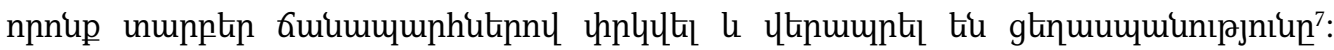

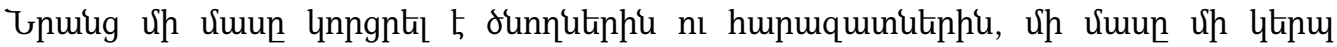

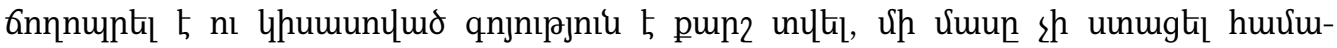

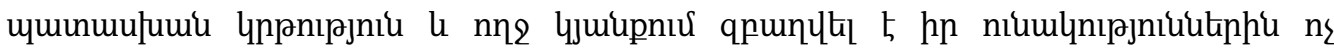

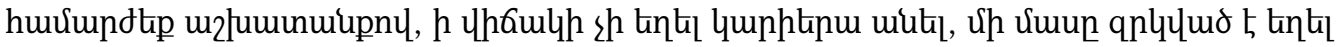

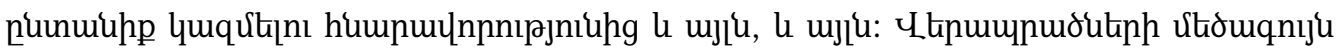

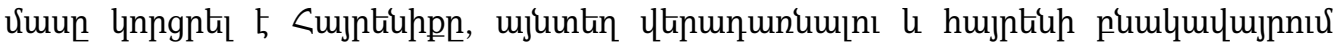

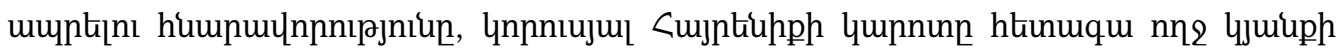

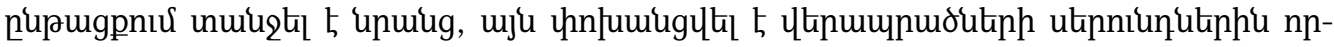

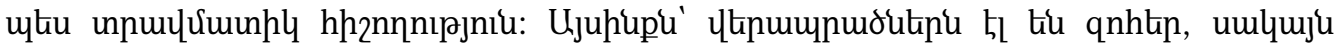

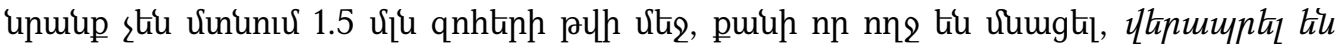
gtnuuщumunıрjnikn:

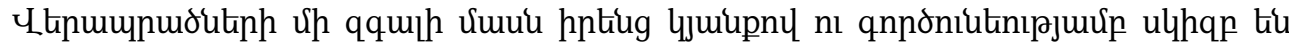

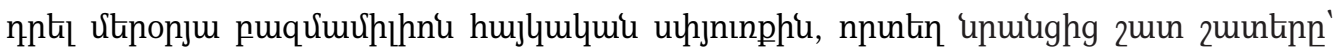

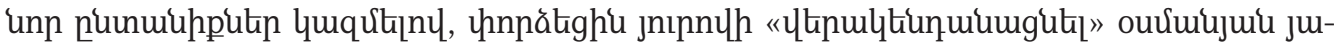

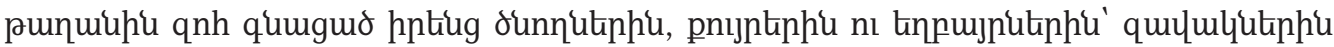

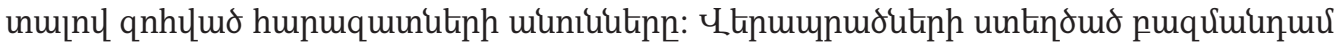

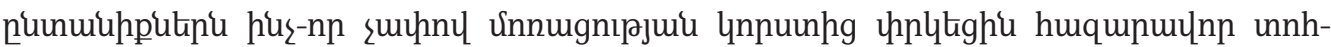

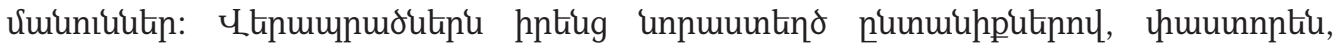

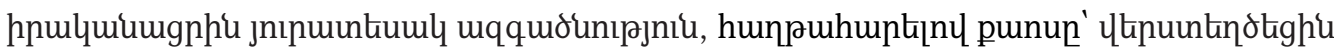

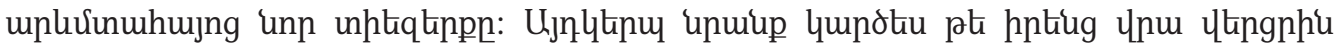

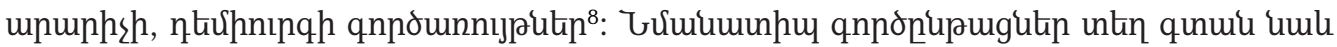
Unlitıjui <ujumunminnı:

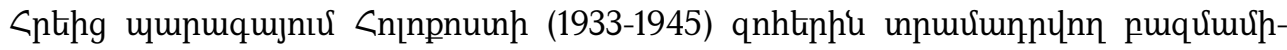

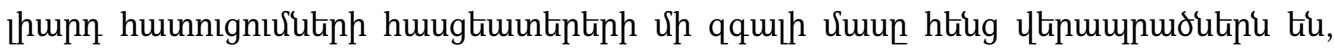

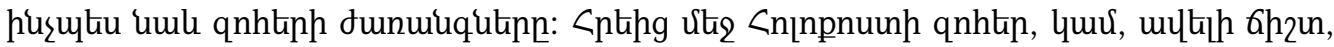

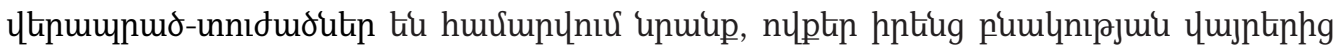

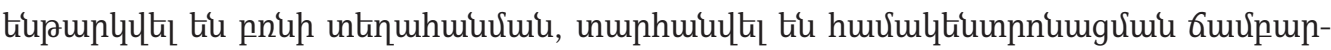

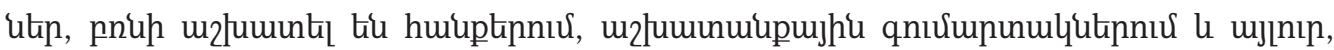

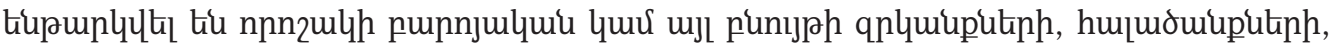

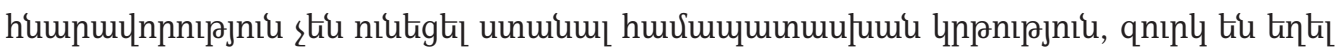

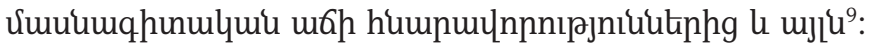

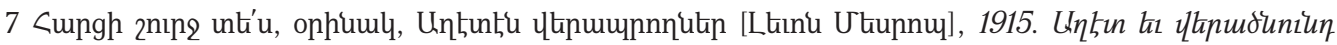
(Фunhq, Unupu, 1952); Donald E. Miller and Lorna Touryan Miller, Survivors: An Oral History of the Armenian Genocide (Berkeley, Los Angeles, London: University of California Press, 1993); Utupdhut

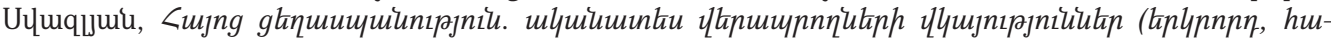

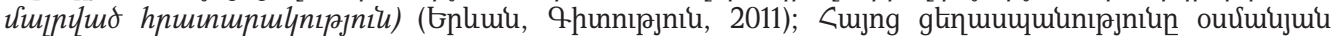

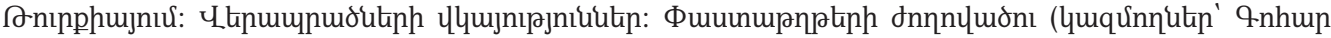

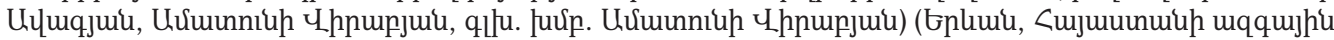
unpupl, h. 1-3, 2012):

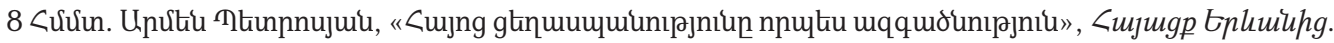
hмјшqһпмиціи 4 (1997), 50-51:

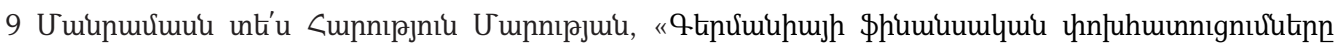




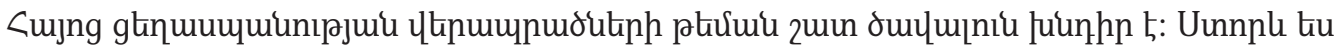

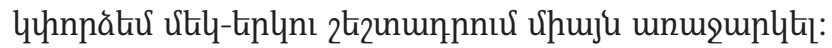

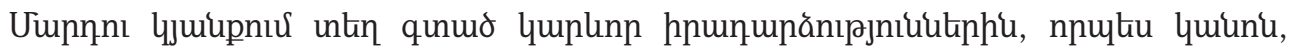

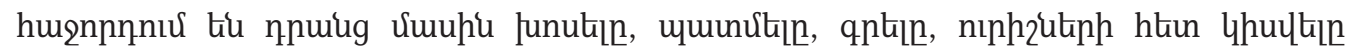

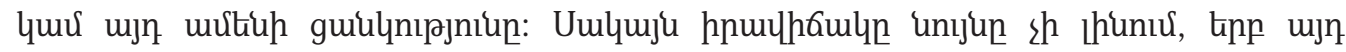

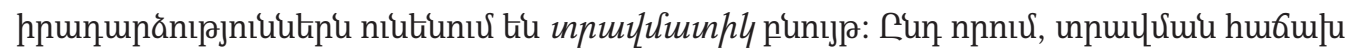

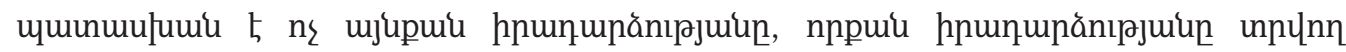

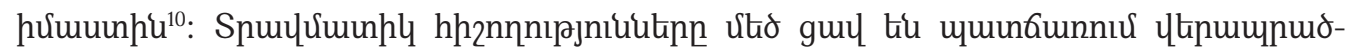

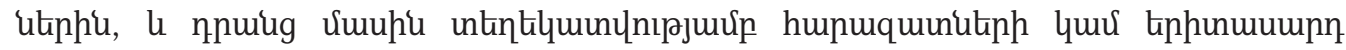

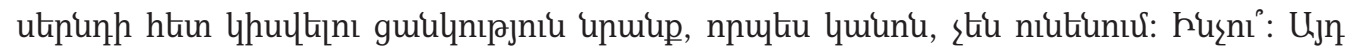

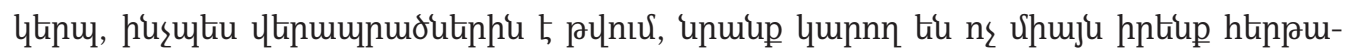

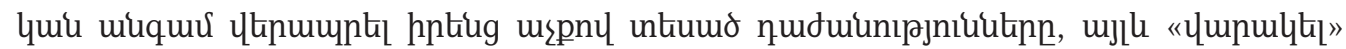

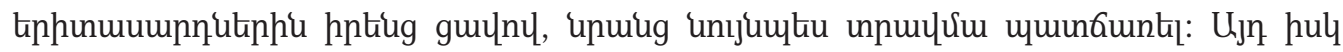

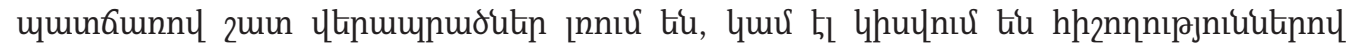

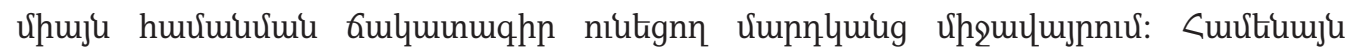

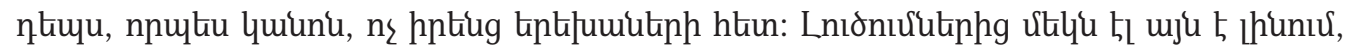

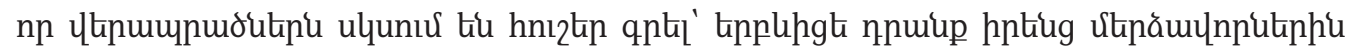

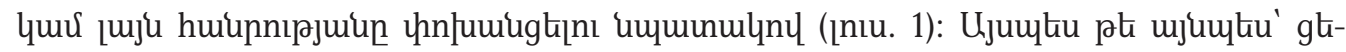

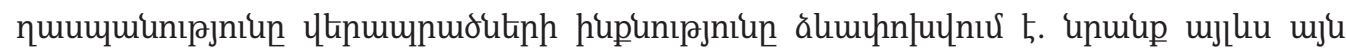

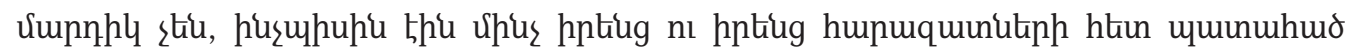

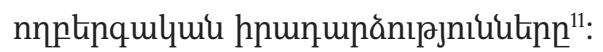

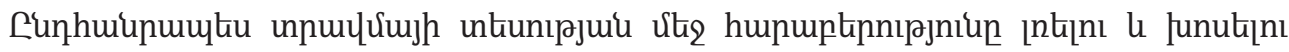

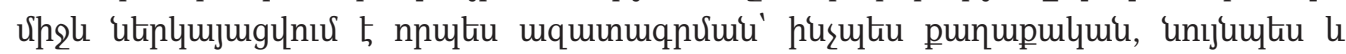

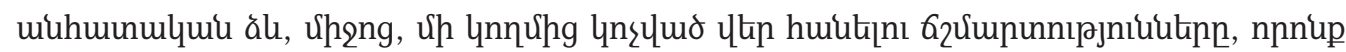

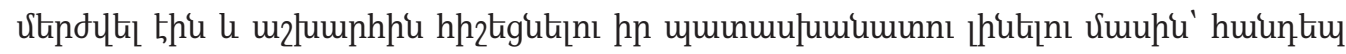

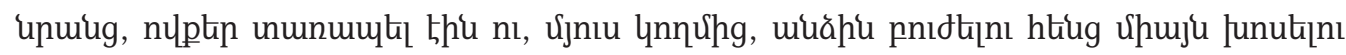

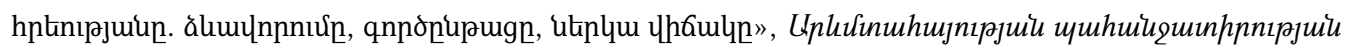

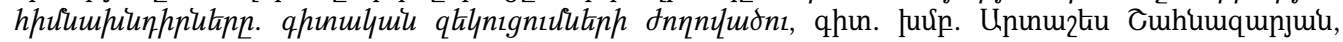

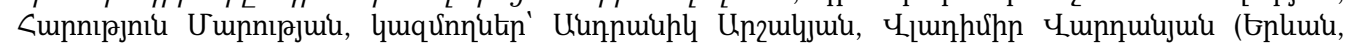

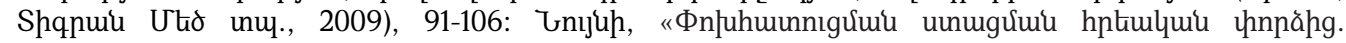

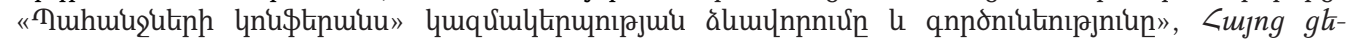

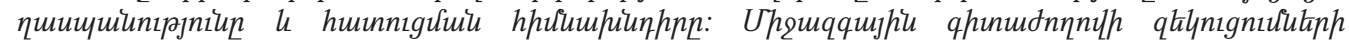

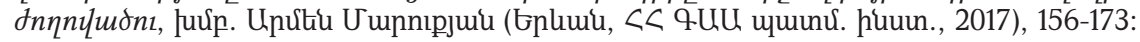

10 Katharine Hodgkin and Susannah Radstone, "Remembering Suffering: Trauma and History: Introduction," in Contested Pasts: The Politics of Memory, ed. Katharine Hodgkin and Susannah Radstone (London and New York: Routledge, 2003), 97.

11 Harutyun Marutyan, "The Armenian Genocide and the Jewish Holocaust: Trauma and Its Influence on Identity Changes of Survivors and Their Descendants," 181. Cungh 2ning untu uul. Cunnıpjniu

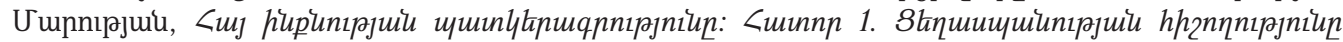

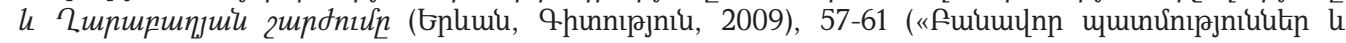

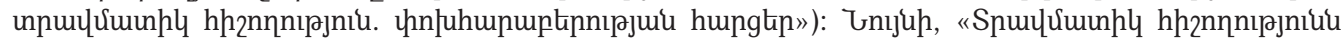

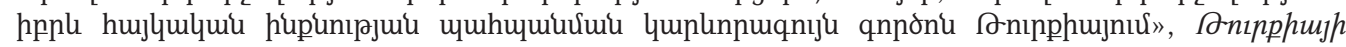

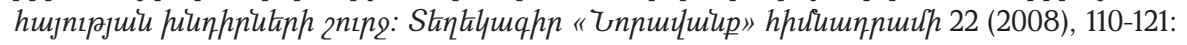




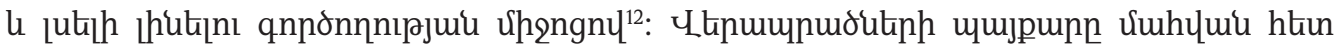

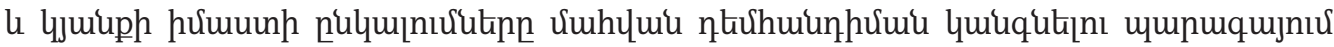

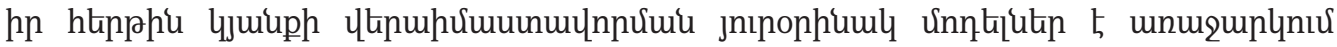

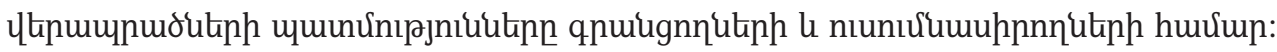

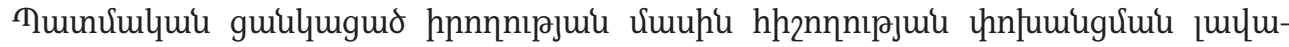

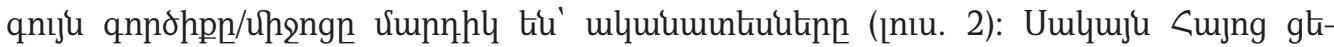

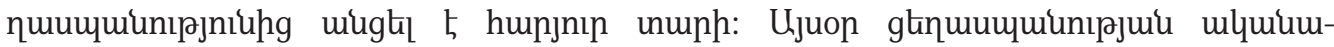

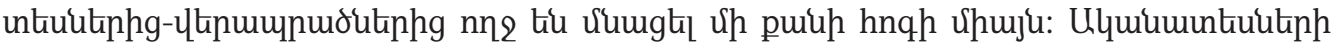

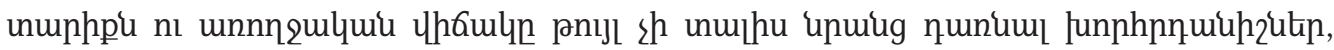

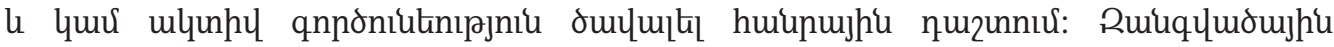

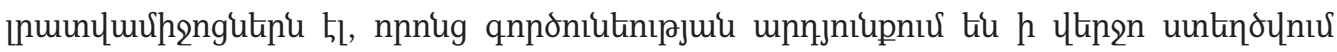

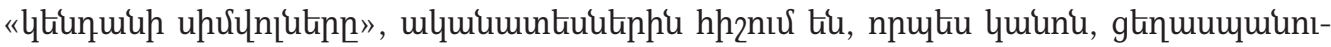

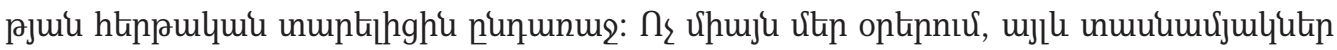

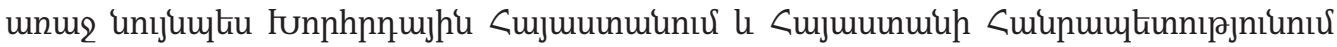

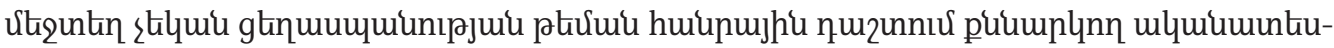

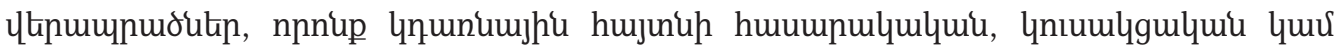

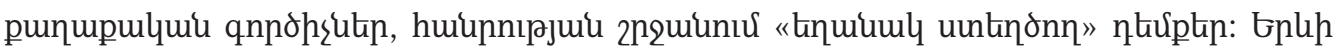

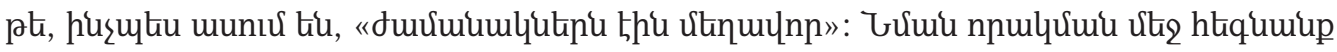

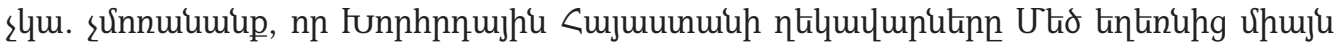

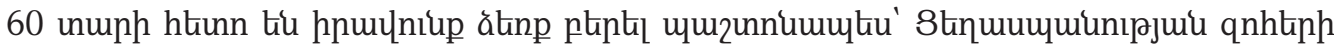

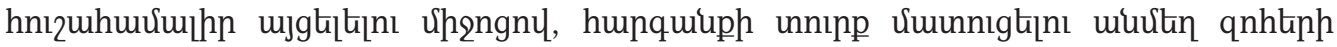

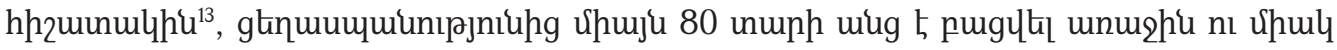

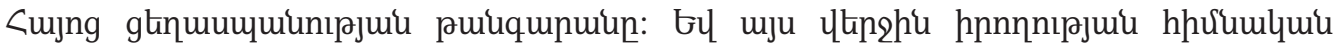

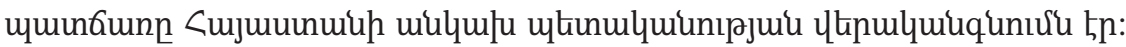

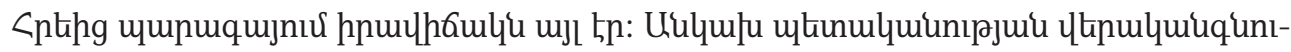

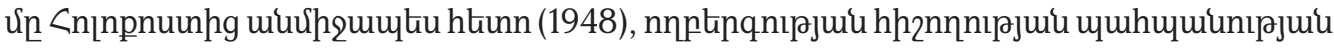

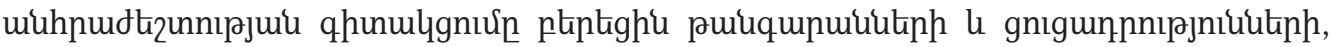

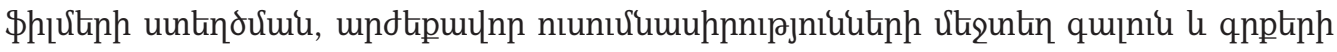

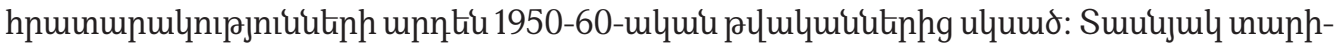

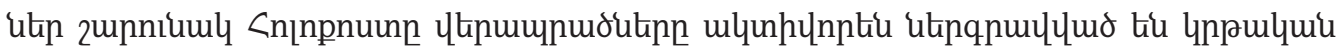

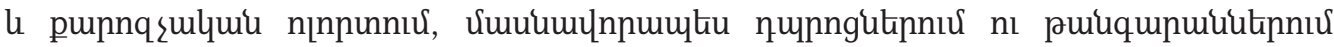

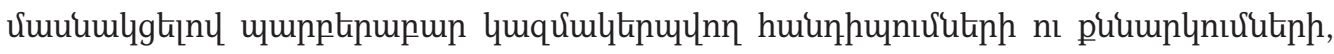

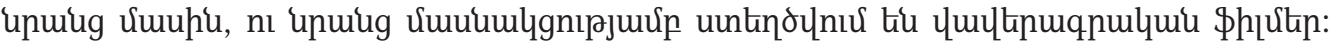

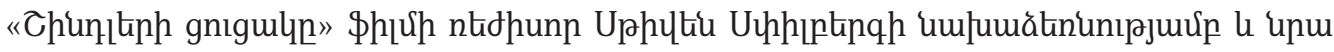

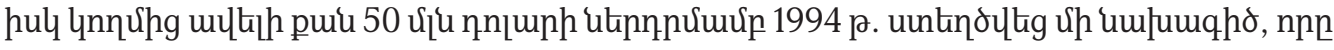

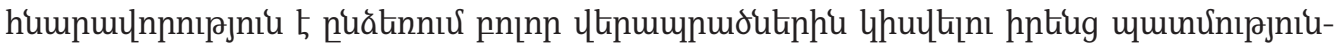

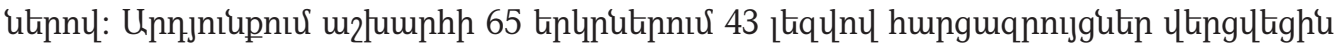

12 Hodgkin and Radstone, "Remembering Suffering," 97-103.

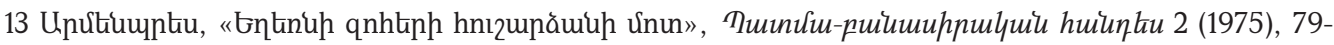
80: 


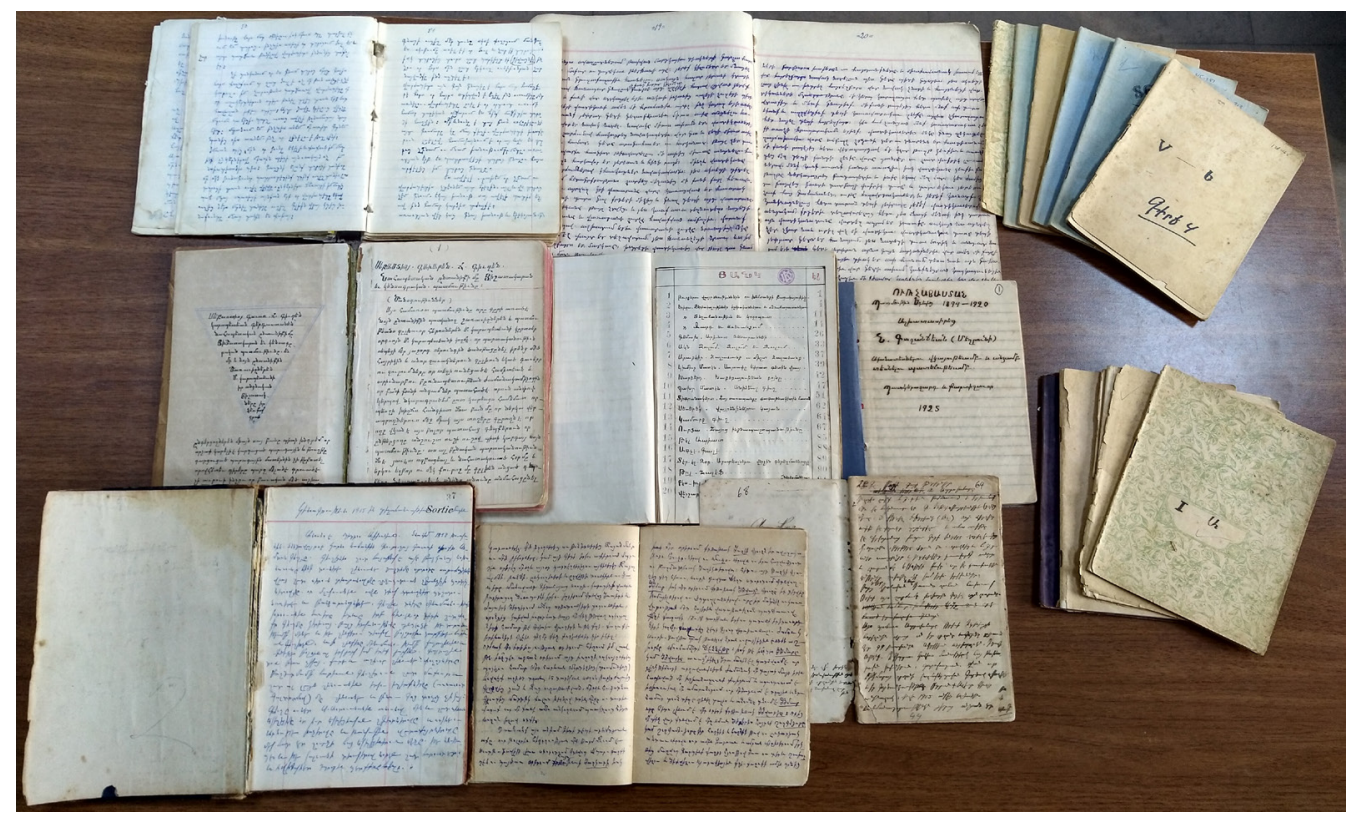

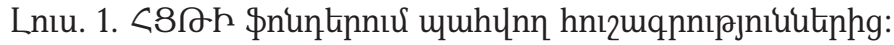

Lnıu-n' <. Uunnıpjuuh:

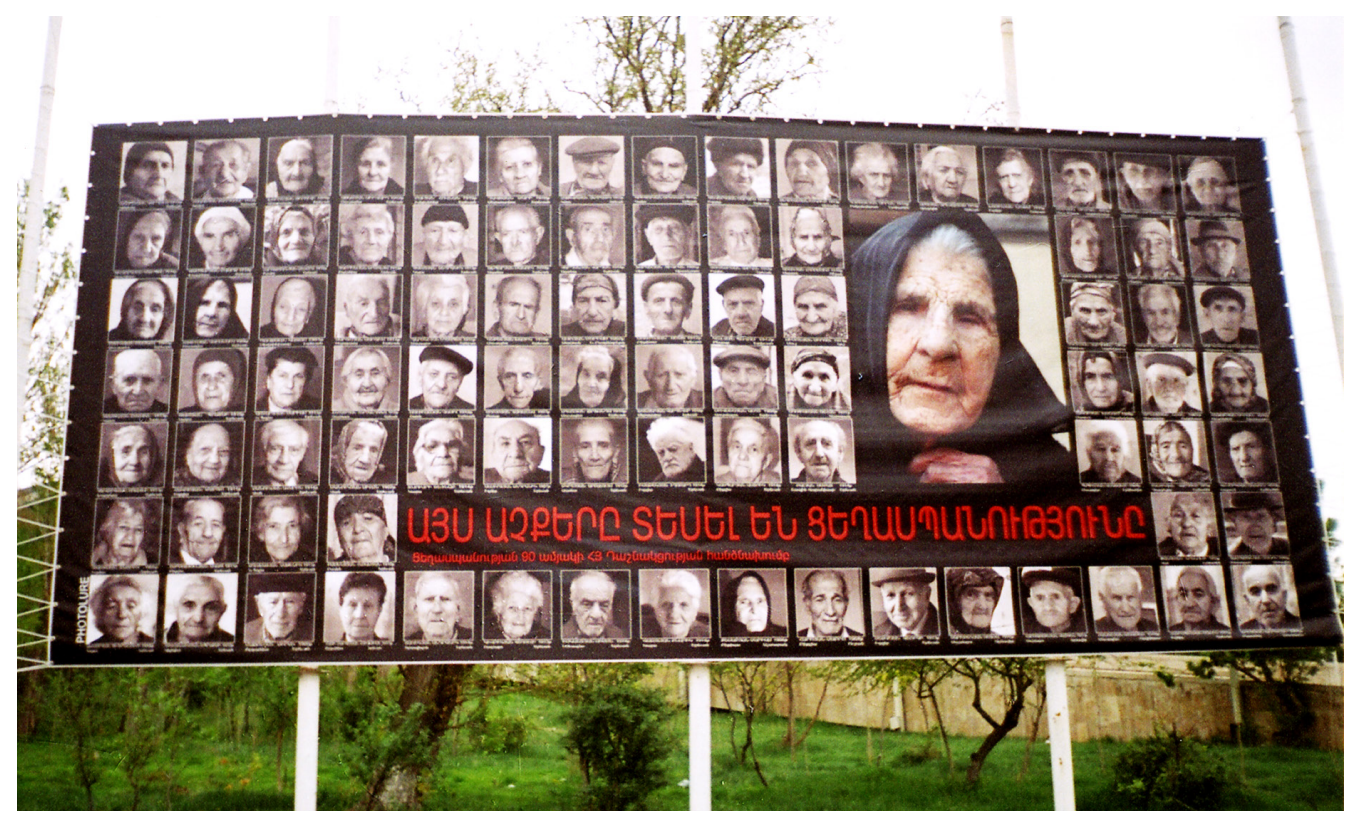

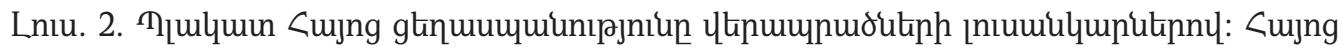

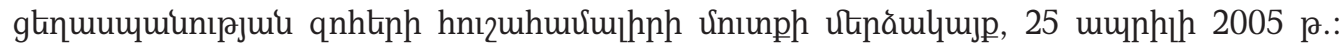
Lnıu-n' <. Uumnıpjuin: 


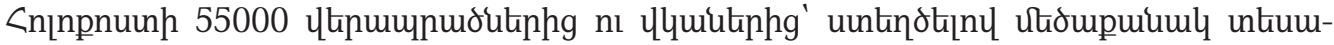

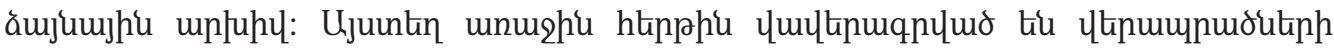

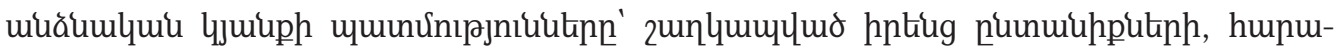

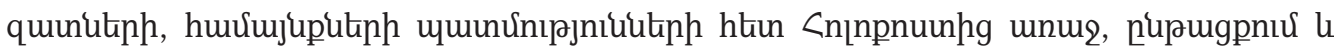

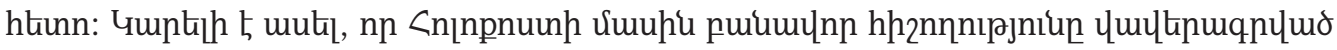

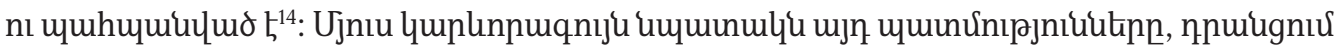

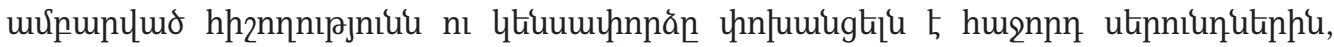

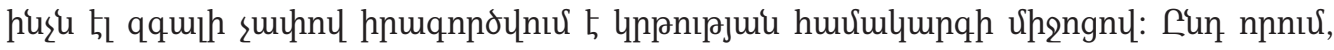

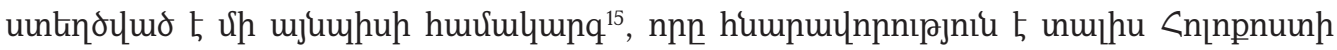

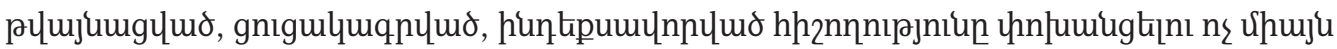

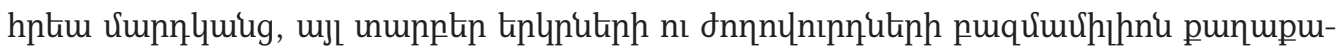
ghutiphu:

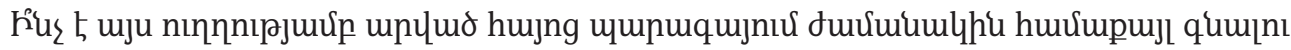

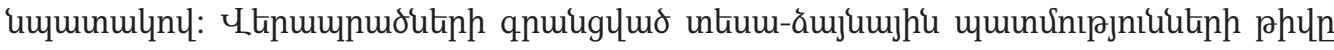

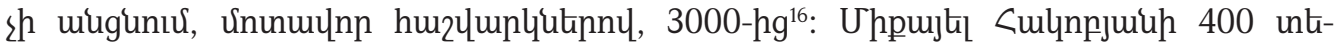

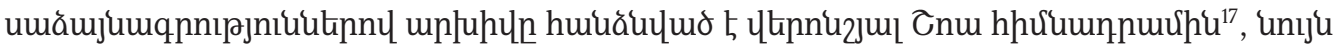

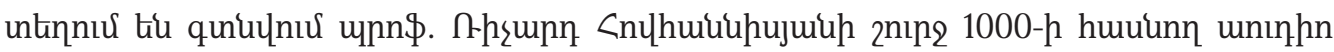

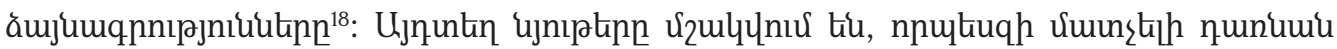

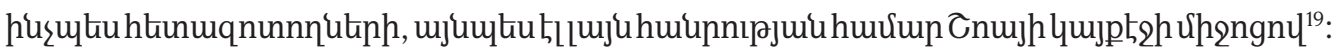

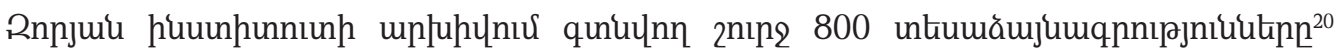

14 Umunưumui unt'u https://sfi.usc.edu/what-we-do/collections, nhunltıl 5 20.09.2021:

15 Uuunuuरuuu unt'u https://iwitness.usc.edu/home, nhunцli 5 20.09.2021:

16 Uumpuruuu untíu Gerard J. Libaridian, "Summary of a Survey on Collections of Video and Audio Recorded Testimonies of Survivors of the Armenian Genocide," http://entriessas.com/research-guides/ testimonies/, nhunцlı 5 20.09.2021:

17 Armenian Film Foundation Delivers 400 Digitized Testimonies to USC Shoah Foundation, http://asbarez. com/122212/armenian-film-foundation-delivers-400-digitized-testimonies-to-usc-shoah-foundation/, 23 April 2014. USC Armenian Studies to Salute Shoah Foundation for Genocide Digitization Project, http://asbarez. com/100703/usc-armenian-studies-to-salute-shoah-foundation-for-genocide-digitization-project/: funut]nu

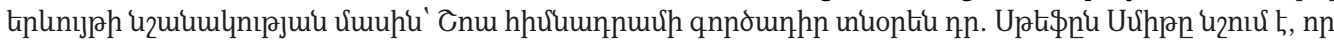

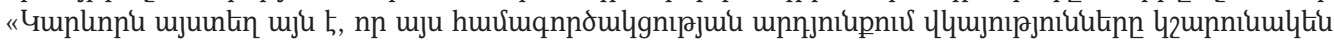

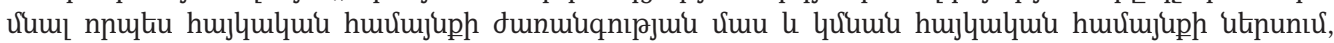

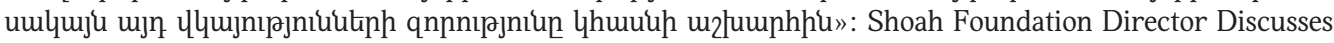
Digitization of Armenian Survivor Testimonies, http://asbarez.com/102344/shoah-foundation-directordiscusses-digitization-of-armenian-survivor-testimonies/, 13 April 2012, nhunltㅣ 5 20.09.2021:

18 https://sfi.usc.edu/content/hovannisian-collection-body-text; The Richard Hovannisian Oral History Collection at the Shoah Foundation, https://massispost.com/2019/03/the-richard-hovannisian-oral-history-

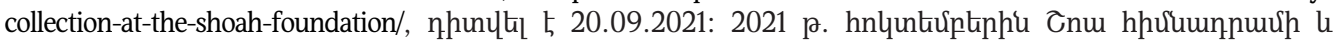

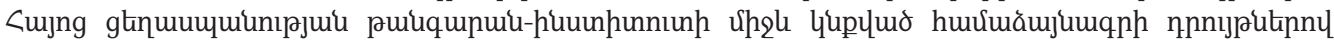

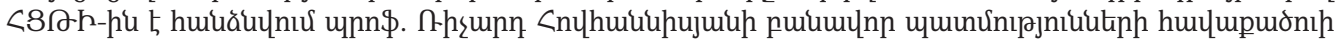

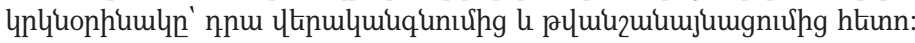

19 St'u ophuml http://iwitness1915.org/survivors-2/, nhunltul 5 20.09.2021:

20 K.M. Greg Sarkissian and George Shirinian, Description of the Oral History Collection at the Zoryan Institute, an expanded version of a presentation made at the "International Conference on Armenian 


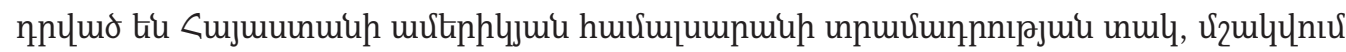

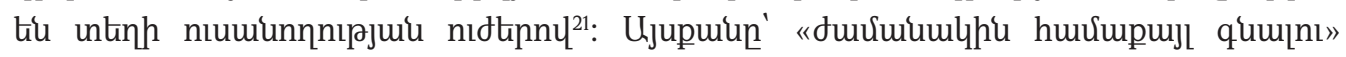

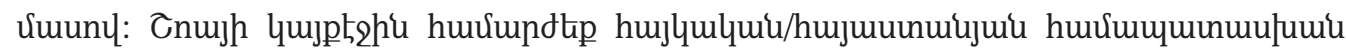

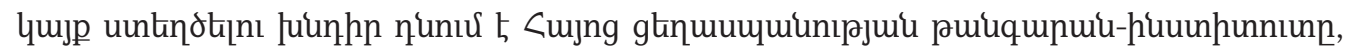

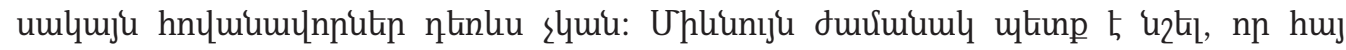

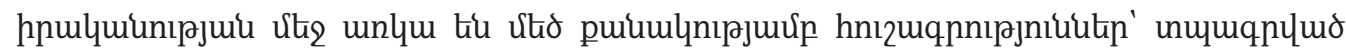

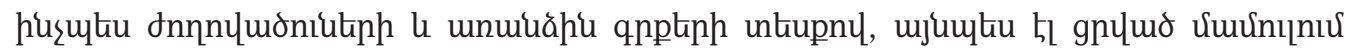

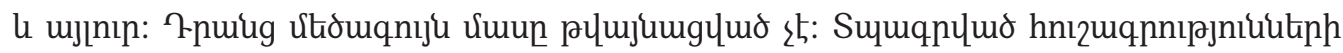

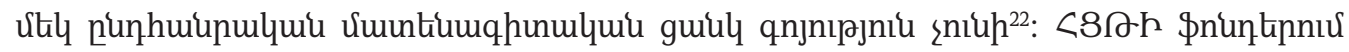

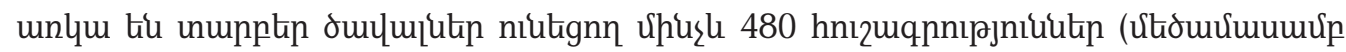

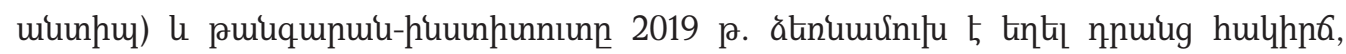

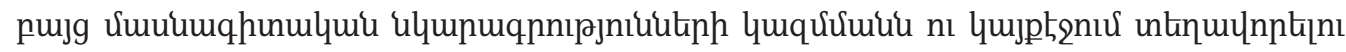

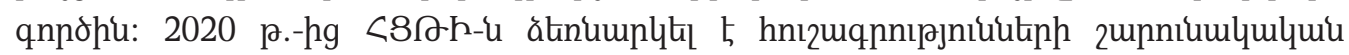

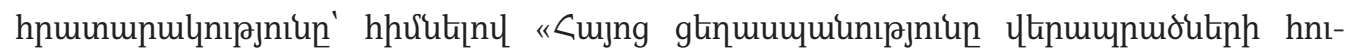

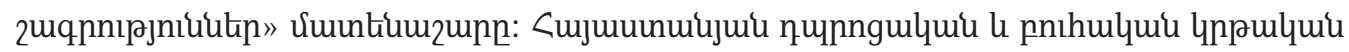

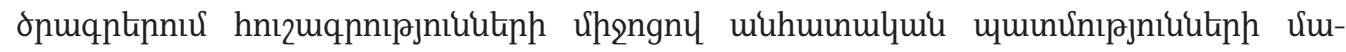

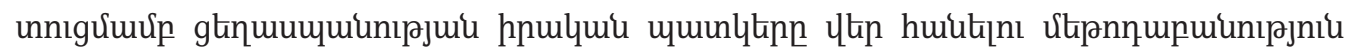
ntinluu qnjnıрjniu sniuh:

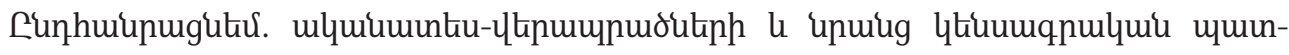

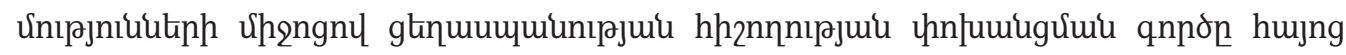

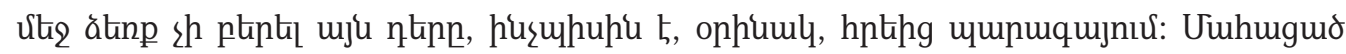

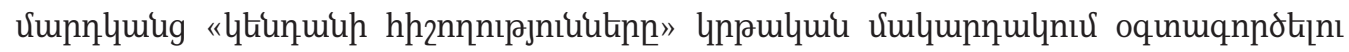
hungn unıjuuktu jning wutihputp niuh:

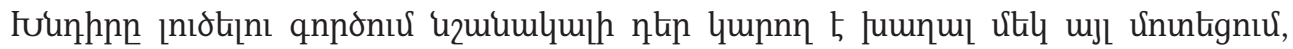

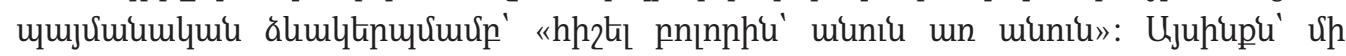

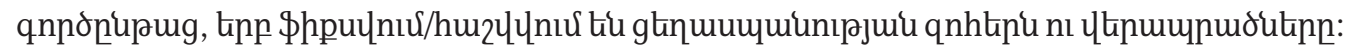

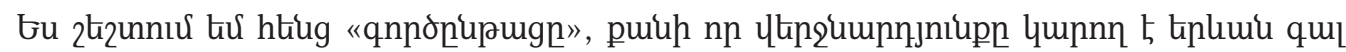

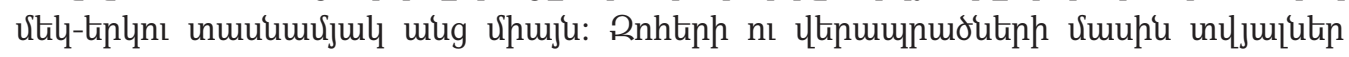

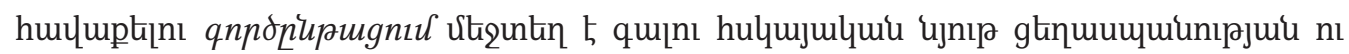

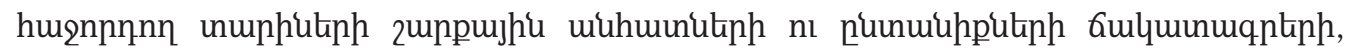

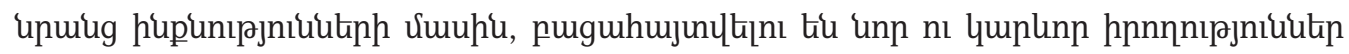

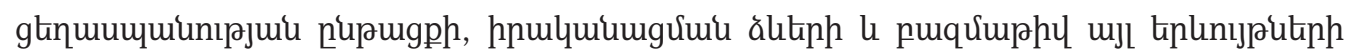

Genocide Oral History Collections in North America: Development, Utilization, Potential," held at the University of California-Los Angeles, 2 April 2011, https://zoryaninstitute.org/wp-content/uploads/2017/04/ oral-history-overview.pdf, nhunltul 5 20.09.2021:

21 The Zoryan Institute, American University of Armenia Launch New Center for Oral History, https:// armenianweekly.com/2019/05/21/the-zoryan-institute-american-university-of-armenia-launch-new-centerfor-oral-history/, nhunцt 5 20.09.2021:

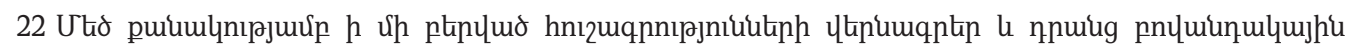

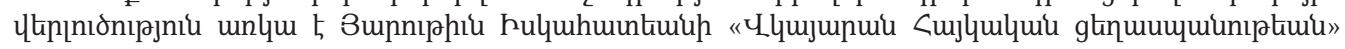

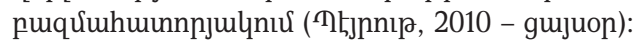




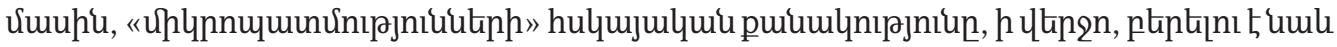

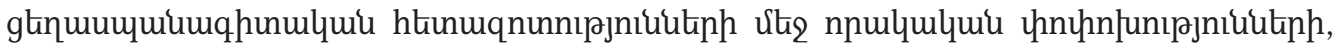

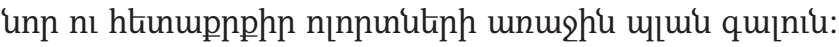

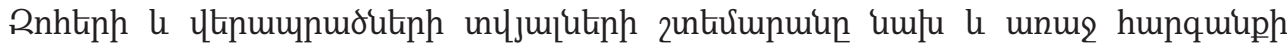

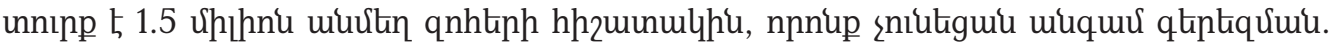

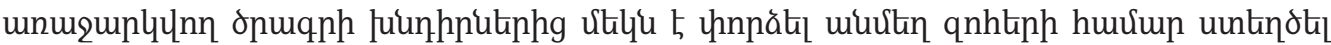

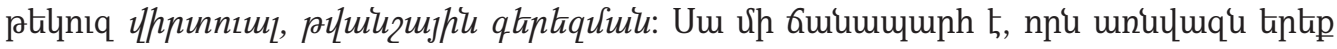

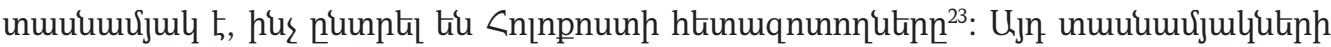

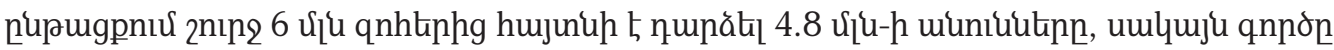

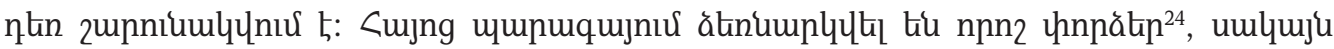

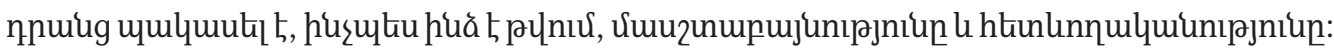

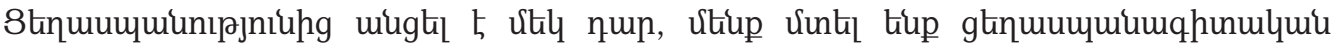

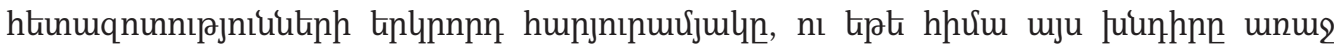

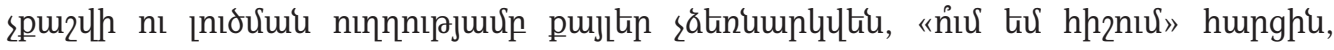

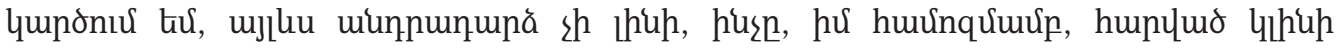

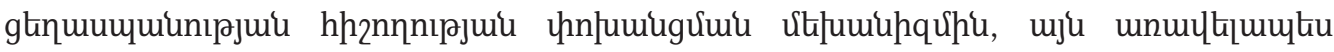

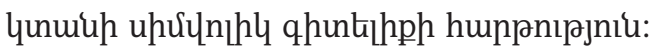

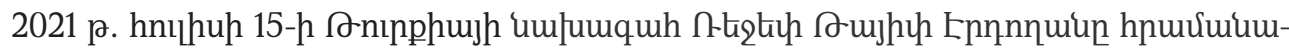

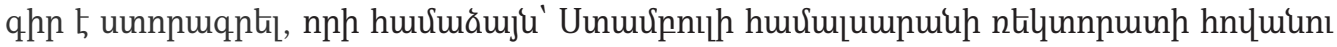

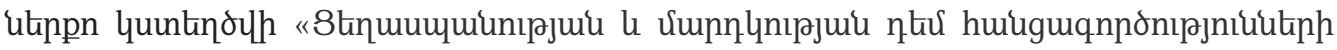

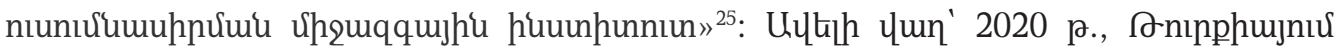

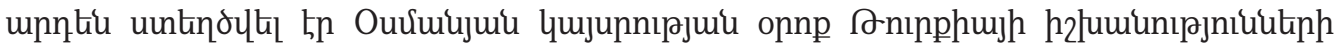

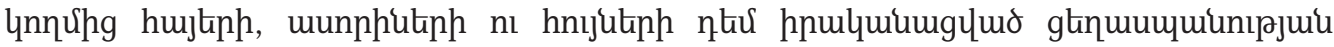

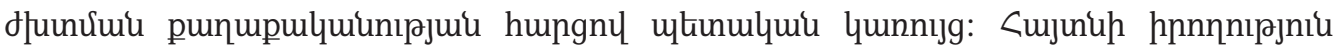

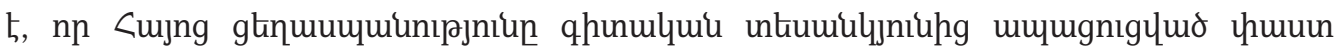

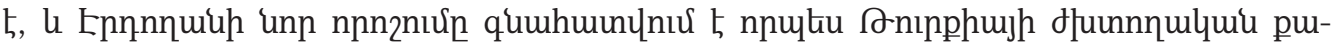

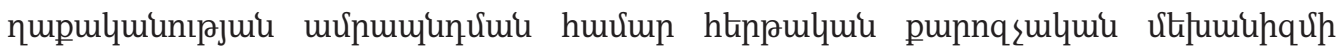

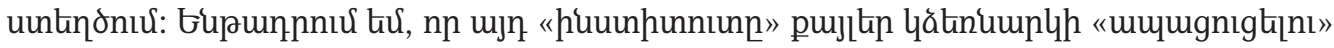

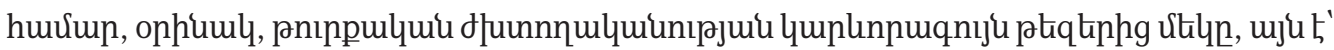

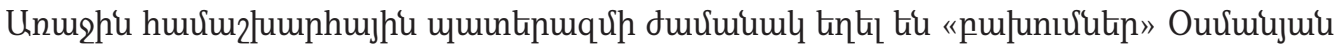

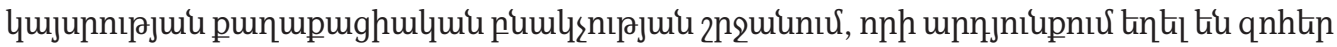

23 Uuunuúuuu unt'u Database of Holocaust Survivor and Victim Names, https://www.ushmm.org/ remember/resources-holocaust-survivors-victims/database-of-holocaust-survivor-and-victim-names, nhunlthl 5 20.09.2021:

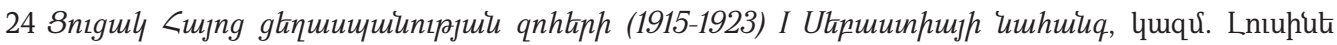

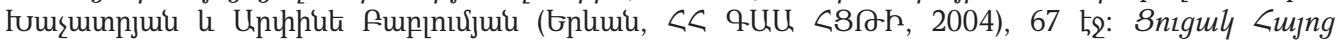

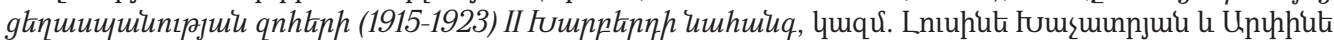

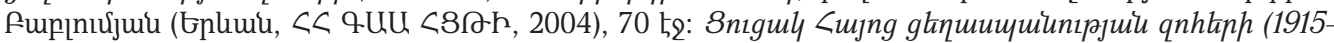

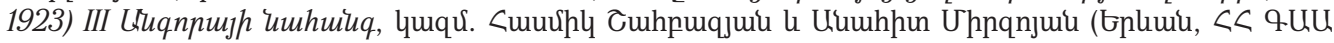
<8คh, 2006), 52 t2:

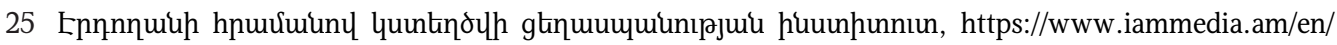
post/recognize-armenian-genocide-15-7, nhunlthl 5 20.09.2021: 


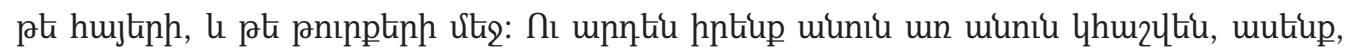

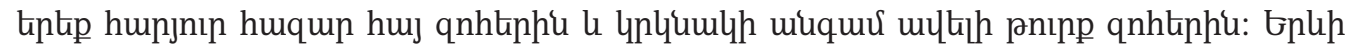

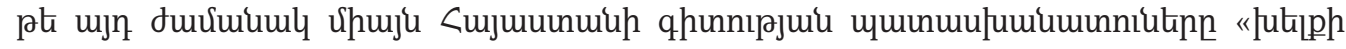

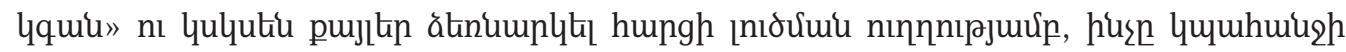

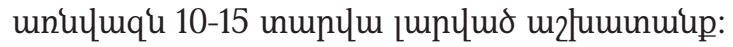

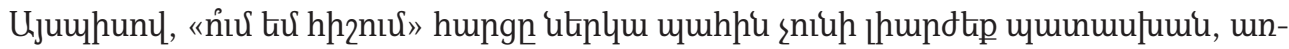

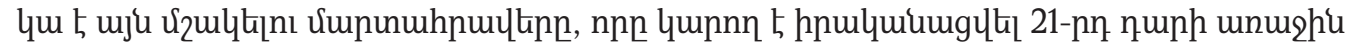

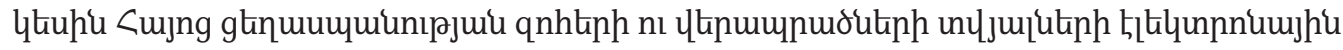

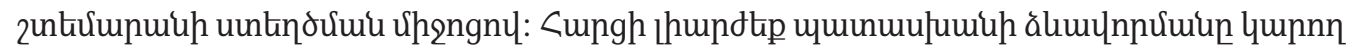

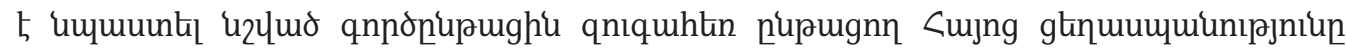

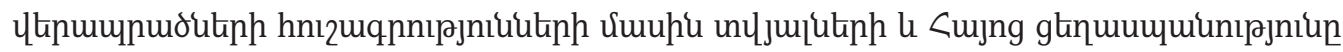

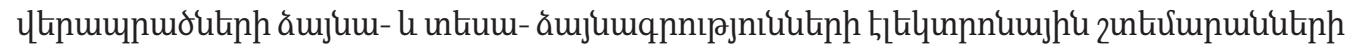

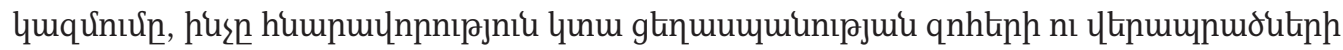

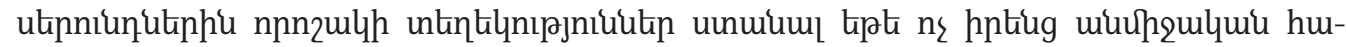

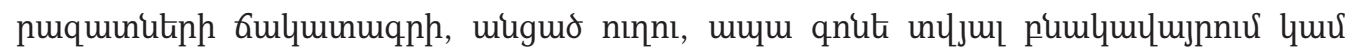

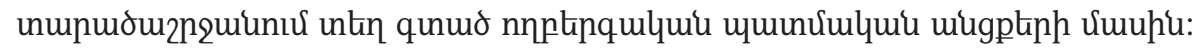

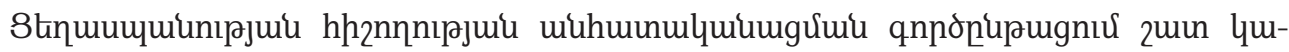

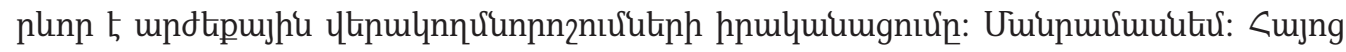

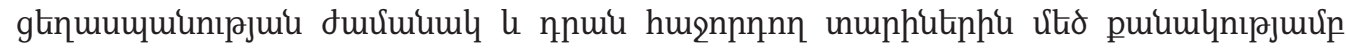

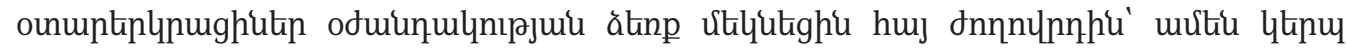

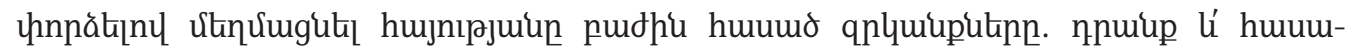

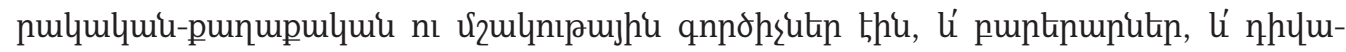

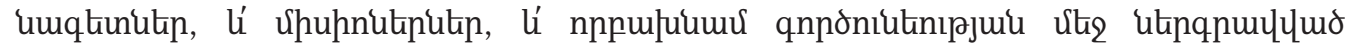

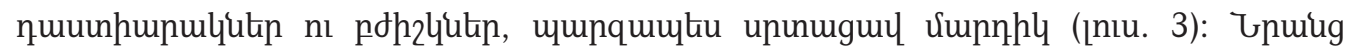

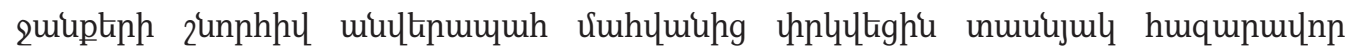

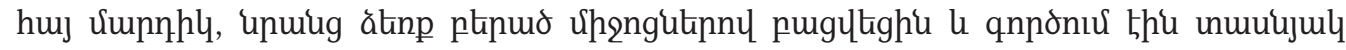

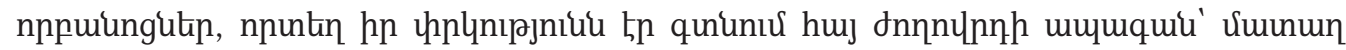

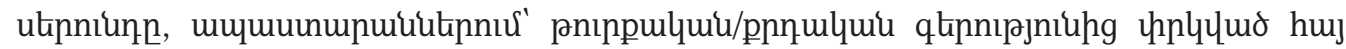

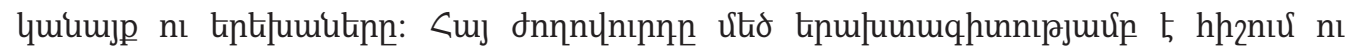

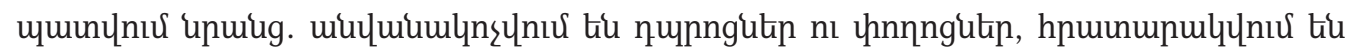

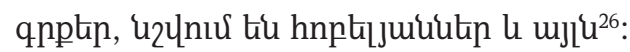

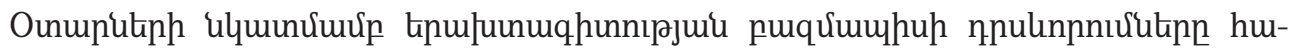

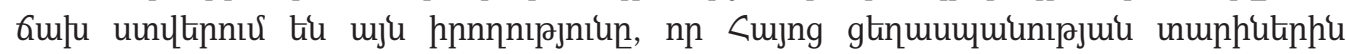

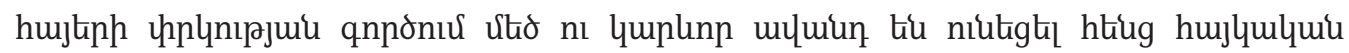

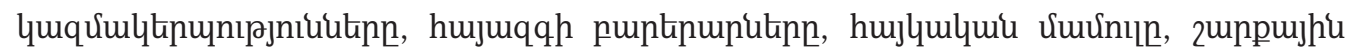

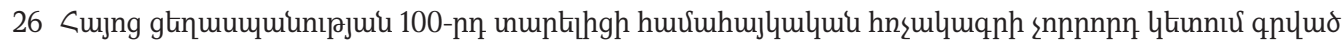

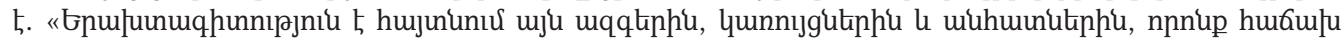

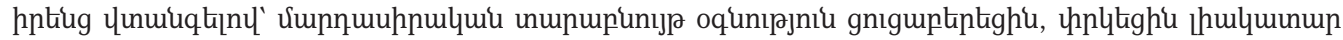

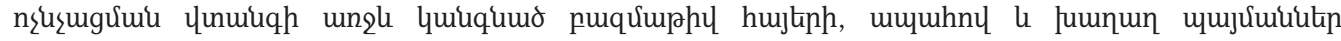

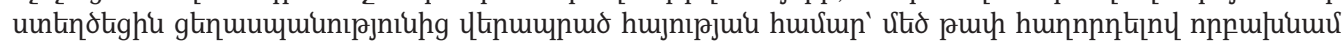

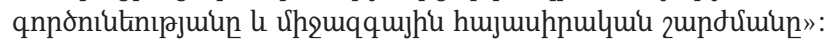




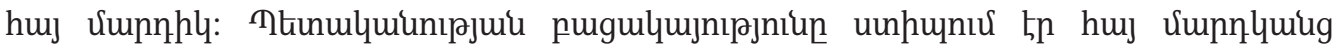

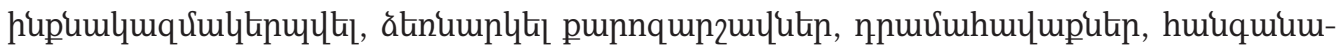

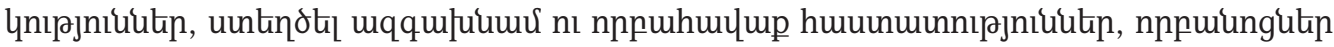

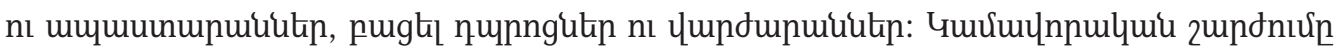

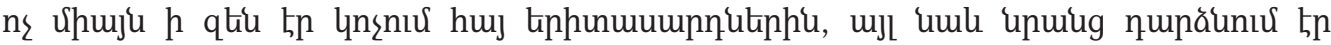

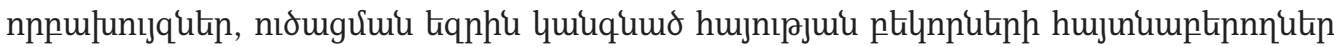

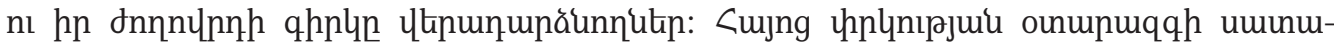

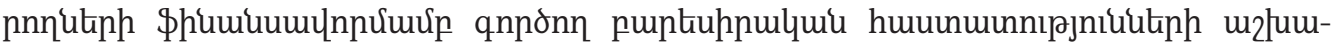

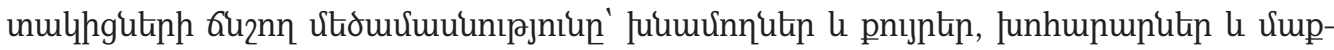

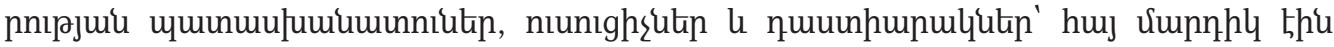

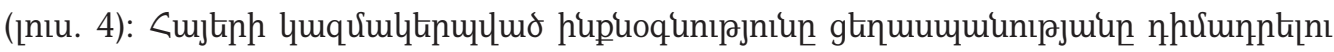

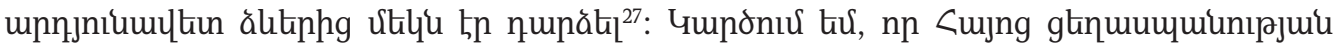

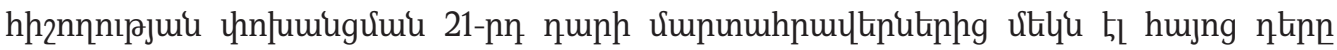

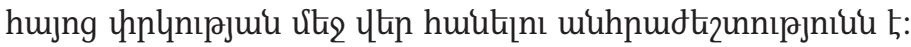

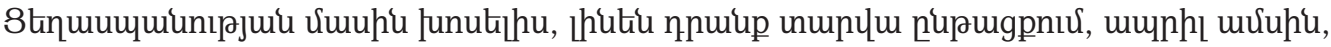

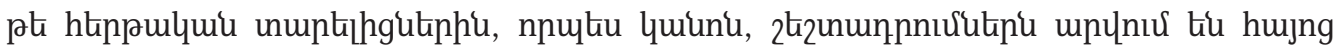

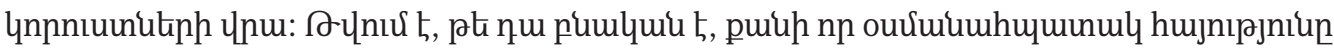

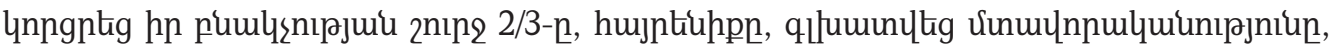

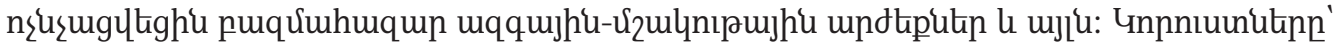

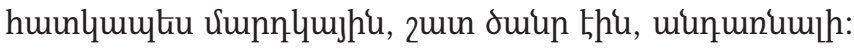

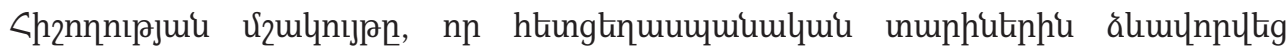

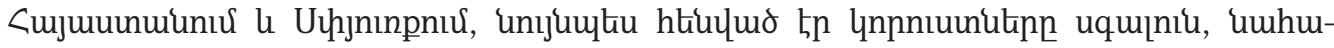

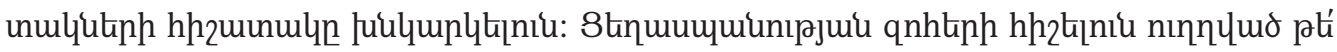

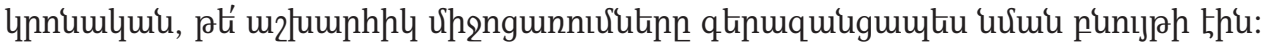

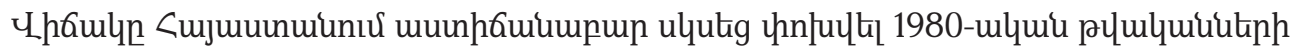

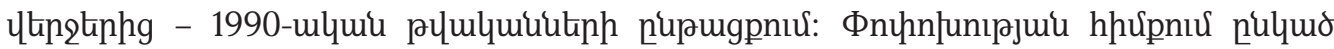

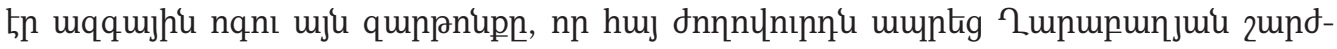

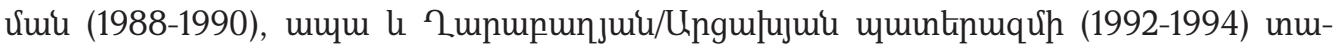

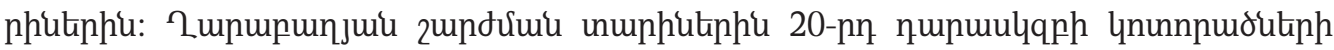

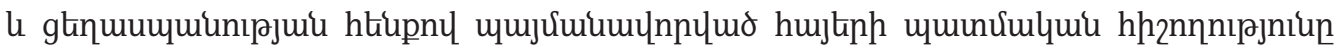

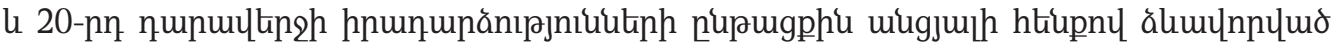

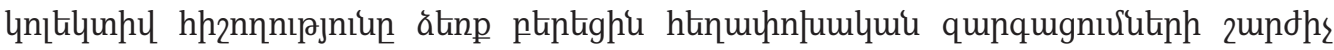

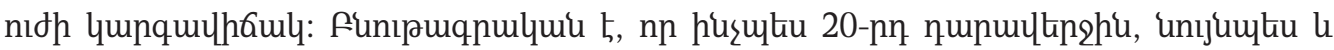

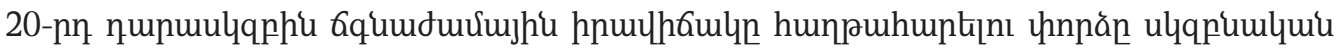

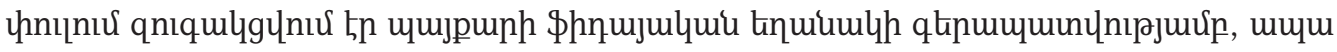

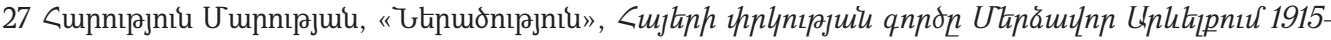

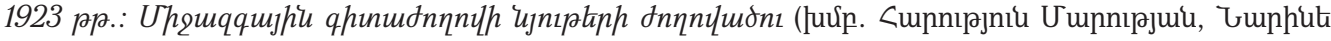

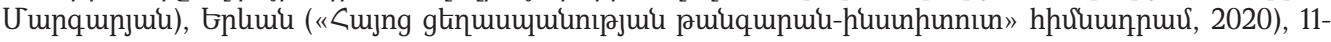
12: 


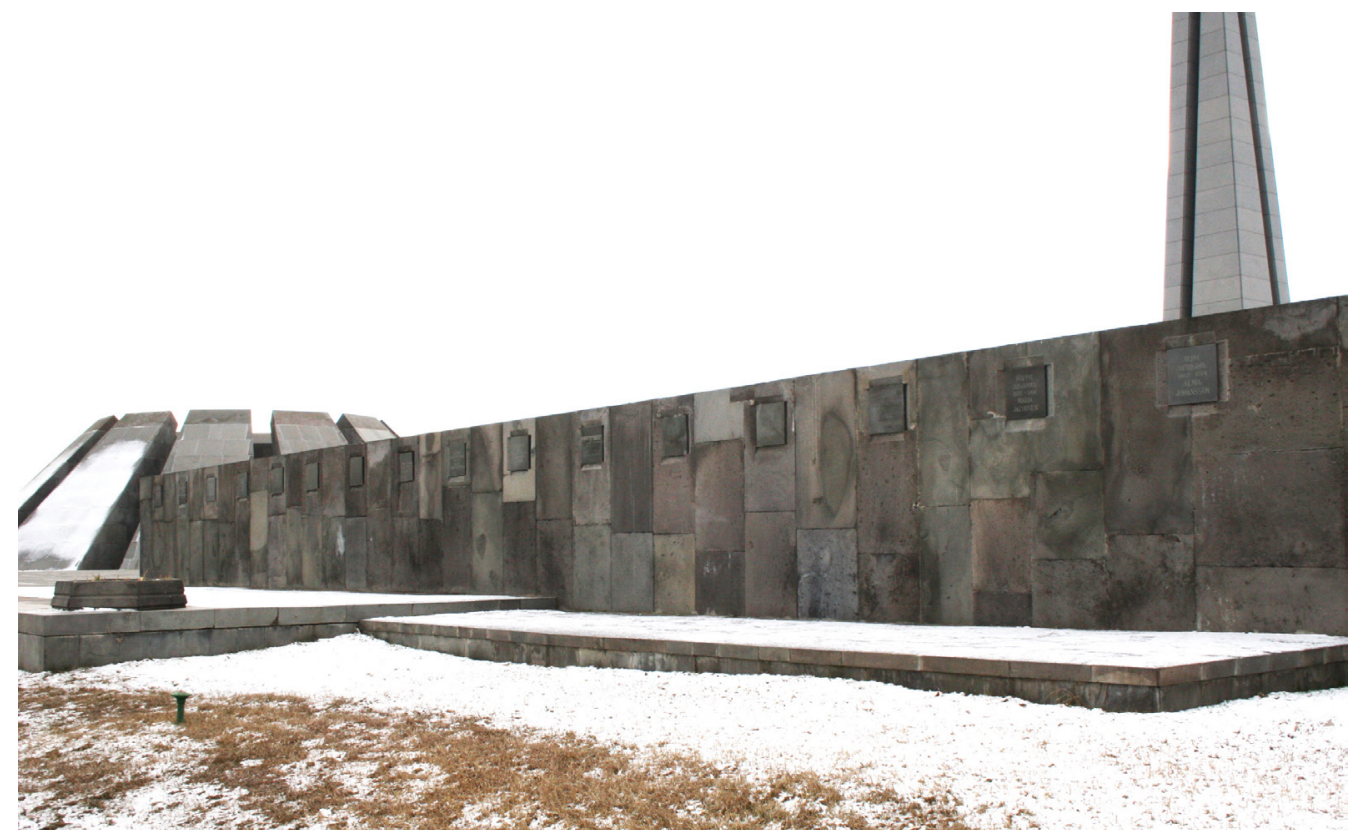

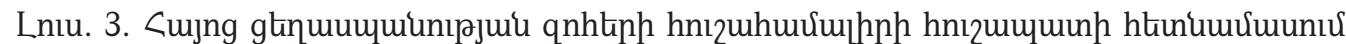

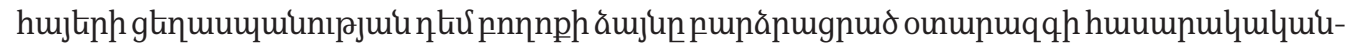

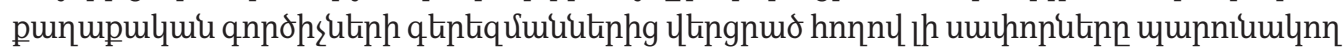

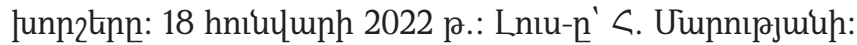

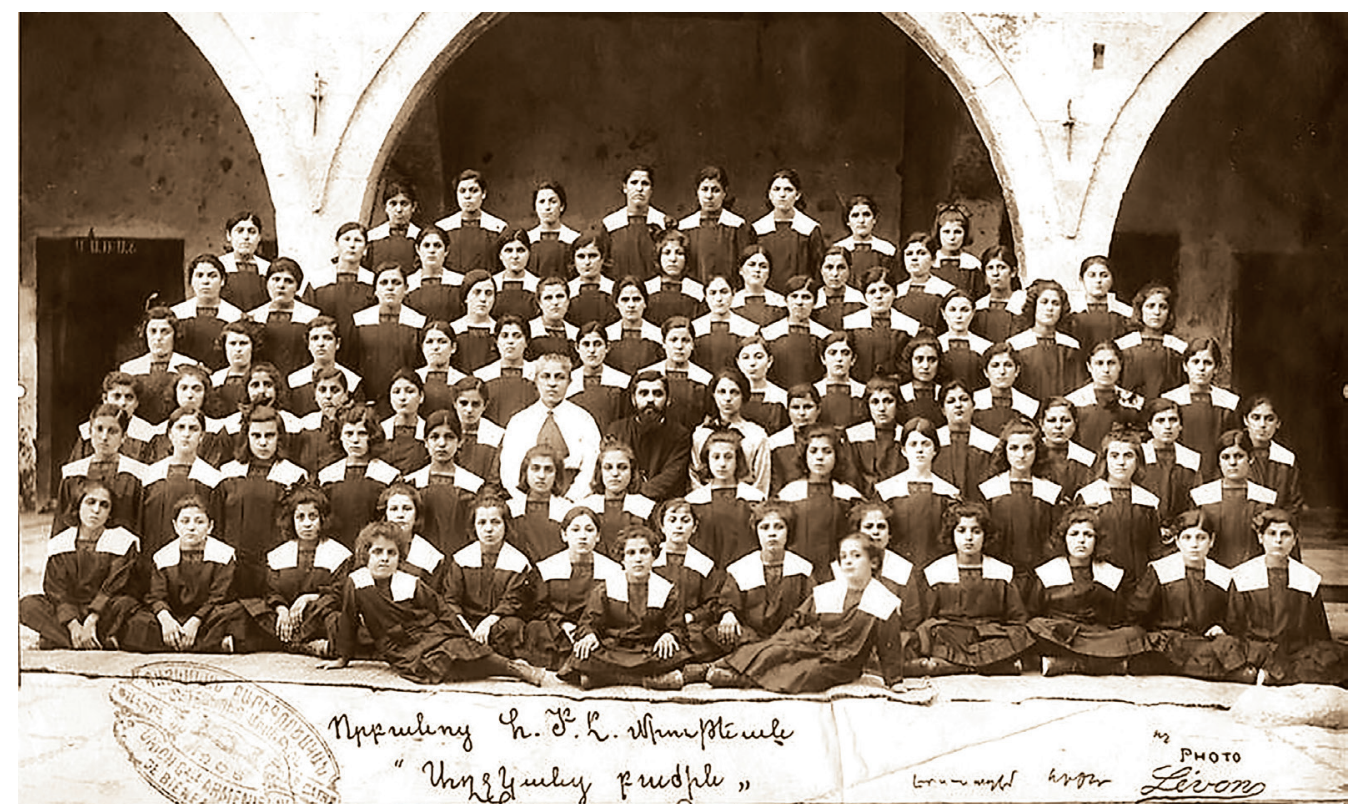

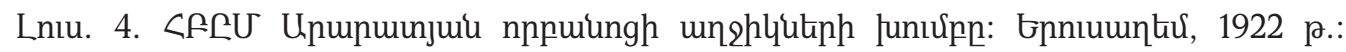
Фuphq, <f尺U tnıpunjuir qnunupui: 


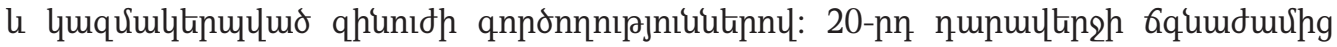

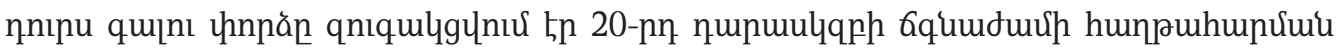

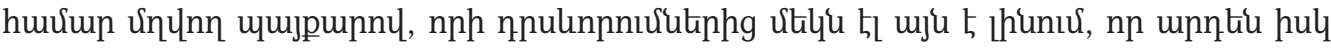

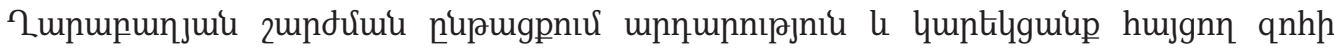

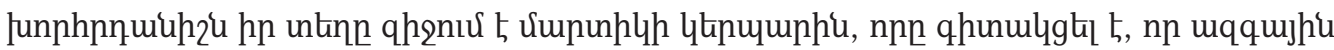

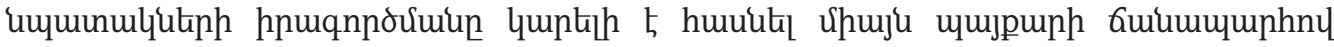

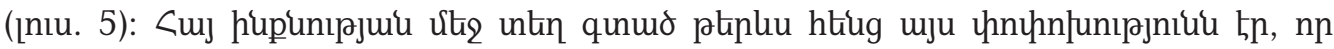

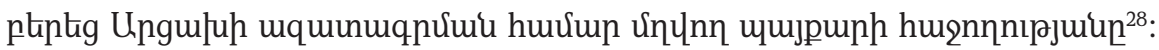

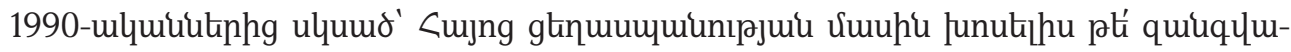

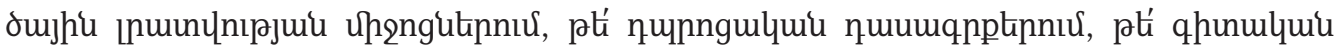

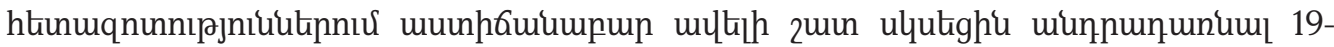

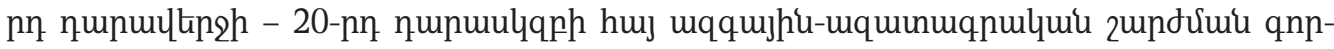

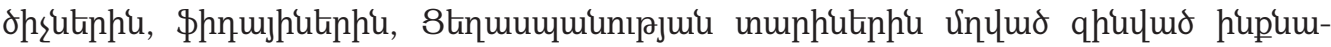

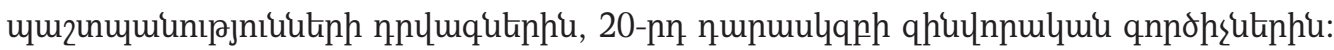

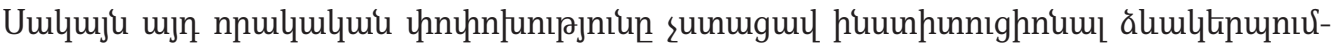

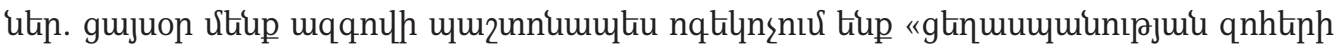

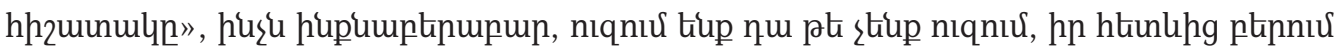

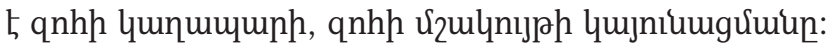

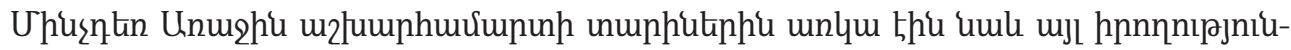

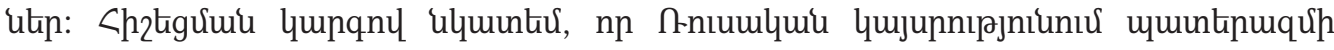

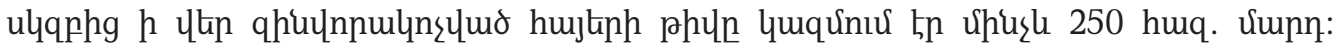

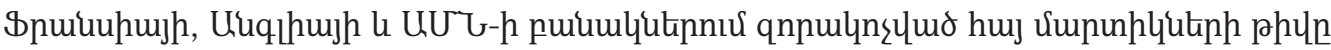

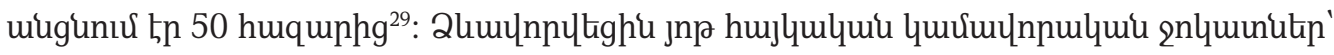

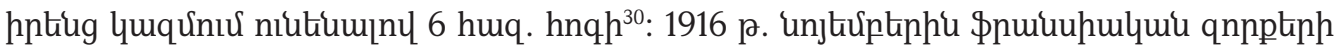

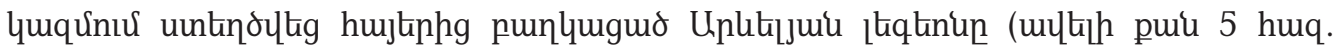

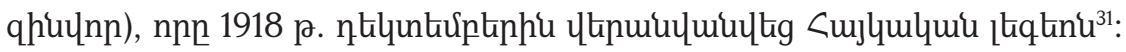

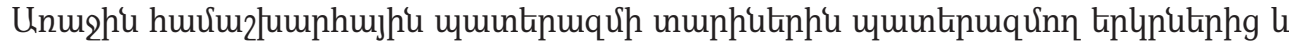

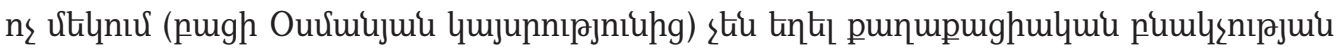

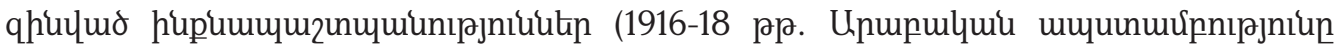

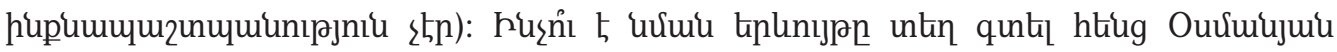

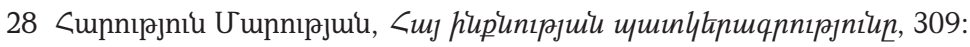

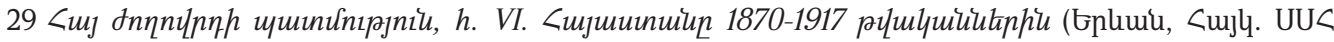

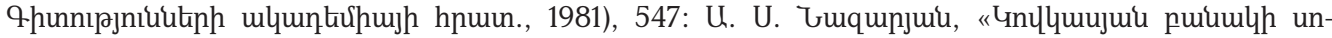

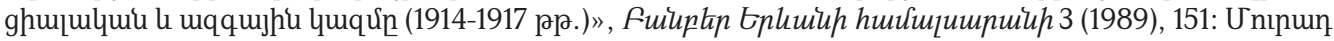

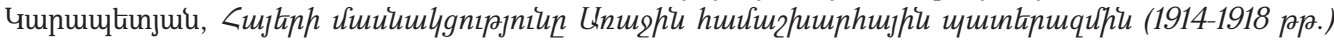
(ङplumu, 9punnıjniu, 2014), 48, 97-98, 122-123, 127:

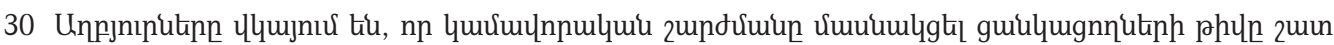

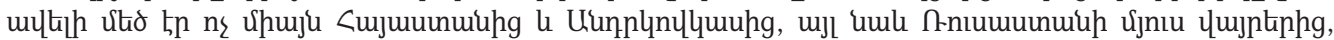

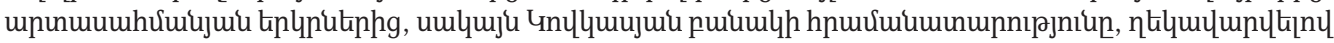

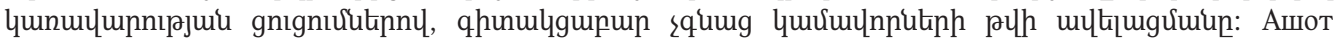
Арутюнян. Кавказский фронт: 1914-1917 гг. (Ереван: Айастан, 1971), 296-297, 317.

31 Армянский вопрос. Энииклопедия, ред. К. С. Худавердян (Ереван, 1991), 59. 


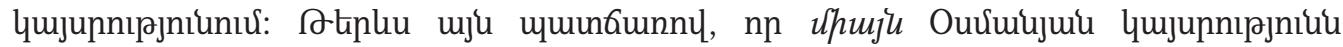

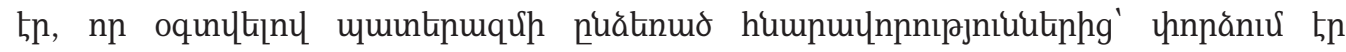

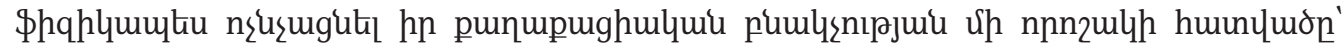

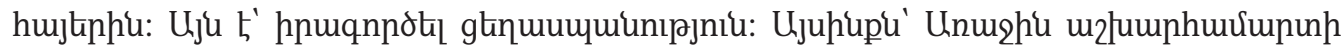

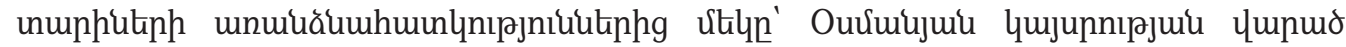

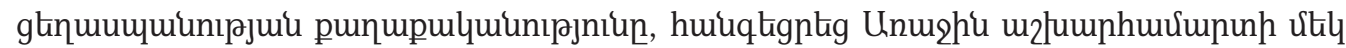

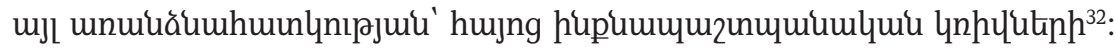

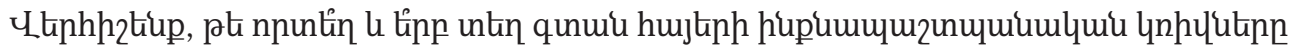

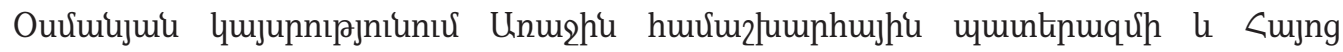

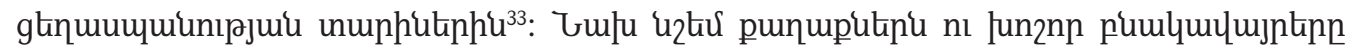

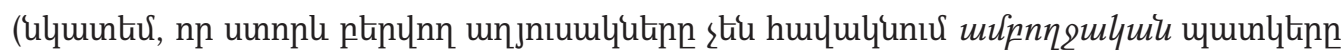
unuiniu).

\begin{tabular}{|c|c|c|}
\hline তuunulu/ßिun & 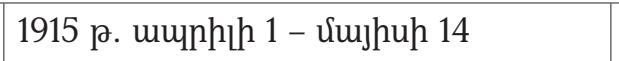 & 45 on \\
\hline પ.ui & 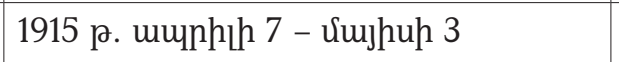 & 27 op \\
\hline Tumpu-qunuhhump & 1915 р. hniuhuh $2-29$ & 28 op \\
\hline Unı2 & 1915 p. hniuhup 26-29 & 4 op \\
\hline Sniunnfiuq & 1915 p. hnıhup 6-26/oqnuunnuh 3 & $21-28$ op \\
\hline กıрфu & 1915 р. ukumukúptiph 29 - hnluntur. 23 & 25 on \\
\hline Uunuz & 1920 p. hnilulunh 21 - hkinnulunh 10 & 21 op \\
\hline Lufinu & 1920 р. шипһц 1 - hnlunturptiph 15 & 6.5 muһu \\
\hline Uјирuи & 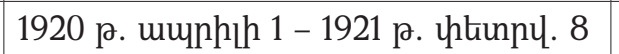 & uцŁц pui 10 uर्uhu \\
\hline
\end{tabular}

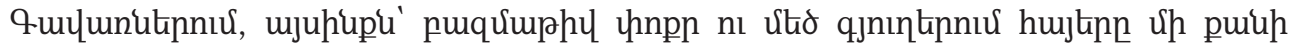

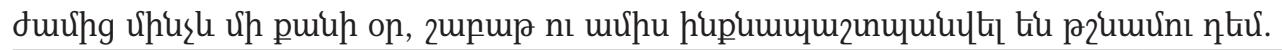

\begin{tabular}{|c|c|c|}
\hline ૧uцu2 (પuuunınuluu) & 1915 р. шunhцh 3 - vuujhuh 11 & 38 op \\
\hline 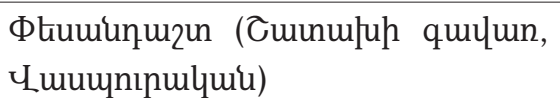 & 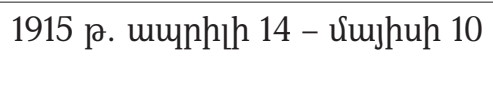 & 27 op \\
\hline
\end{tabular}

32 Cunghu hưưunnu uunpununăn unt'u Арутюн Марутян, "К вопросу об иконографическом

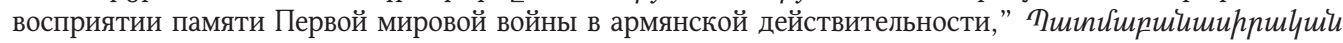
huiunku 1 (2013), 3-5:

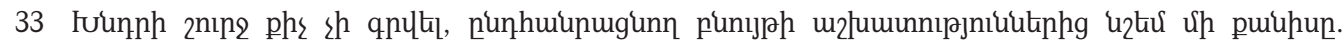

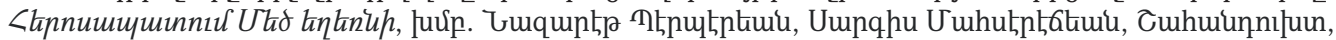

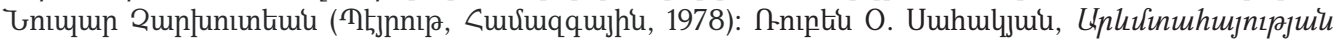

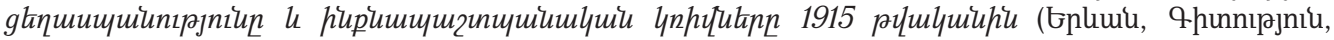

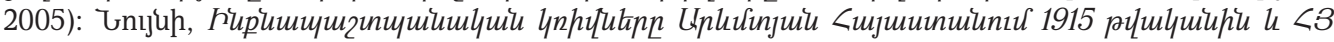

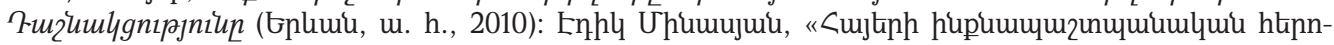

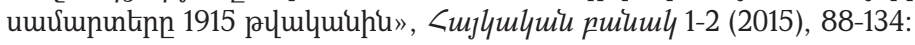




\begin{tabular}{|c|c|c|}
\hline 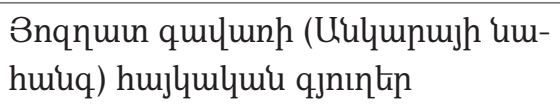 & 1915-1917 ра. & \\
\hline Uuuniu & 1915 р. шuщn L - oqnuunnu & 5 uuीpu \\
\hline Unıuu-ןlinuiu qunıntip & 1915 р. hnıhuh 21 - ukuщu. 12 & 53 op \\
\hline ¡ưnıu quulunh hujluuluu qjnıntp & 1915 р. Uujhu & \\
\hline Iununnpgnıph quulun & 1918 р. hniluцunh 20 - Uujhu & 3.5 uuhu \\
\hline
\end{tabular}

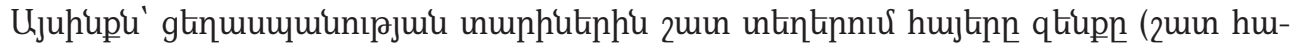

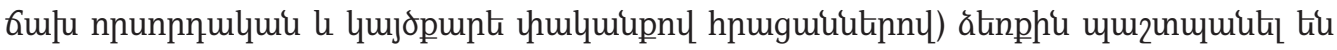

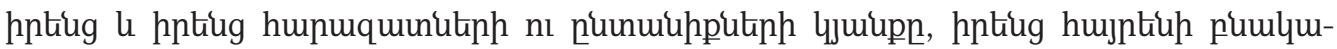

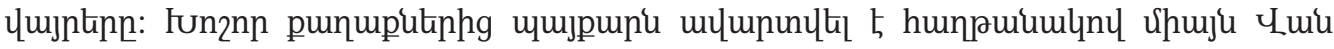

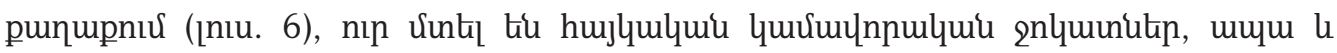

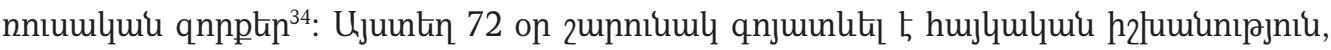

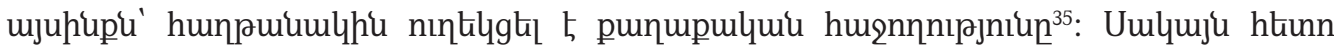

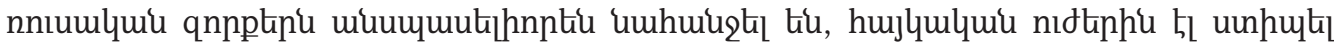

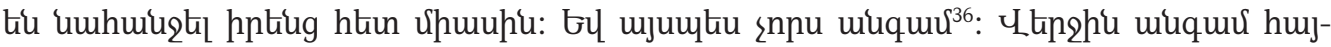

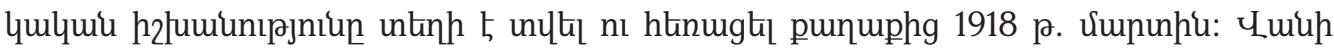

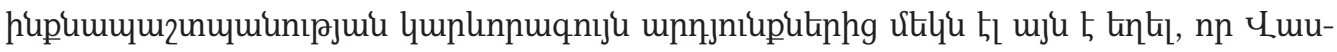

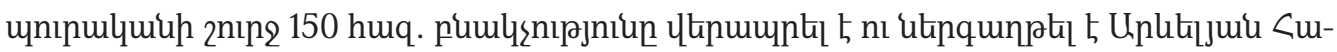

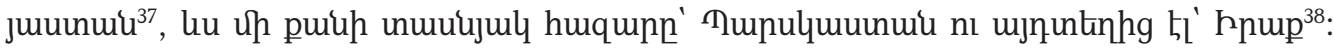

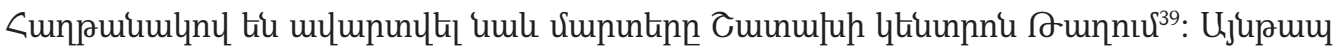

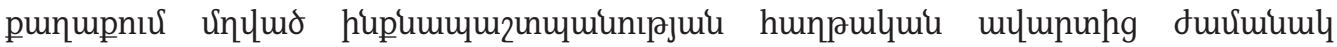

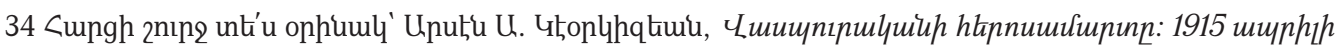

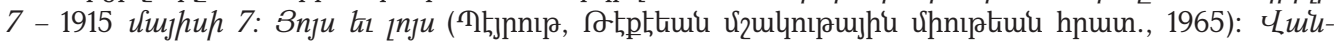

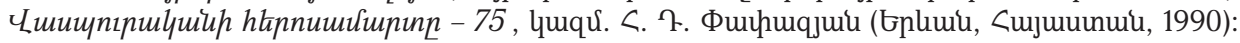

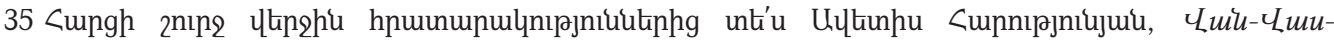

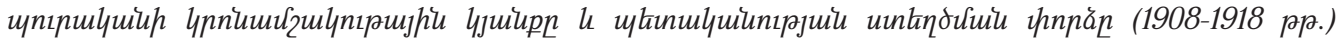

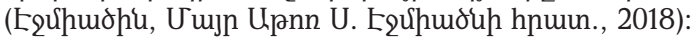

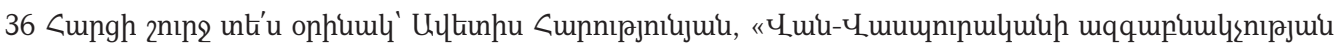

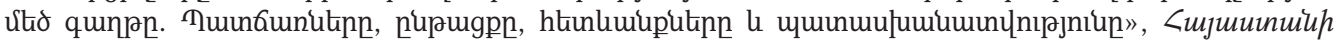

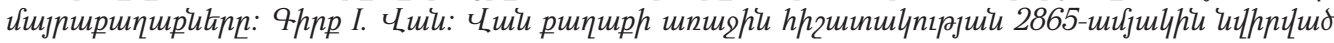

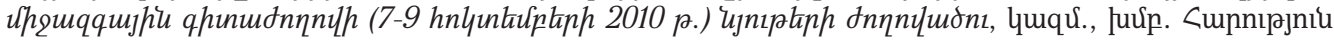
Uunnıрjui (Gpluwu, qpunnıрjniu, 2013), 170-196:

37 Robert Tatoyan, "WWI Armenian Refugees Census Data as a Source for Ottoman Armenian Population Numbers on the Eve of the Armenian Genocide," International Journal of Armenian Genocide Studies 5 , no. 1 (2020): 58-59.

38 Seda Ohanian, “The Passage of Van-Vaspourakan Refugees' Through Persia, March - August 1918 (Under the Leadership of Kosti Hambardzoumian and Levon Shaghoyan)," Review of Armenian Studies 2 (2019): 30-45.

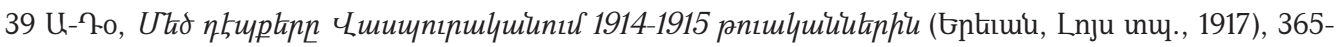
403: 


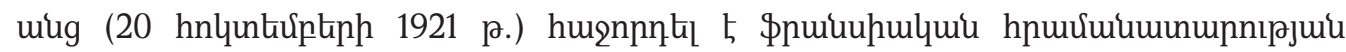

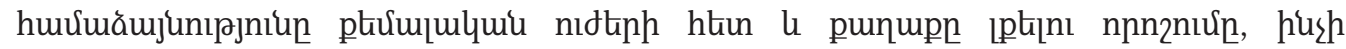

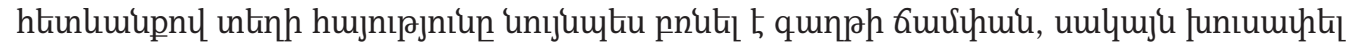

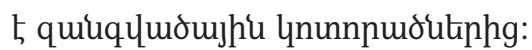

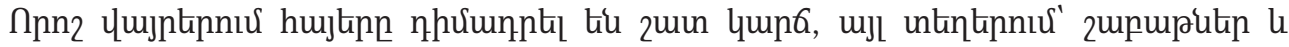

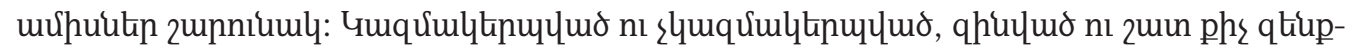

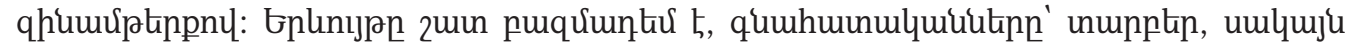

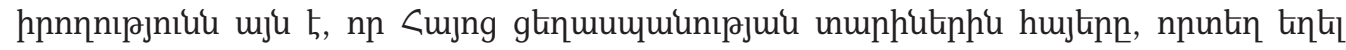

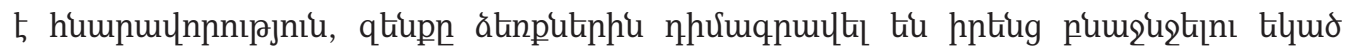

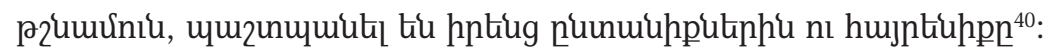

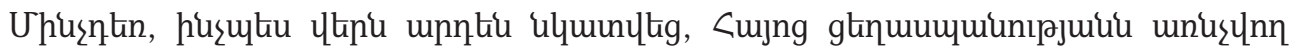

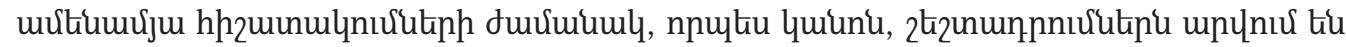

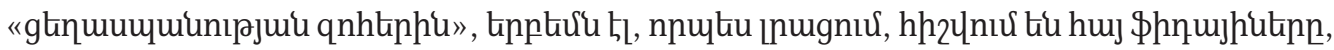

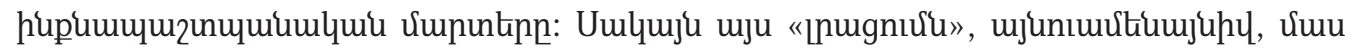

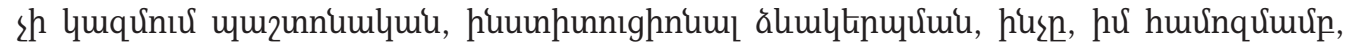

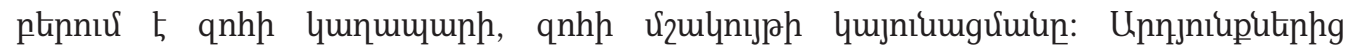

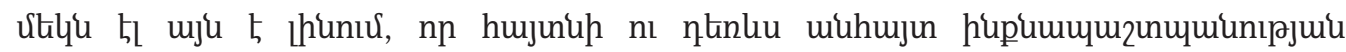

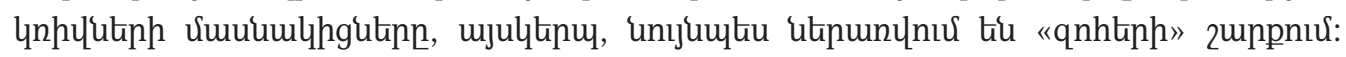

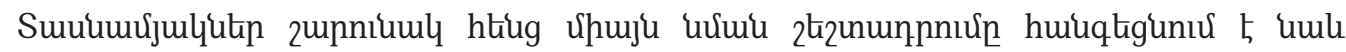

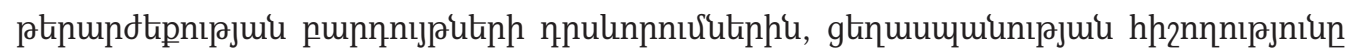

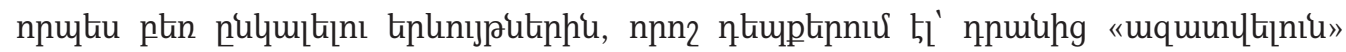

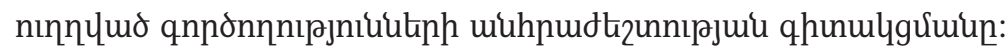

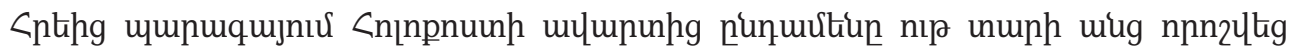

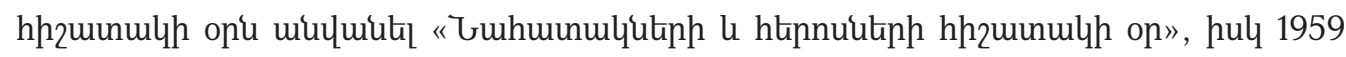

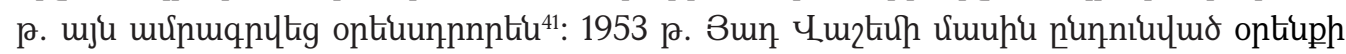

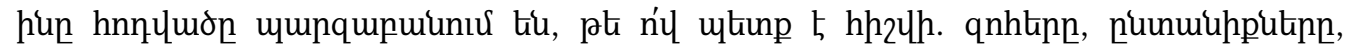

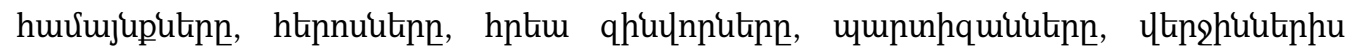

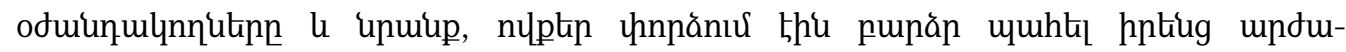

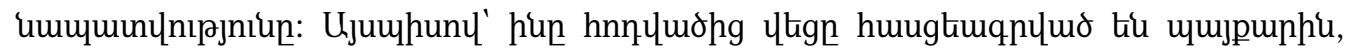

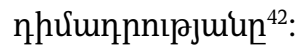

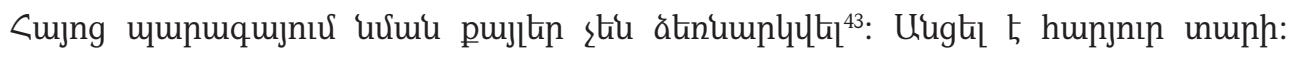

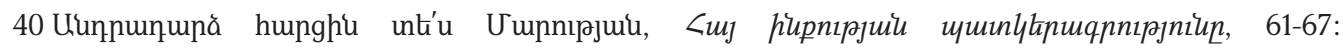

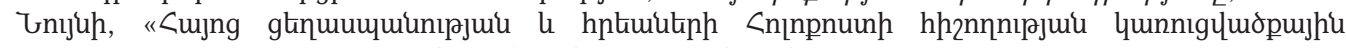

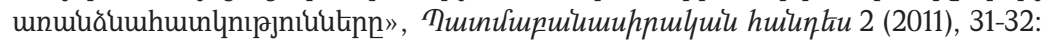

41 Holocaust Martyrs' and Heroes' Remembrance Day, https://knesset.gov.il/shoah/eng/shoah_ memorialday_eng.pdf, nhunцli 5 20.09.2021:

42 Martyrs' and Heroes Remembrance (Yad Vashem) Law 5713-1953, https://www.yadvashem.org/about/ yad-vashem-law.html, nhunlthl 5 20.09.2021:

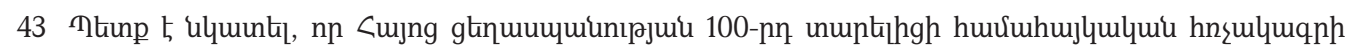

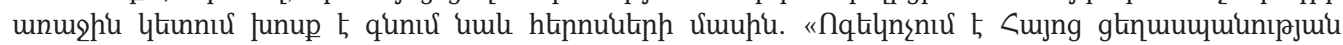

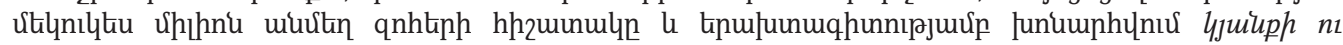

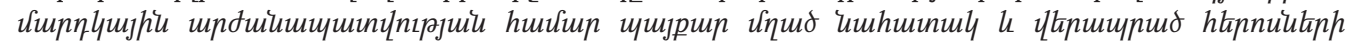




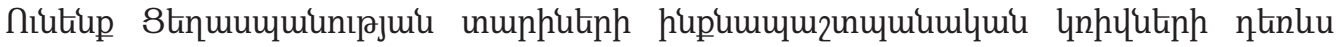

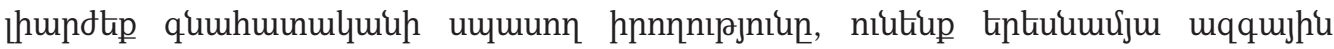

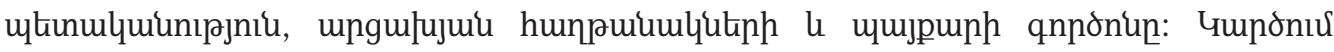

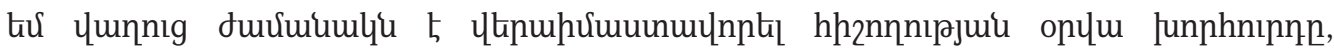

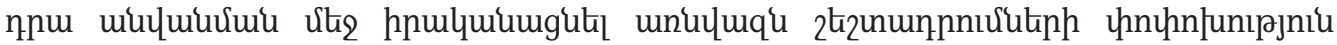

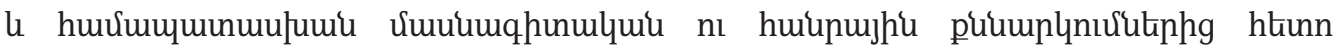

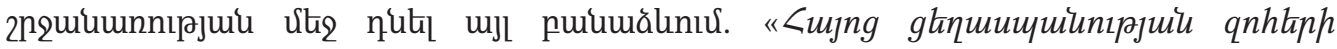

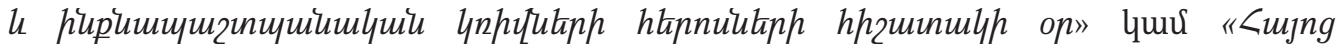

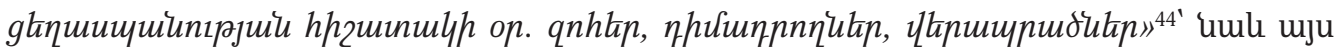

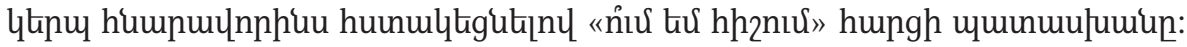

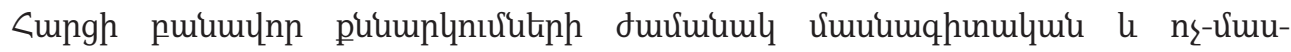

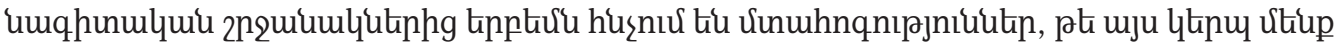

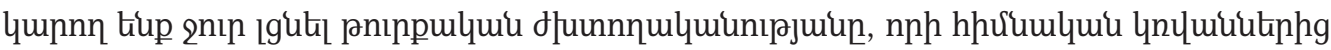

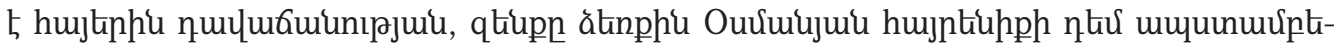

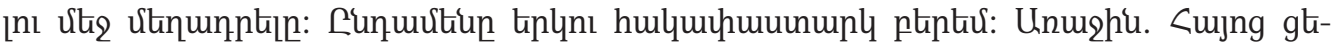

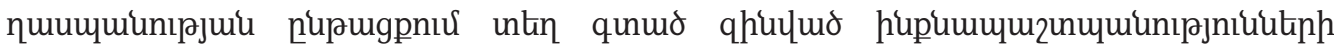

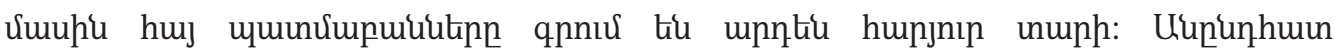

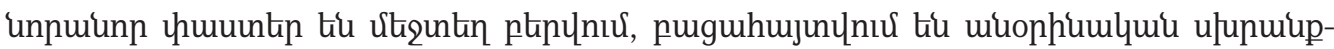

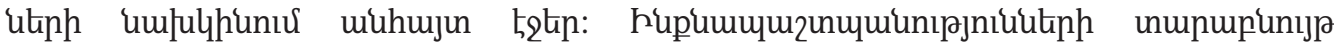

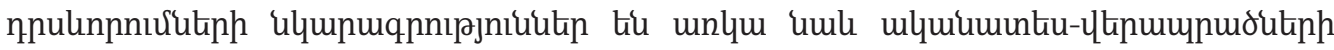

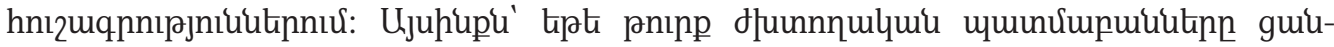

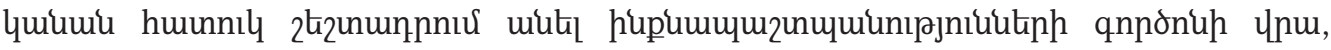

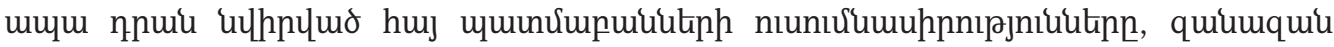

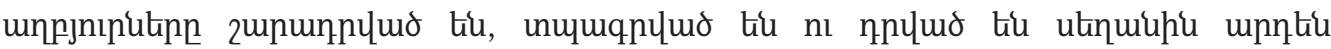

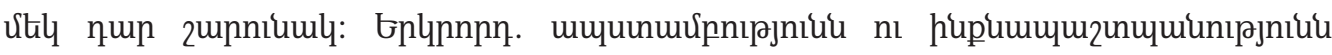

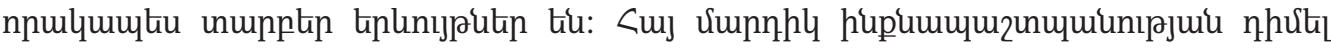

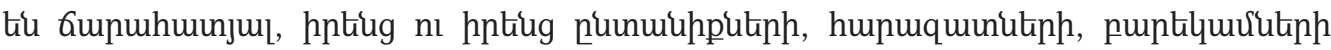

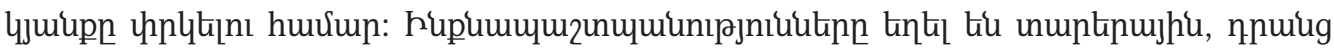

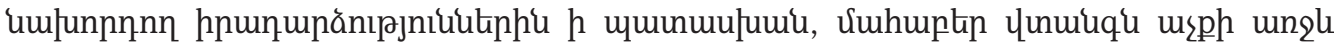

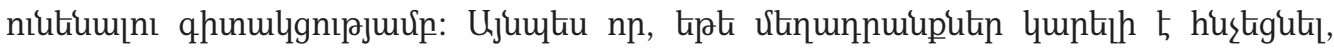

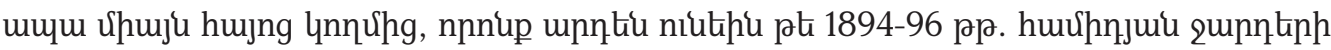

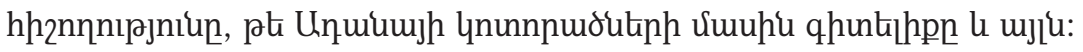

ungl» [nunqodnưu hưu $5-$ - C.U.]:

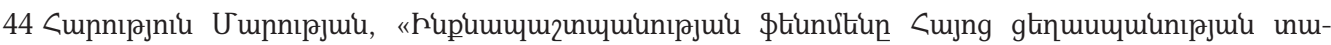

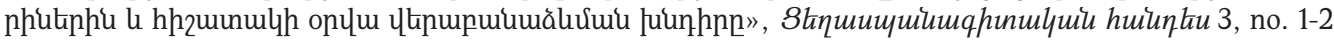

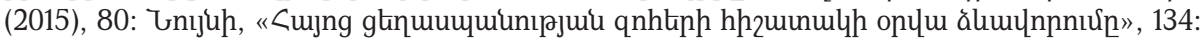




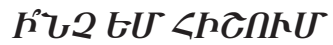

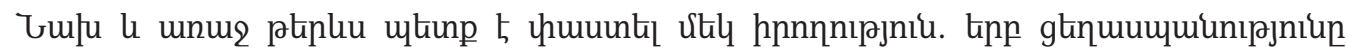

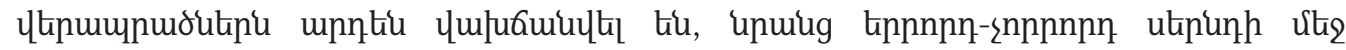

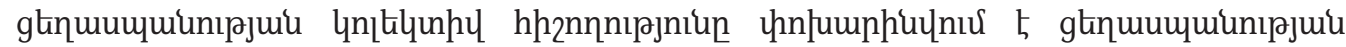

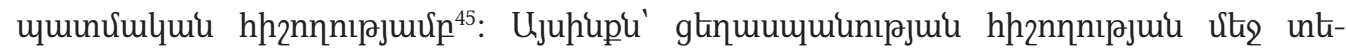

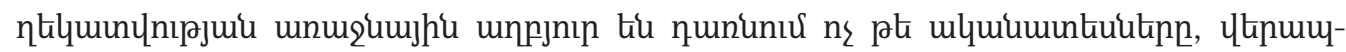

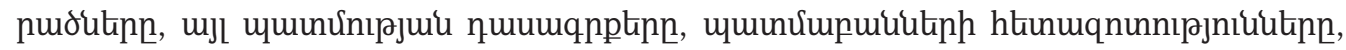

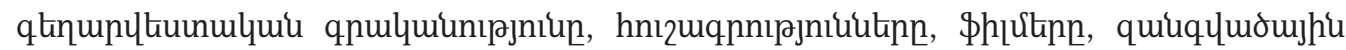

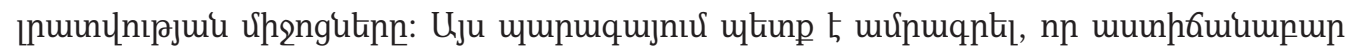

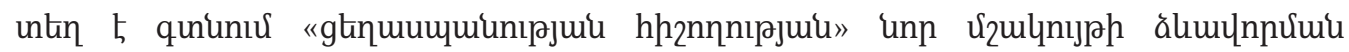

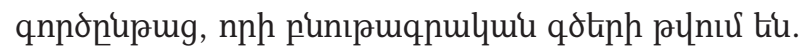

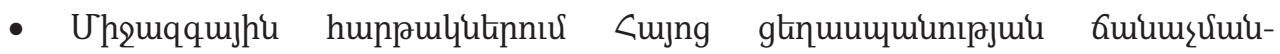

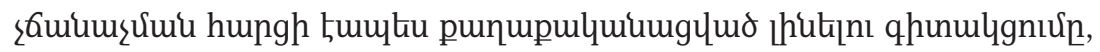

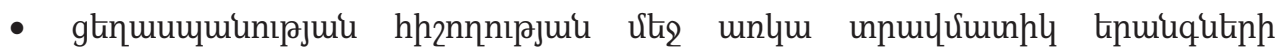

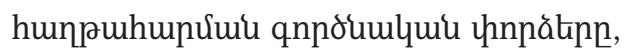

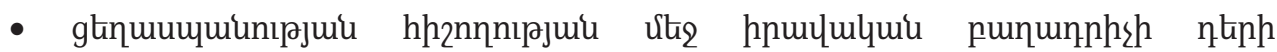

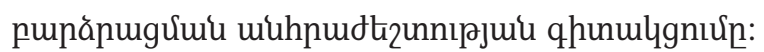

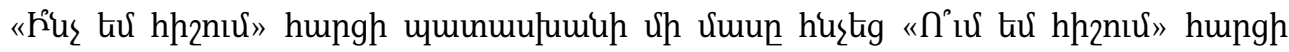

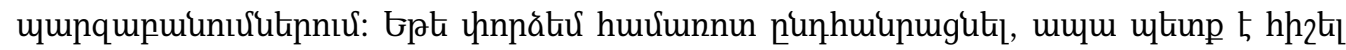

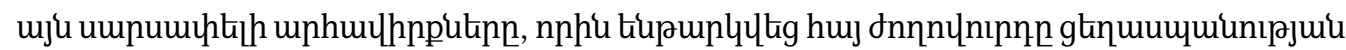

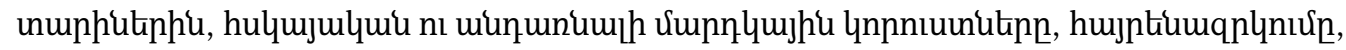

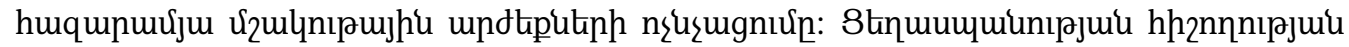

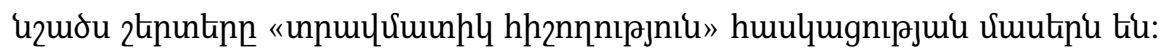

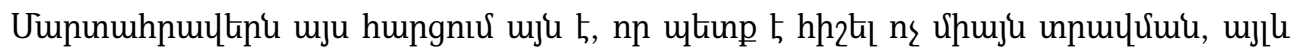

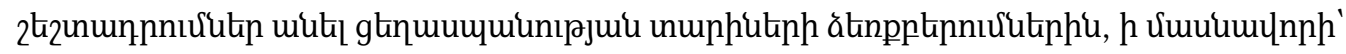

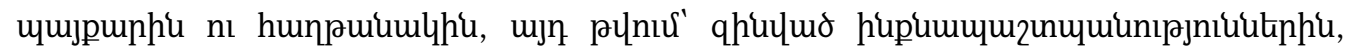

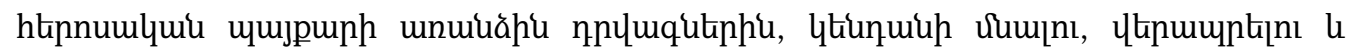

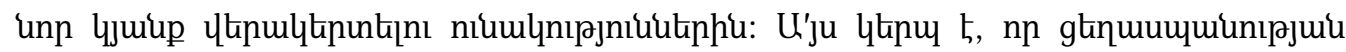

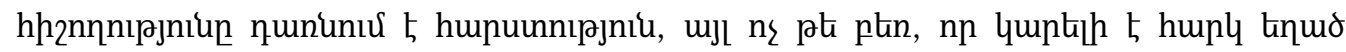

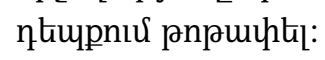

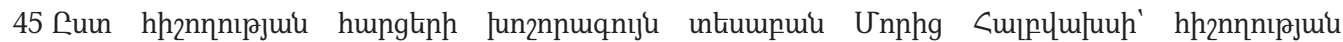

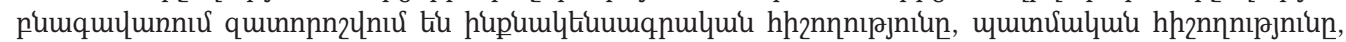

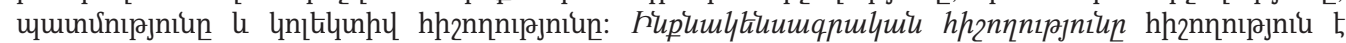

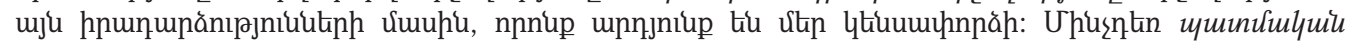

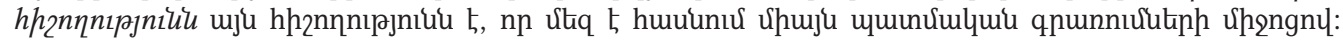

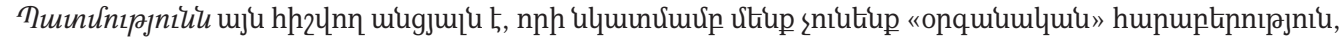

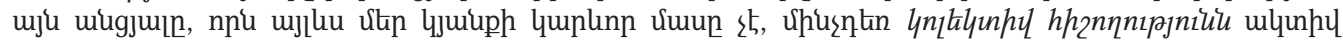

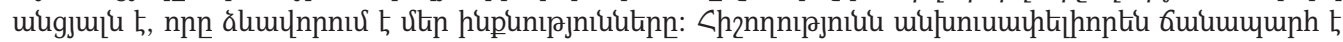

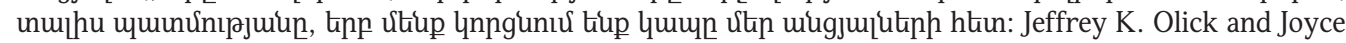
Robbins, "Social memory Studies: From "Collective Memory" to the Historical Sociology of Mnemonic Practices," Annual Review of Sociology 24 (1998): 111; Jeffrey K. Olick, "Collective Memory: The Two Cultures," Sociological Theory 17, no. 3 (1999): 335. 


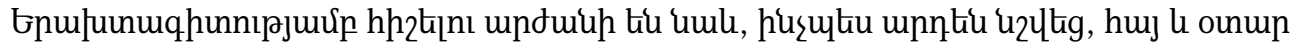

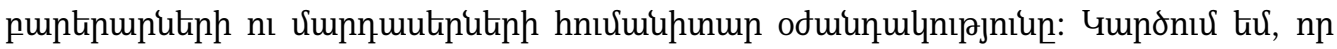

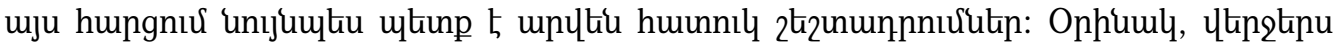

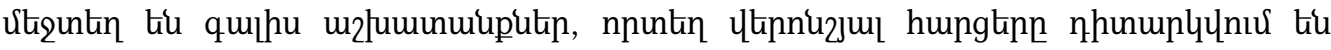

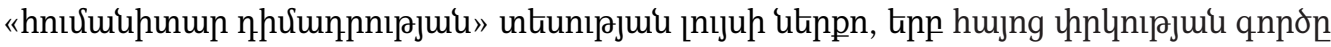
пununıর

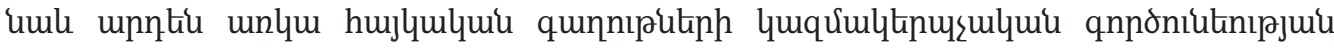

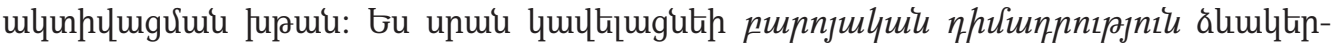

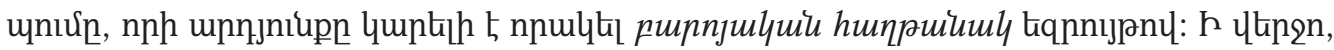

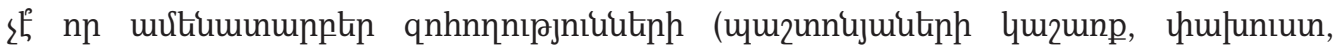

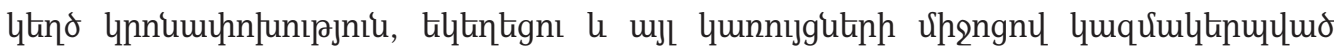

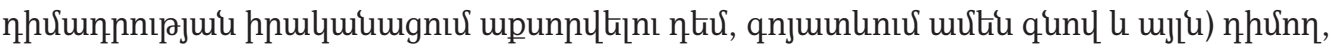

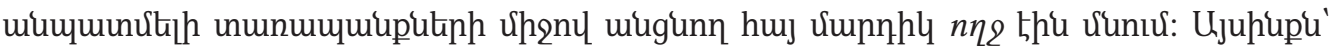

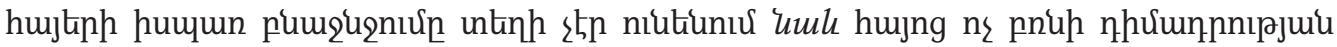
2unphpl46:

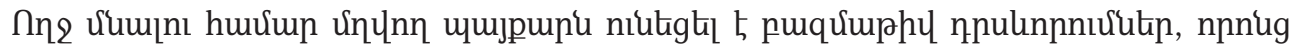

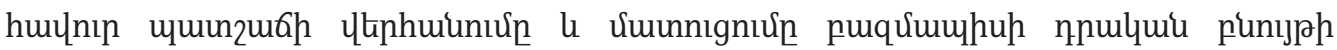

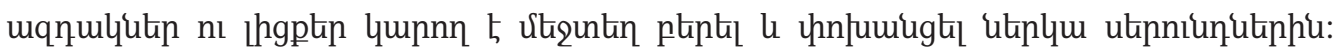

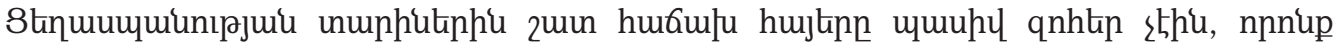

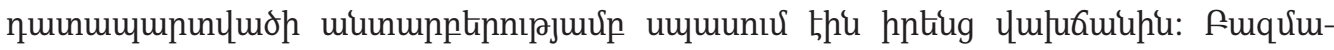

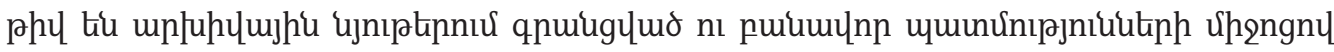

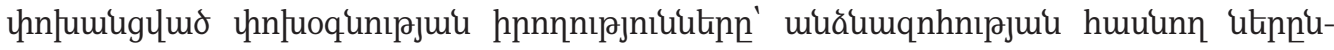

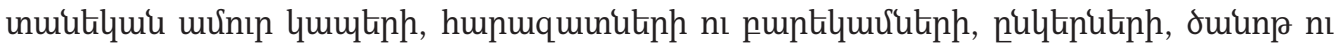

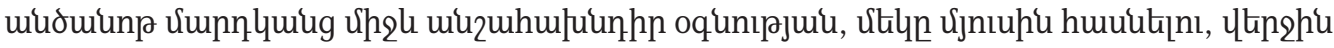

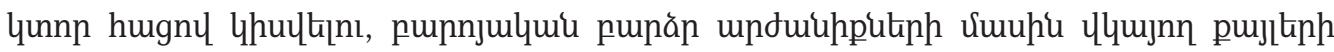

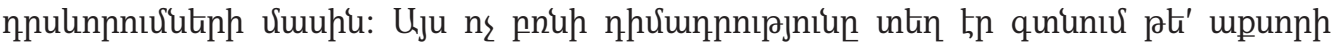

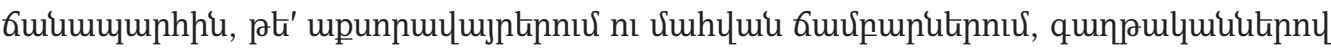

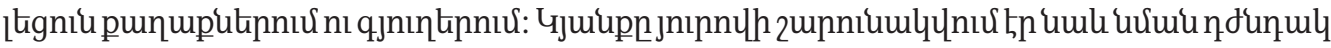

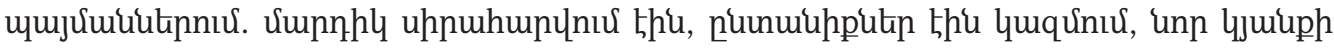

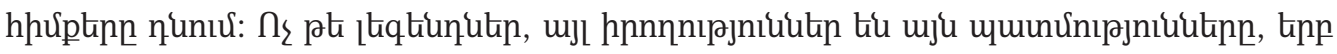

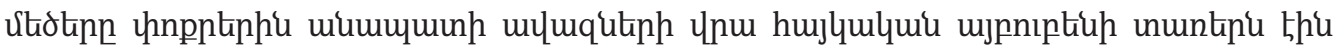

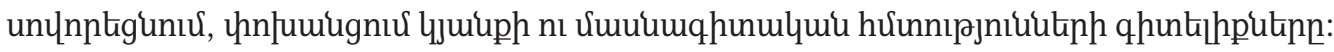

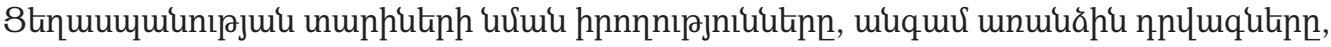

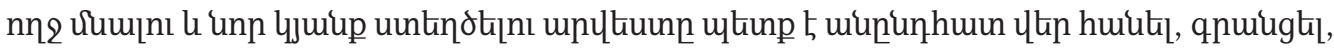

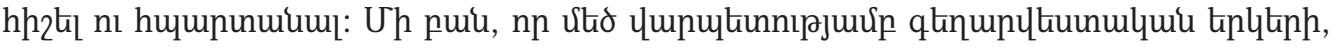

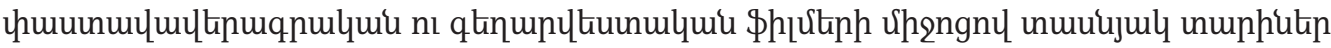

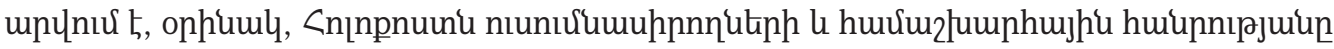

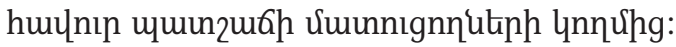

46 Uumpưuuuu unt'u Khachig Mouradian, The Resistance Network: The Armenian Genocide and Humanitarianism in Ottoman Syria, 1915-1918 (East Lansing: Michigan State University press, 2021). 


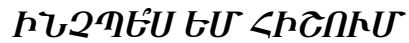

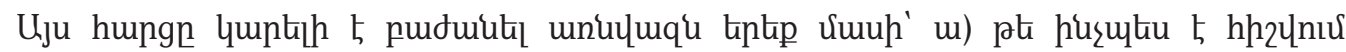

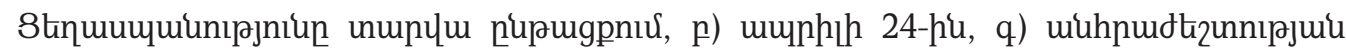

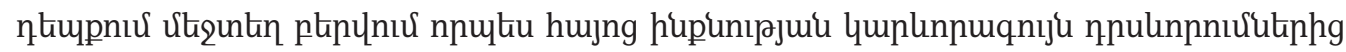
utuln:

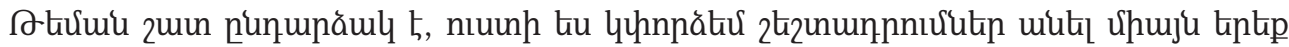

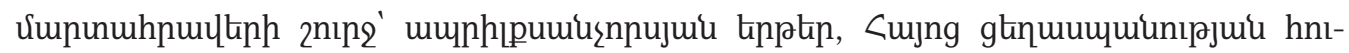

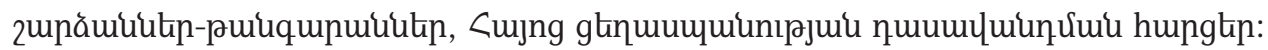

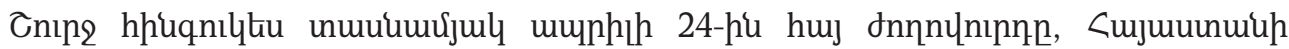

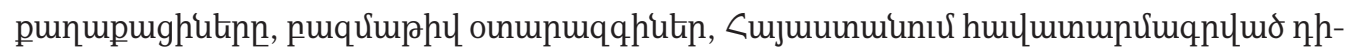

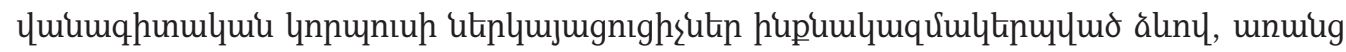

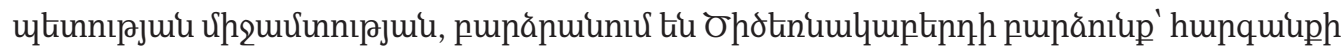

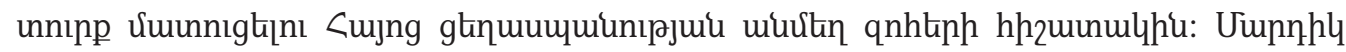

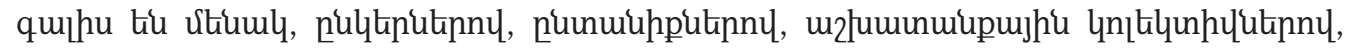

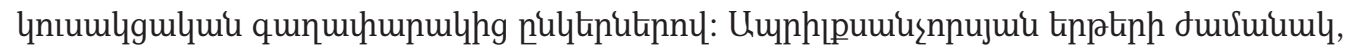

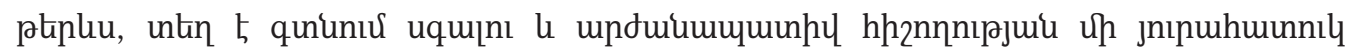

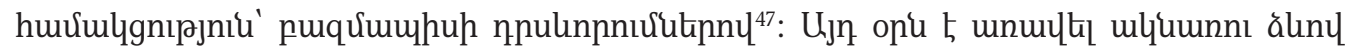

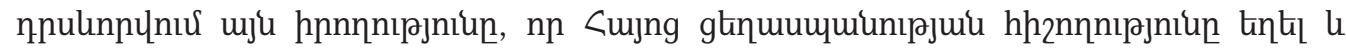

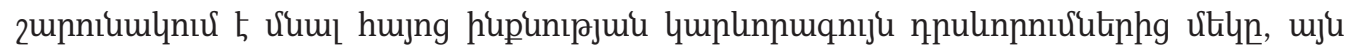

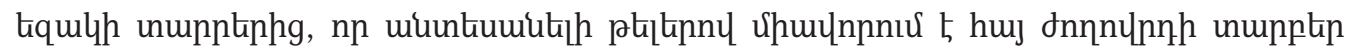

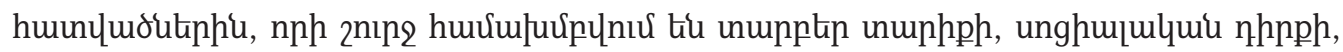

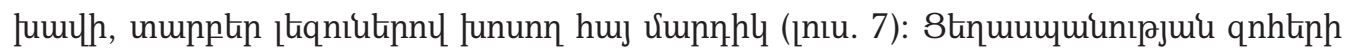

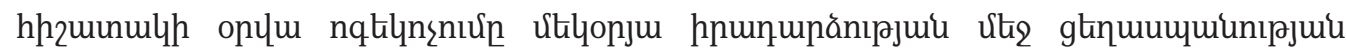

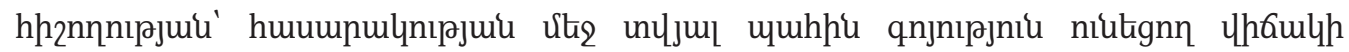

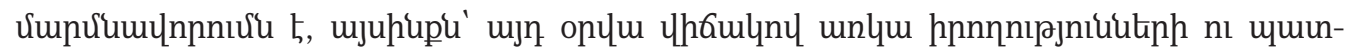

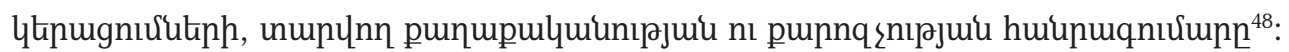

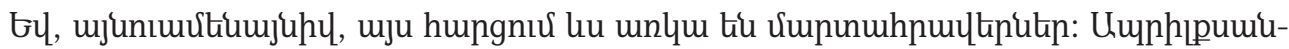

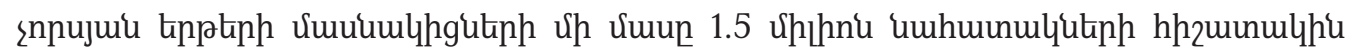

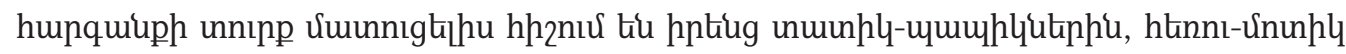

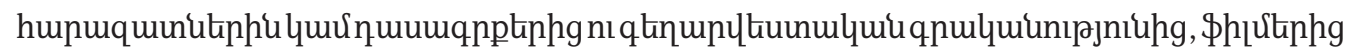

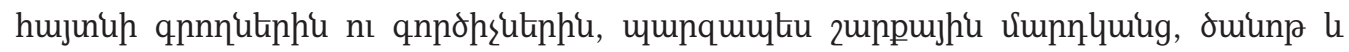

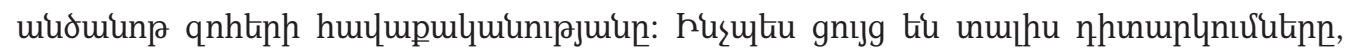

47 Cungh huuquưuuuph puumplnıú unt'u Арутюн Марутян, “Памятник жертвам геноцида в контексте ритуалов памяти армянского народа," Этнографическое обозрение 3 (2008): 119-

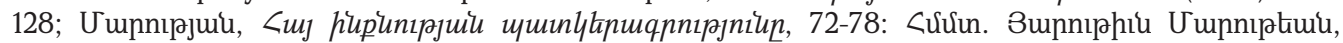

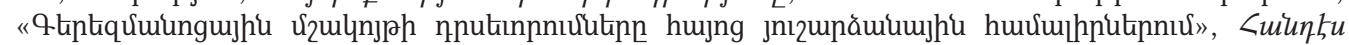
UUuopkuj 1-12 (2020), 445-468:

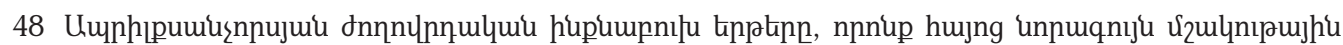

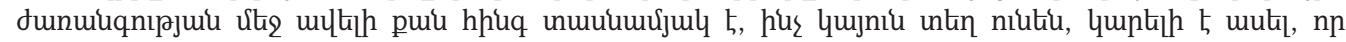

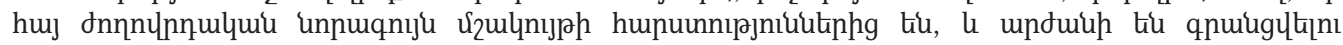

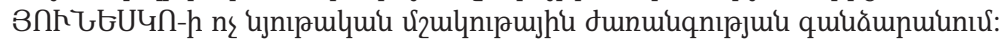




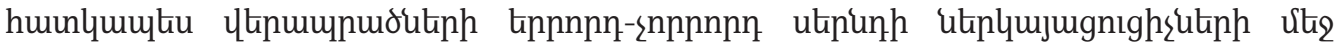

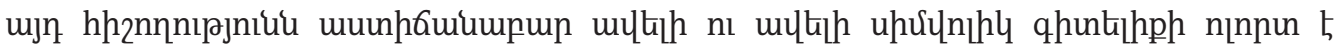

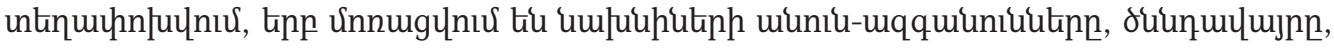

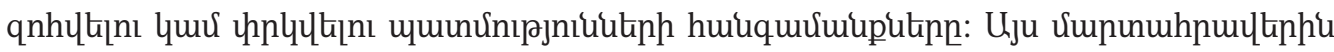

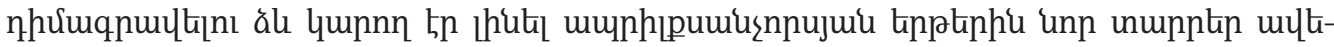

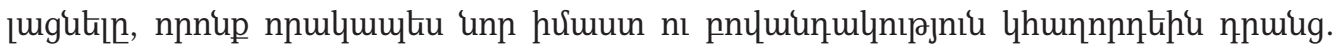

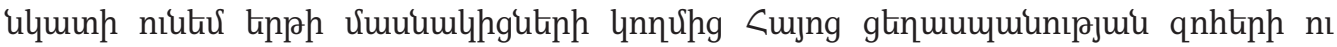

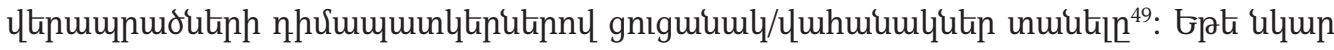

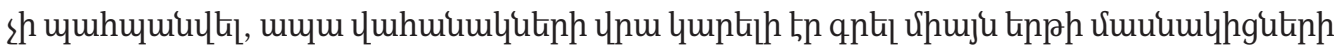

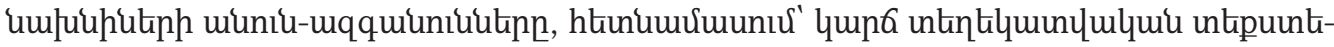

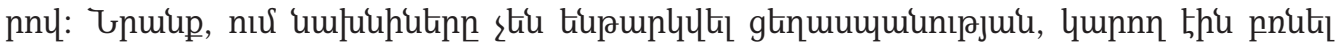

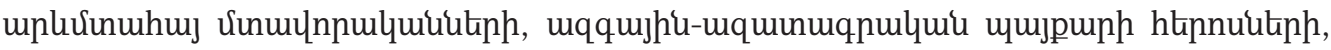

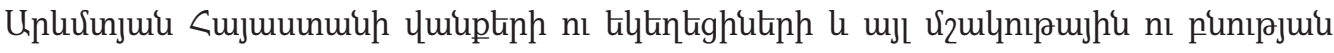

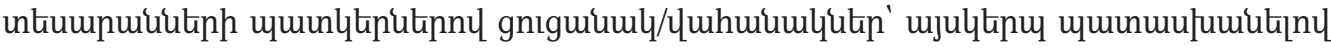

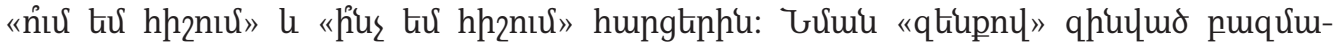

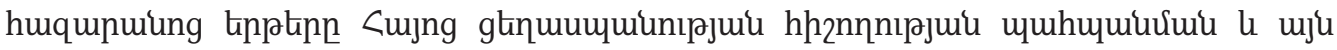

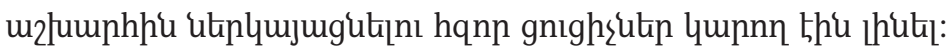

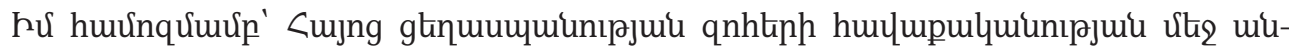

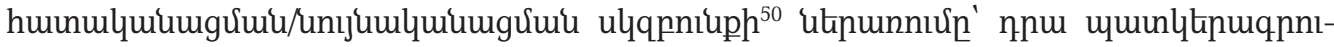

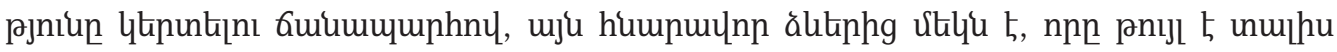

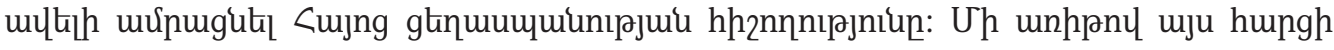

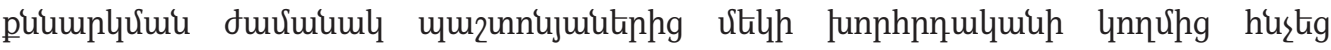

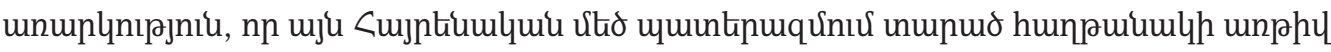

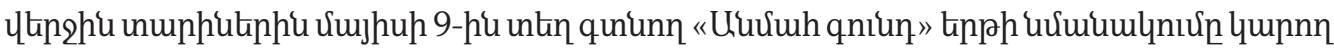

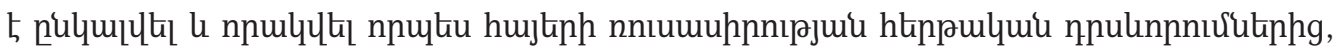

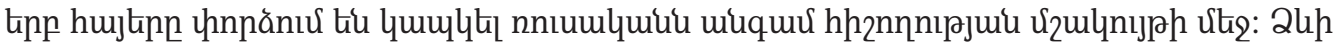

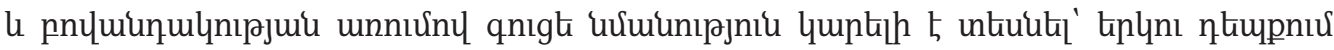

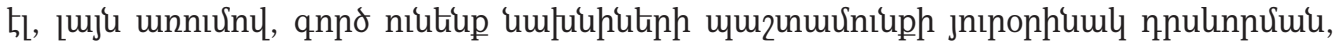

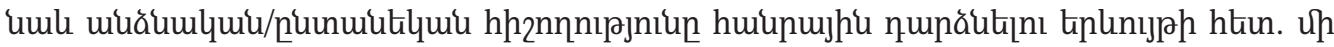

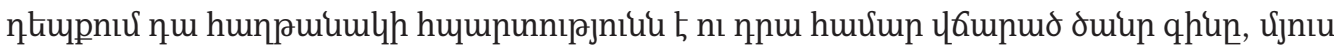

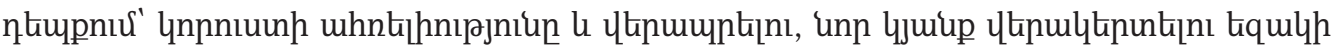

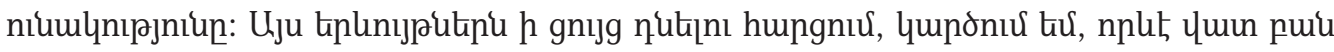

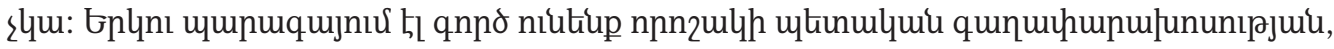

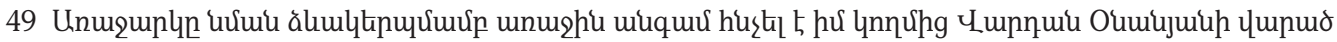

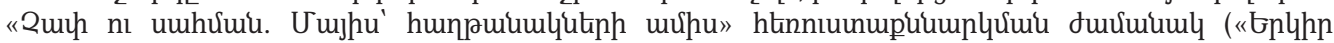

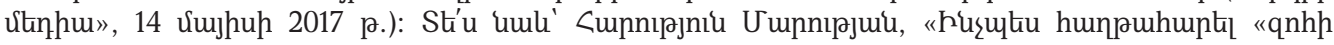

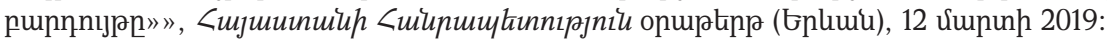

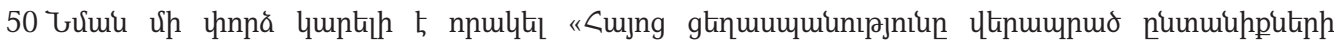

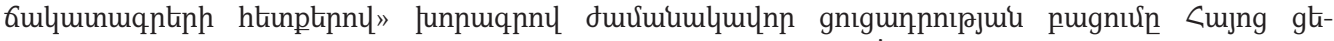

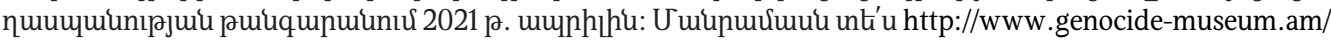
arm/21.04.2021.php: Stuu uulu http://www.genocide-museum.am/arm/12.10.21.php, nhunltal 5 20.09.2021: 


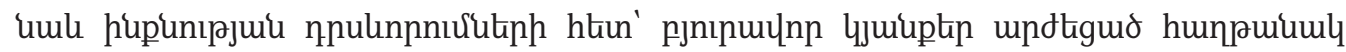

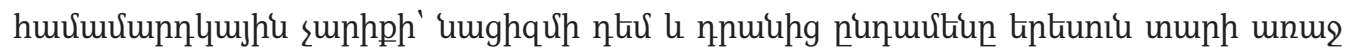

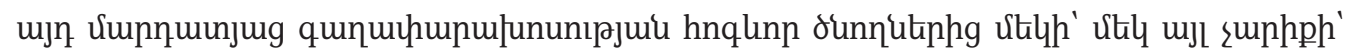

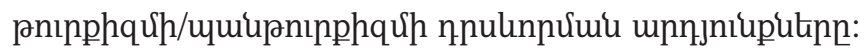

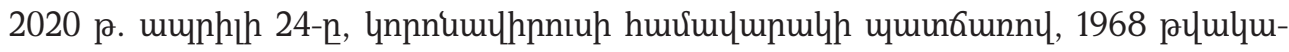

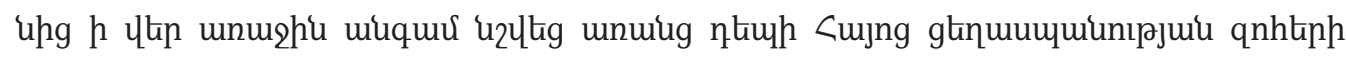

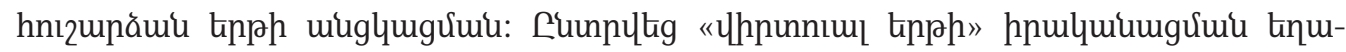

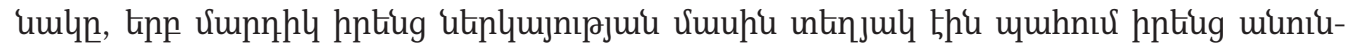

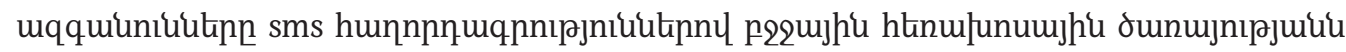

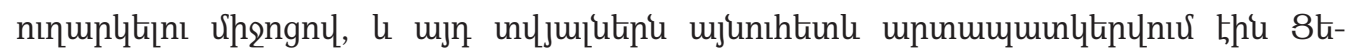

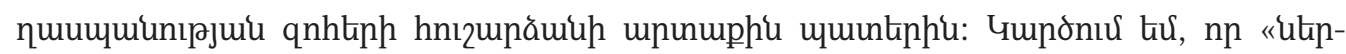

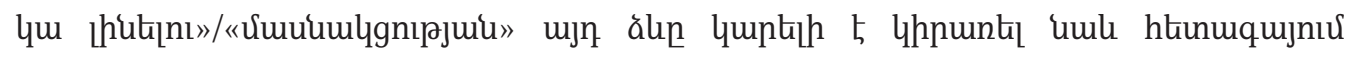

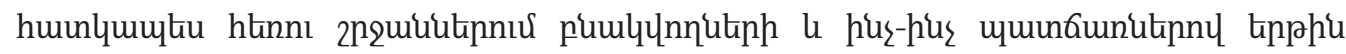

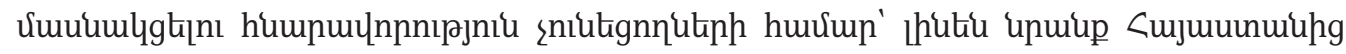

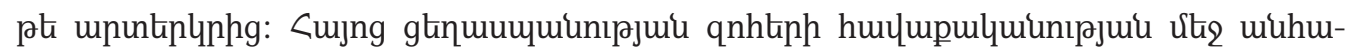

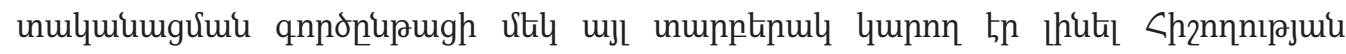

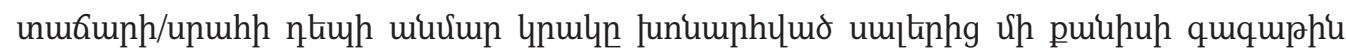

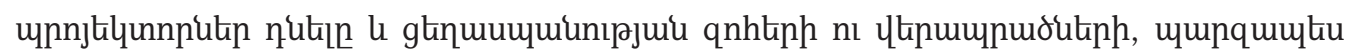

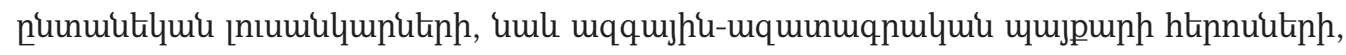

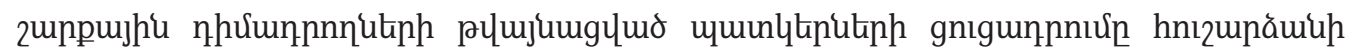

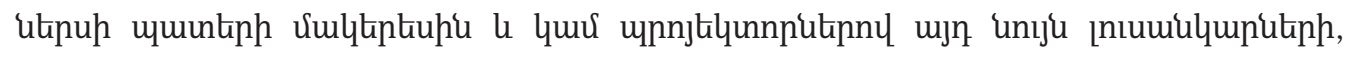

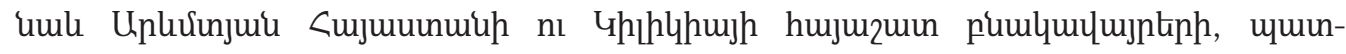

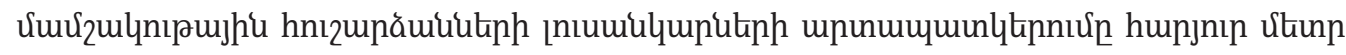

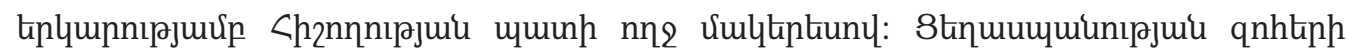

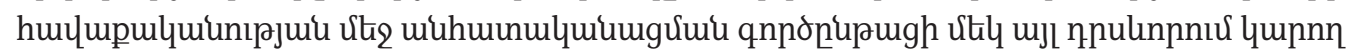

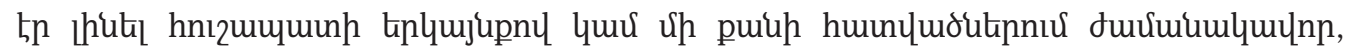

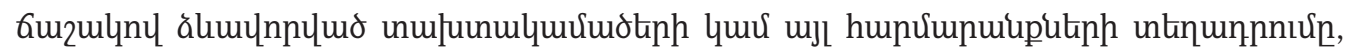

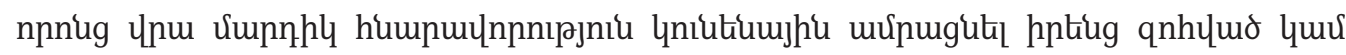

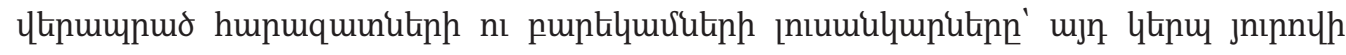

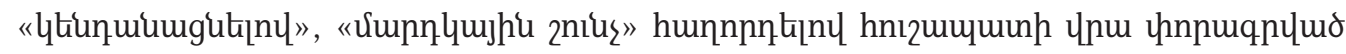

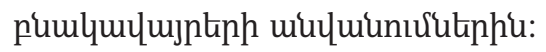

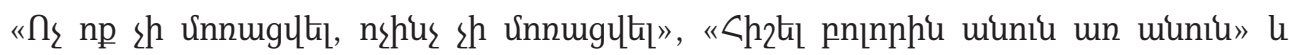

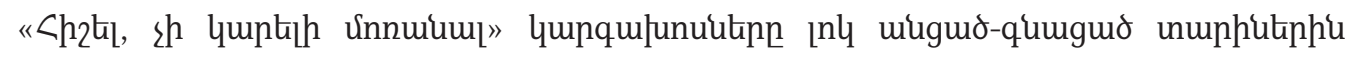

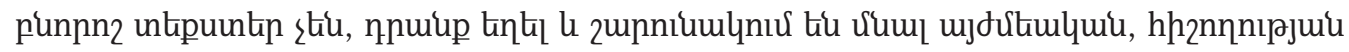

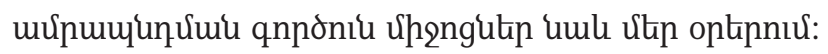

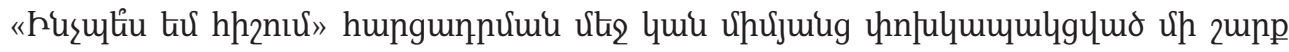

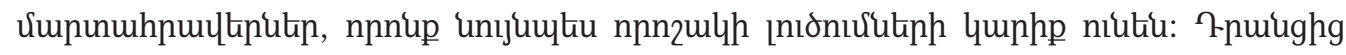

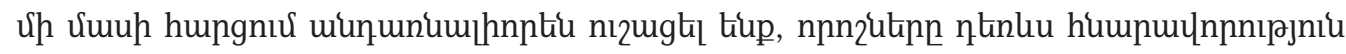

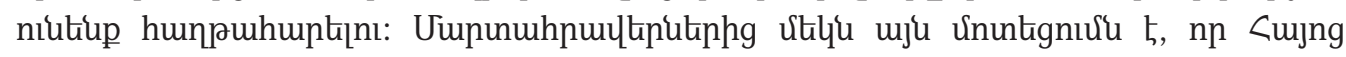

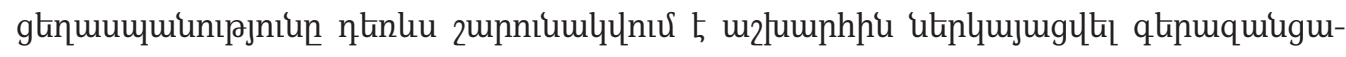




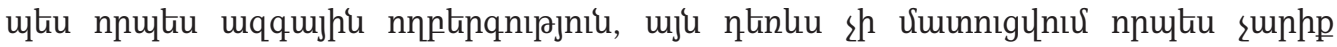

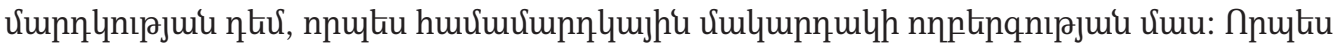

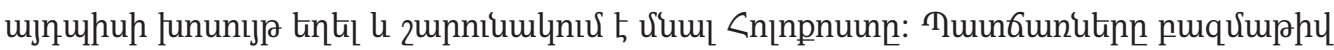

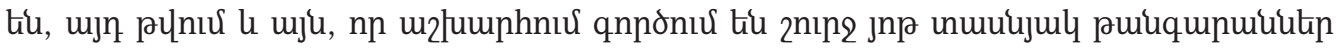

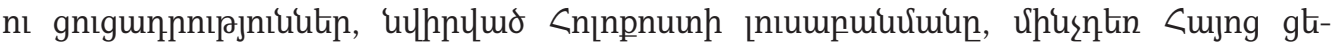

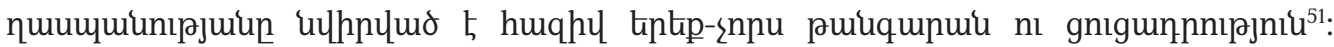

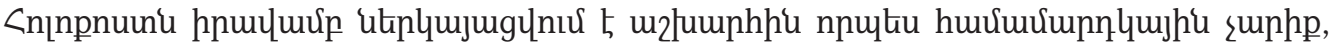

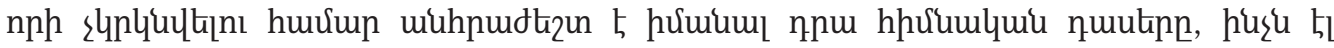

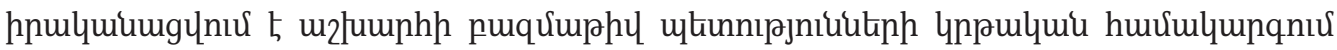

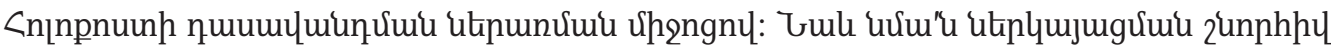

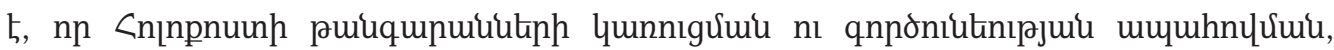

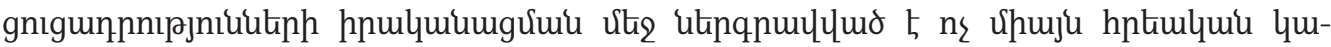

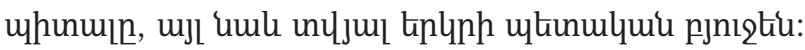

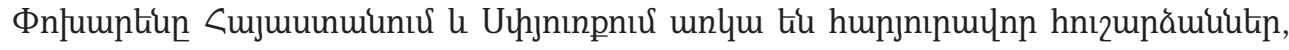

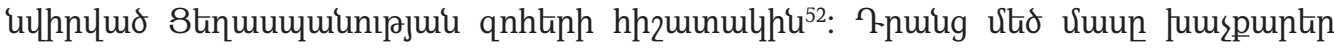

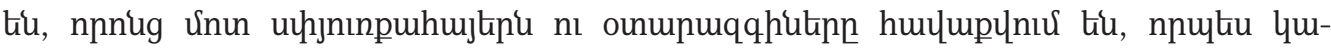

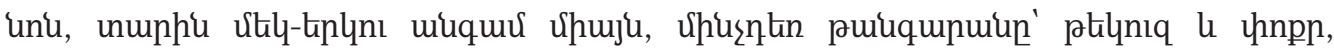

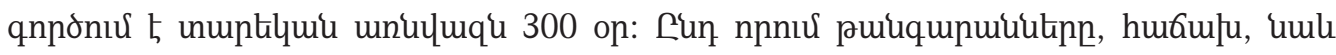

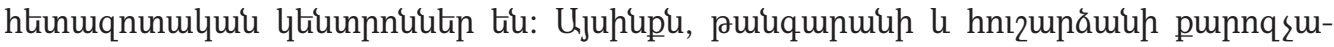

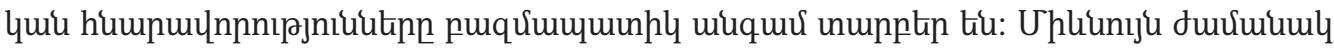

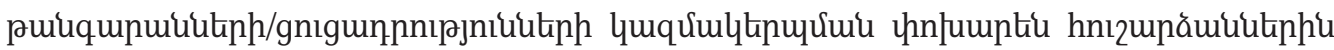

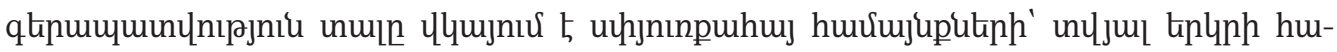

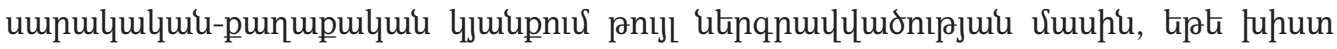

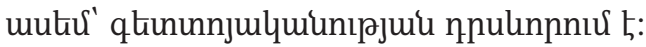

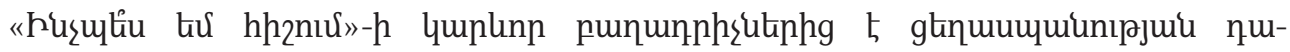

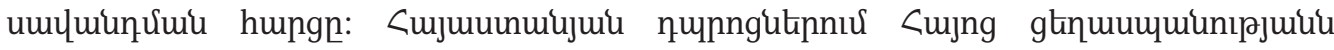

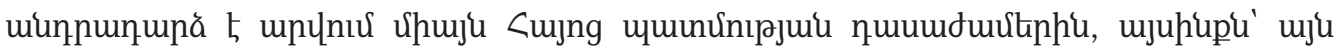

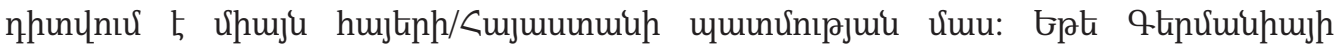

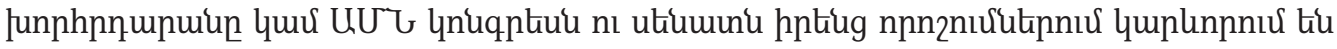

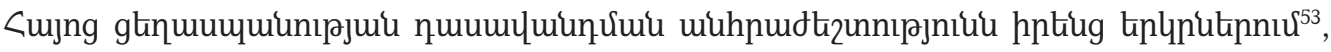

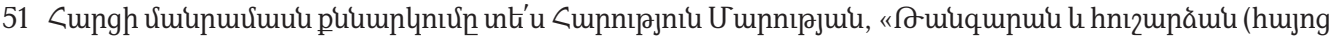

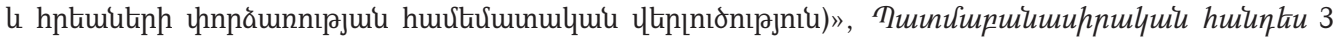
(2014), 58-79; Harutyun Marutyan, "Museums and Monuments: Comparative Analysis of Armenian and Jewish Experiences in Memory Policies," Études Arméniennes Contemporaines 3: Juifs, Arméniens: un siècle d'État (2014): 57-79.

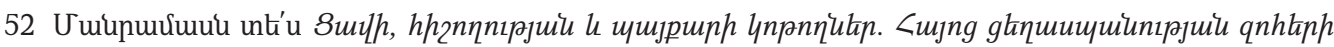

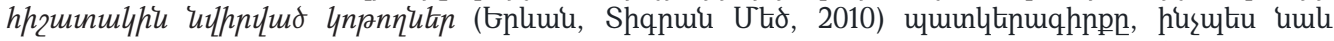

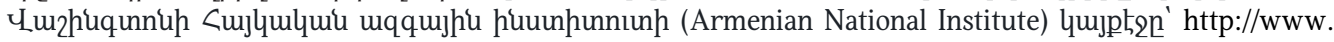
armenian-genocide.org/memorials.html, nhunltkl 5 20.09.2021:

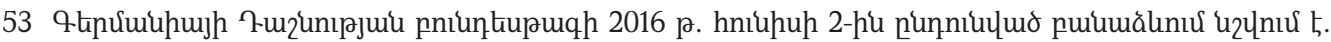

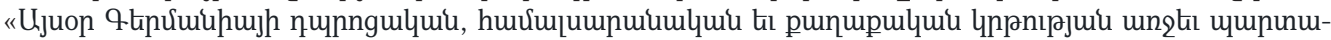

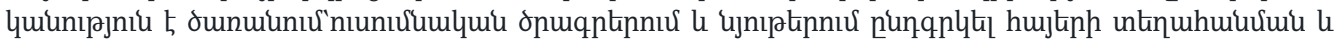




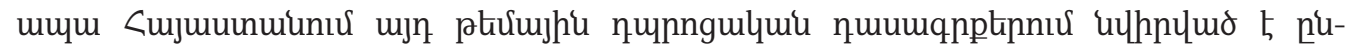

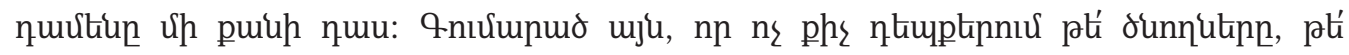

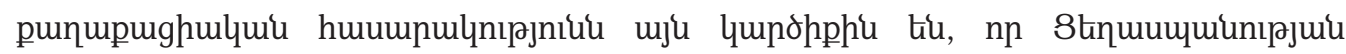

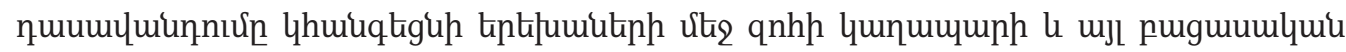

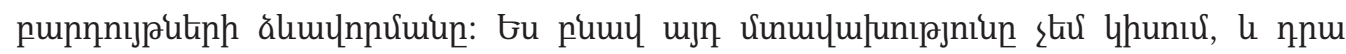

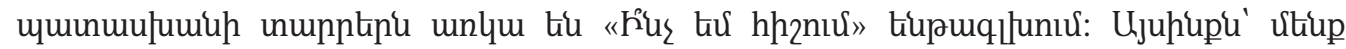

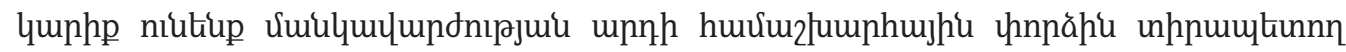

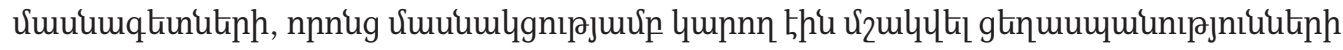

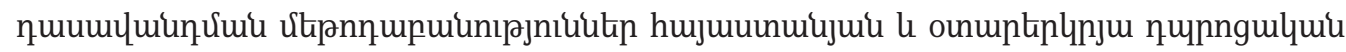

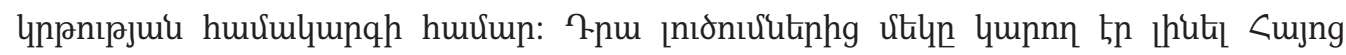

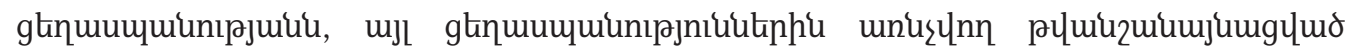

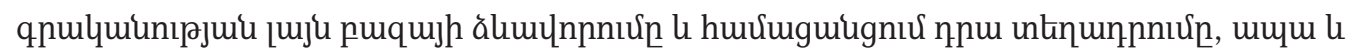

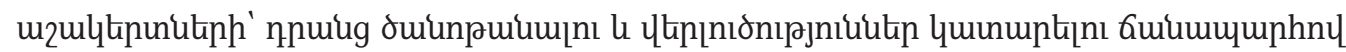

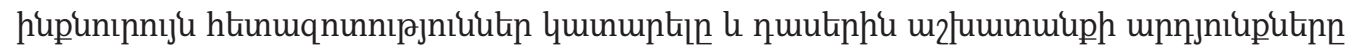

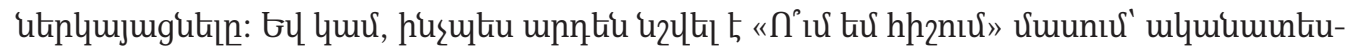

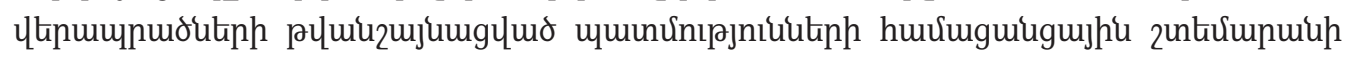

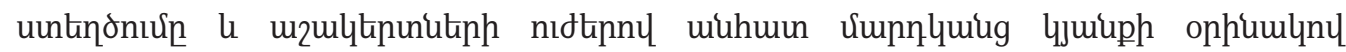

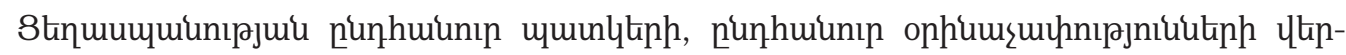

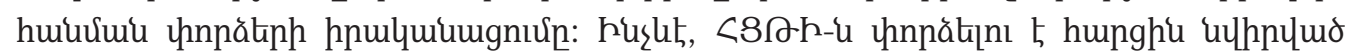

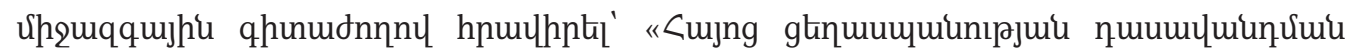

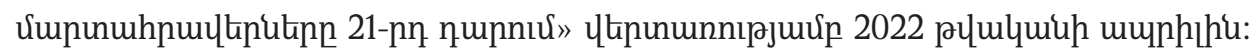

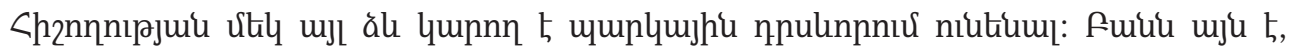

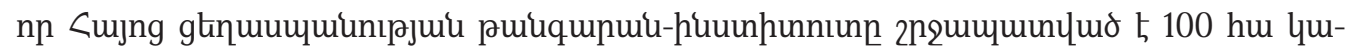

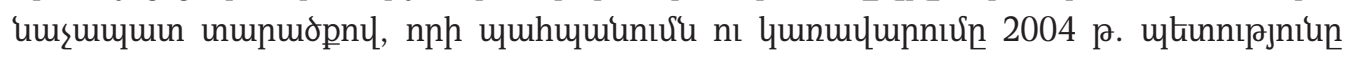

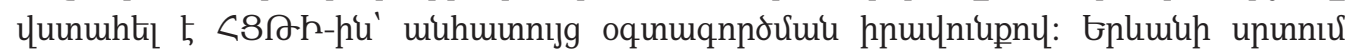

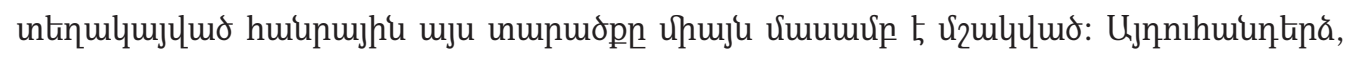

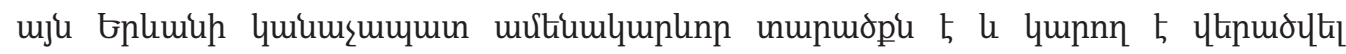

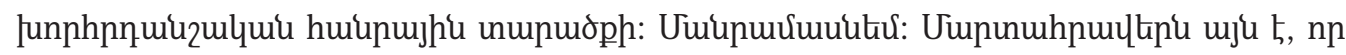

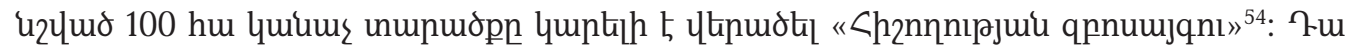

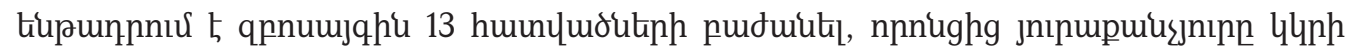

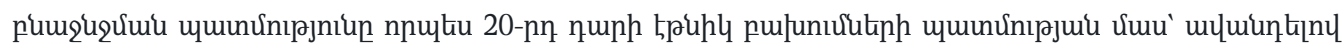
uju quihp uknniunuthpu», http://www.genocide-museum.am/arm/Germany.php: UU lunuqntup

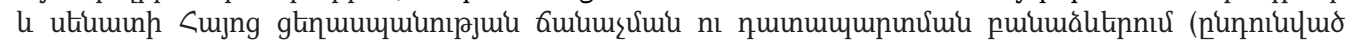

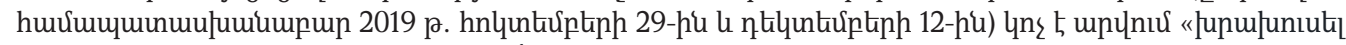

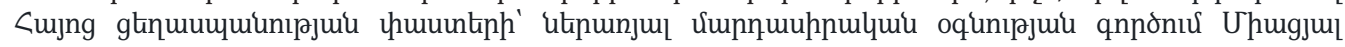

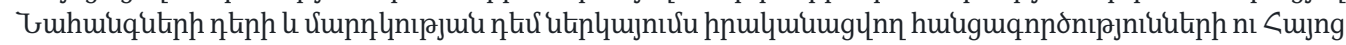

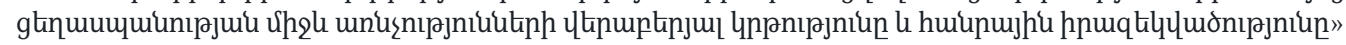
http://www.genocide-museum.am/arm/30.10.2019-USAcongress.php; http://www.genocide-museum.am/ arm/news-H_RES150.php, nhunlkı 5 20.09.2021:

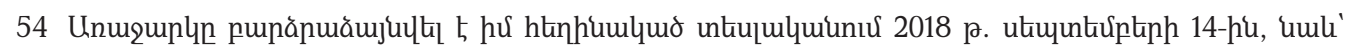

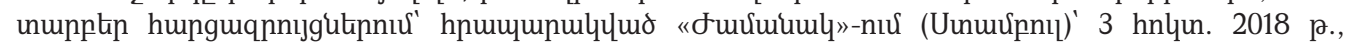

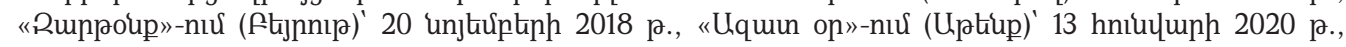

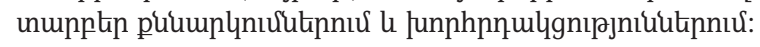




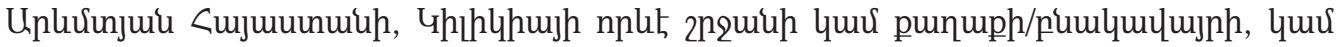

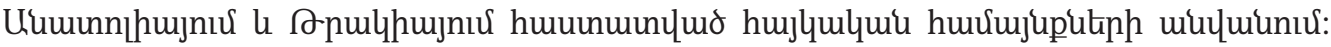

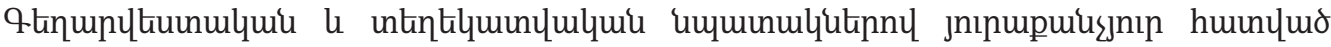

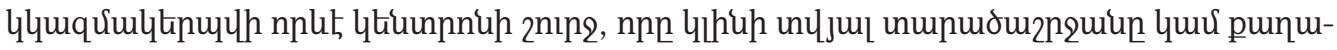

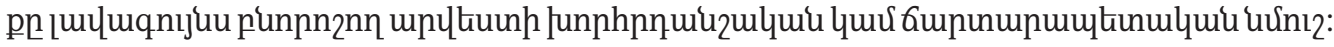

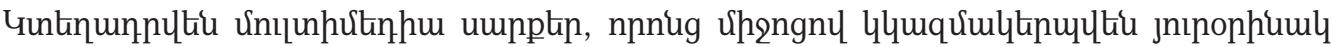

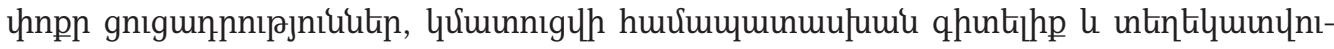

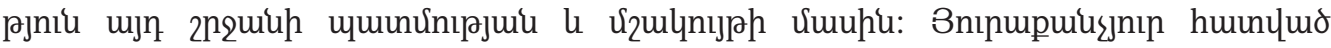

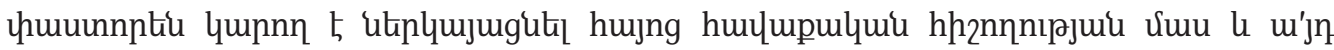

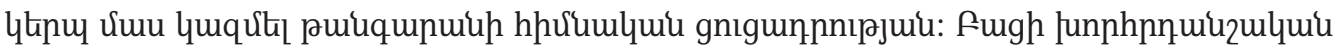

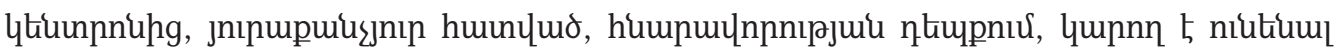

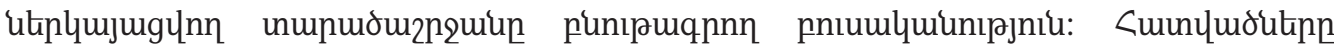

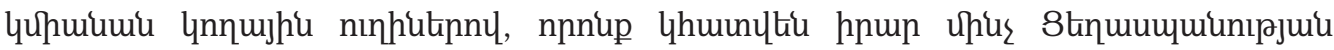

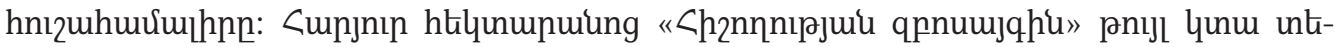

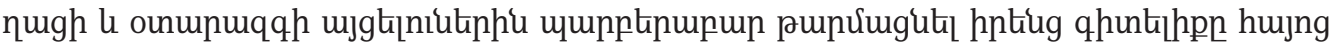

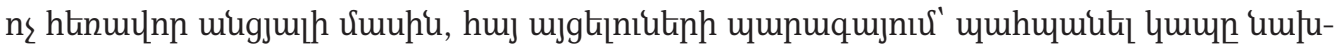

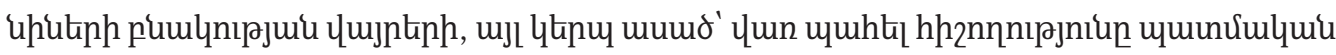

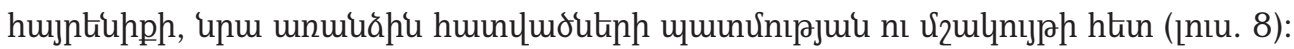

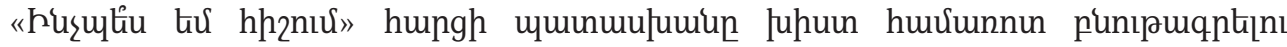

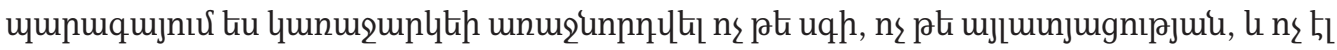

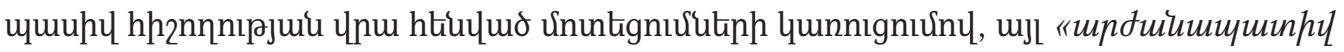

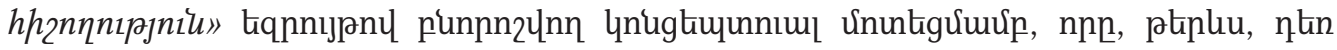

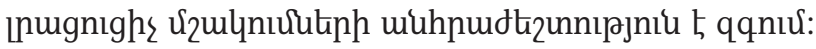

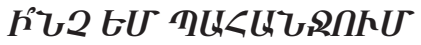

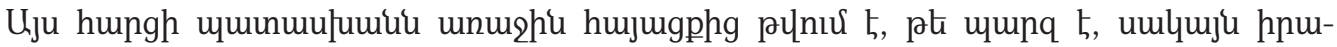

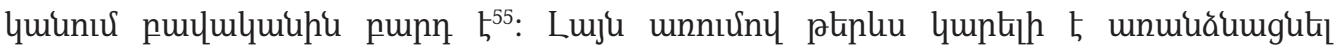

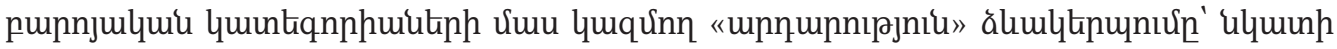

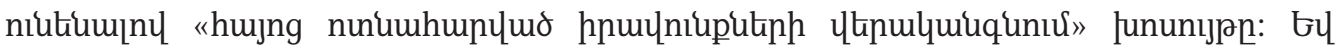

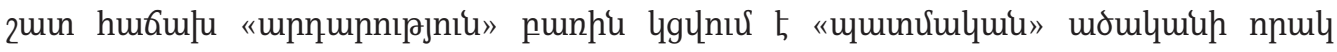

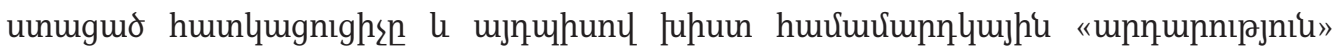

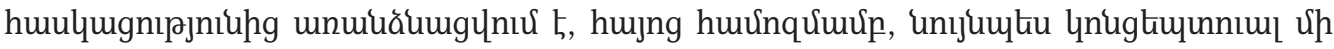

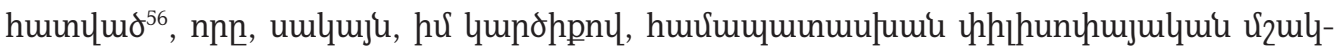

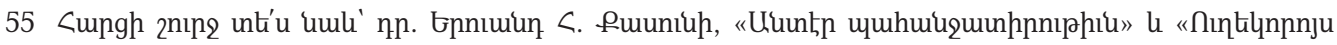

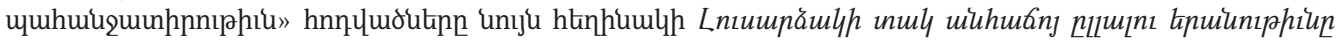

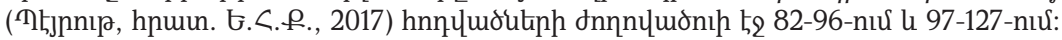

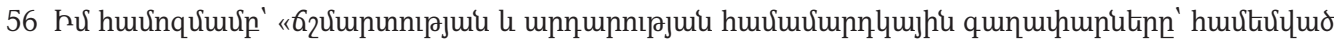

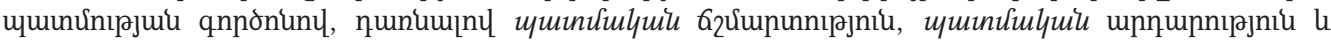

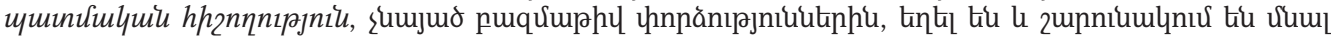

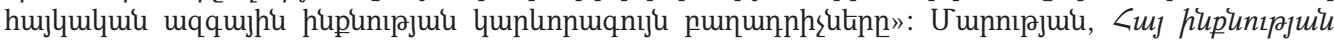




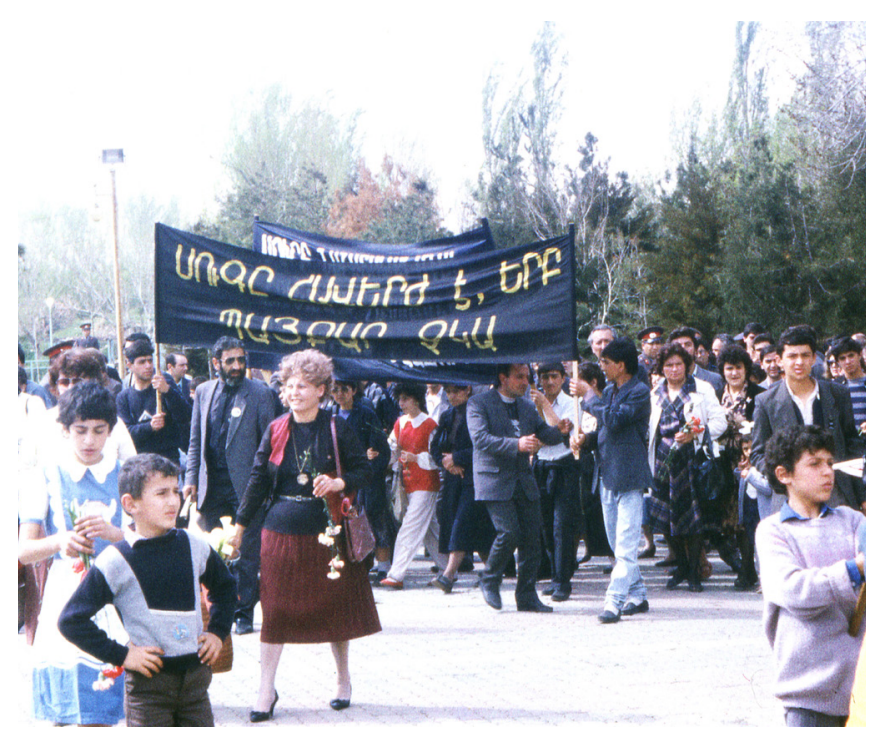

Lniu. 5. Ћpцuq hpruunulh pujlinphg: Lujng gt-

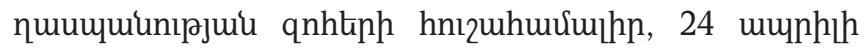
1990 p.: Lnıu.-n’ ' C. Uupnıpjuun:

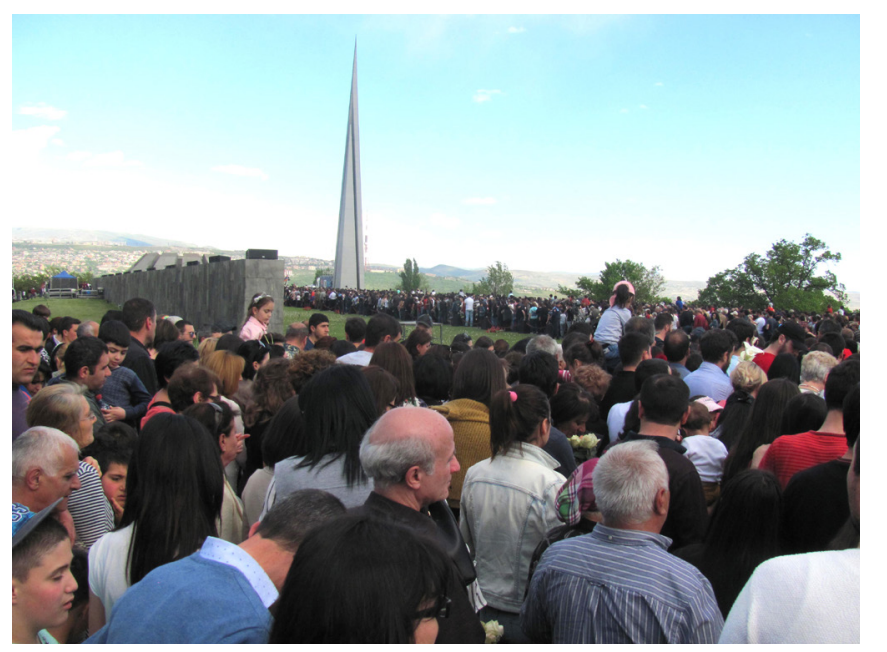

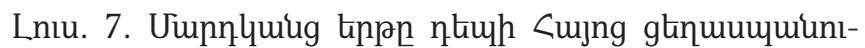
pjuu qnhtinh hnı2unămu: 24 wu्यhıh 2018 p.: Lnıu.-n' C. Uunnıрjuup:

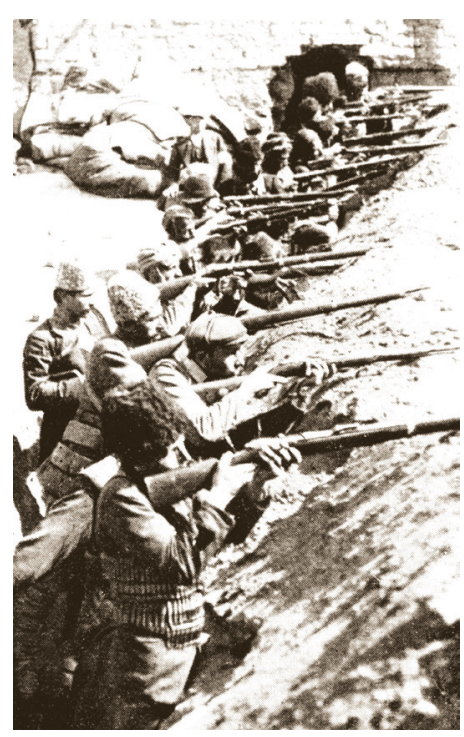

Lniu. 6. १рџmq Ч wü

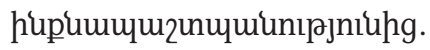
шu्यhl-\{uujhu 1915 р.:

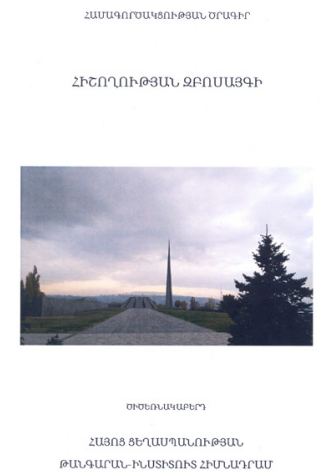

Lnıu. 8. «டhə2nпnıрjui qpnumjqh» umuumqhøn: 2019-20 рр.: 


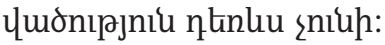

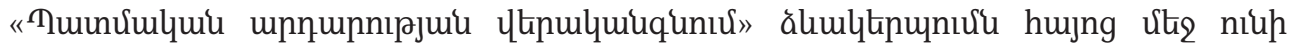

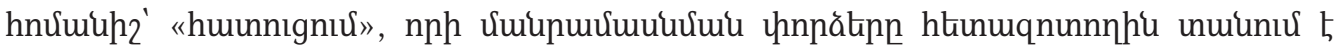

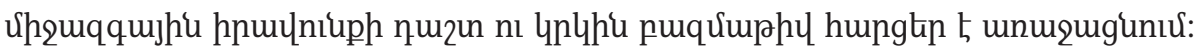

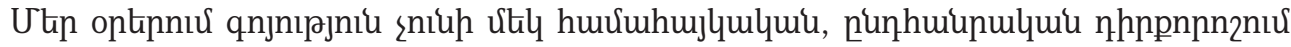

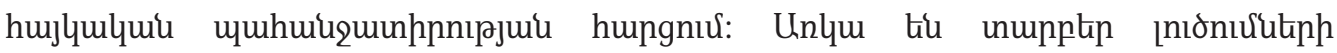

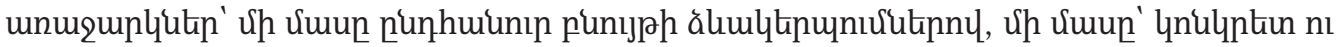

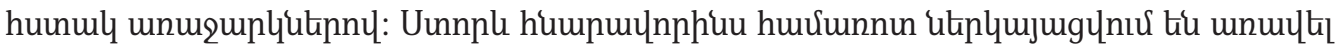
hujunup úp puuh ununtgniưutin $p^{57}$ :

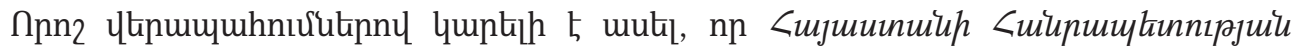

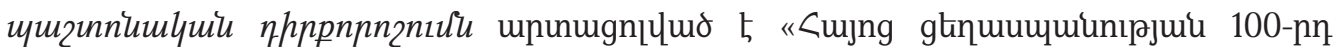

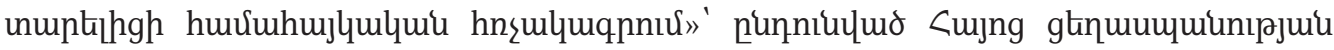

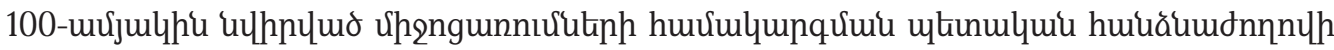

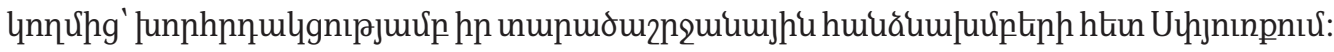

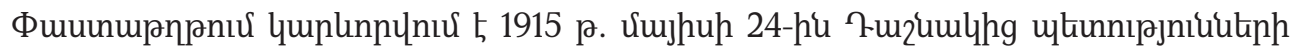

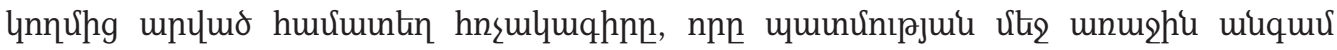

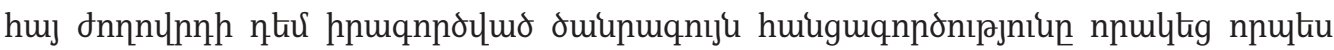

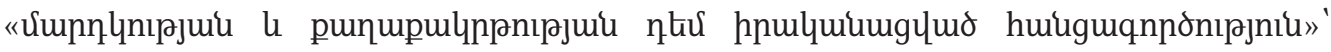

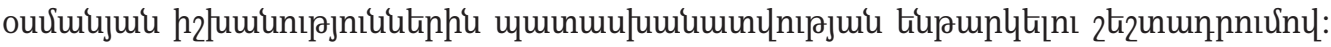

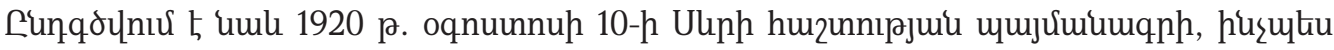

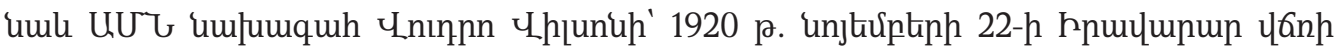

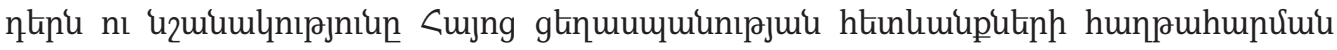
hungniu:

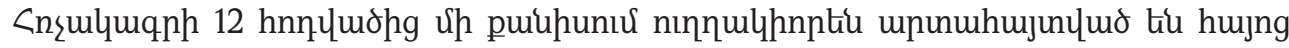

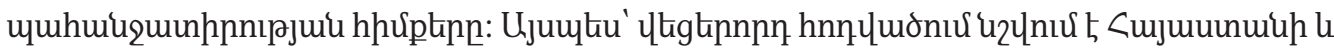

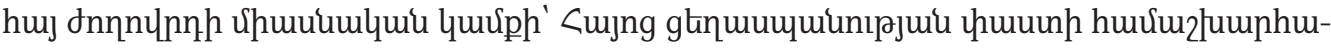

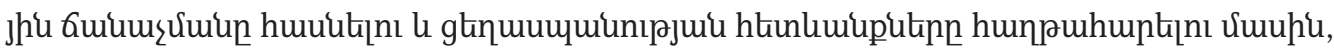

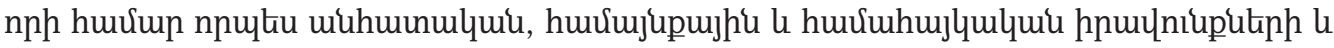

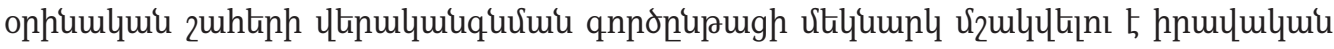

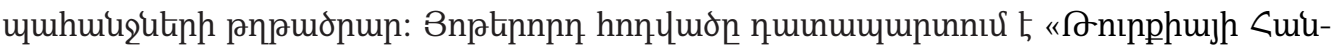

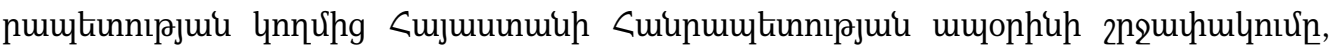

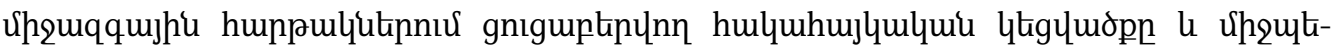

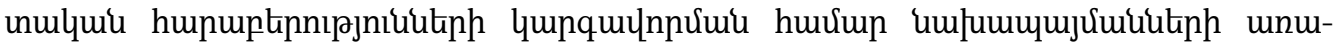

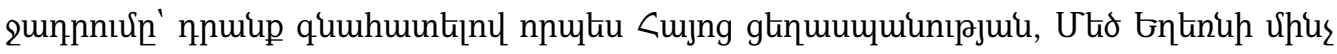

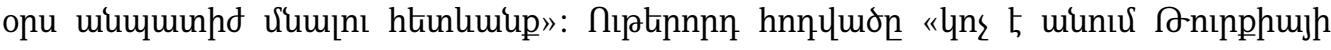

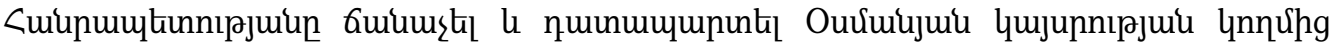

umuinliknuqpnipjniun, t, 176:

57 U munuưuuu unt'u Harutyun Marutyan, "Boundaries/Borders of the Armenian Claims and Possibilities of Inter National Dialogue," in 141 Days in Action. January 19 ${ }^{\text {th }}$ Initiative ([Yerevan], United in Rights, 2017), 048-058. 


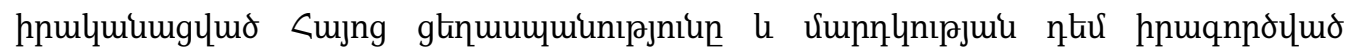

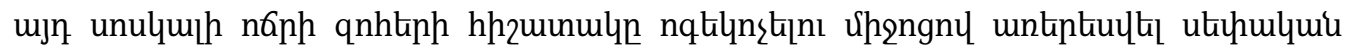

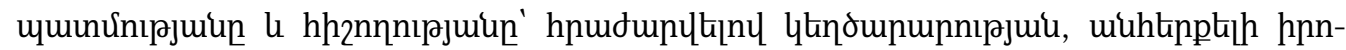

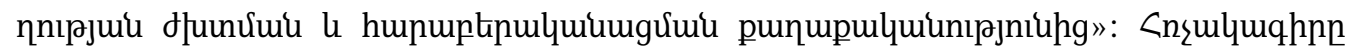

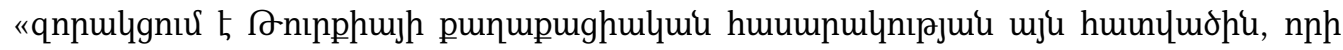

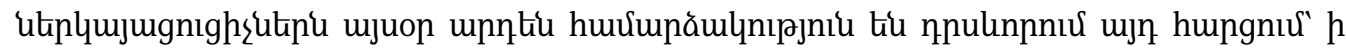

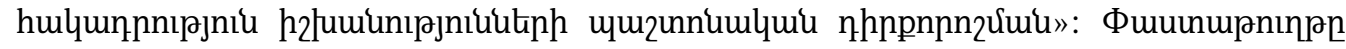

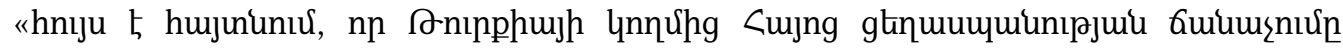

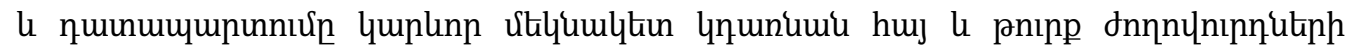

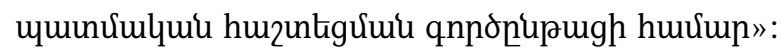

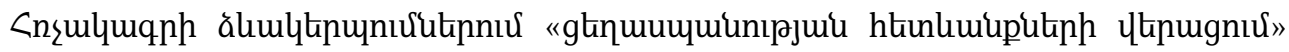

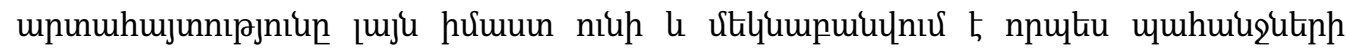

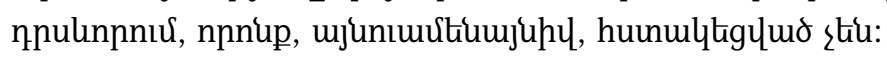

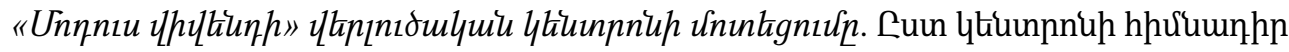

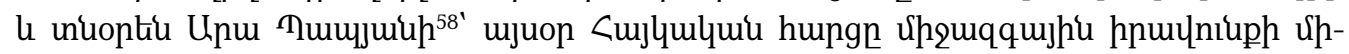

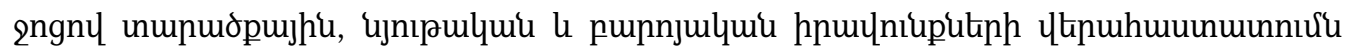

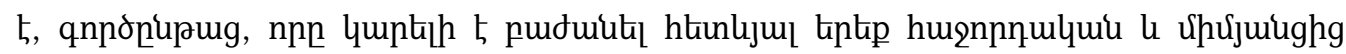

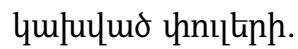

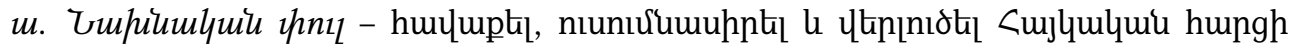

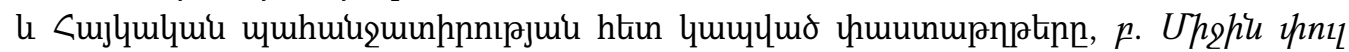

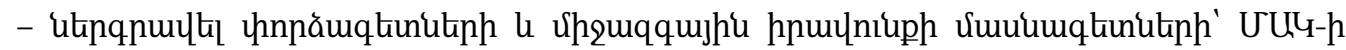

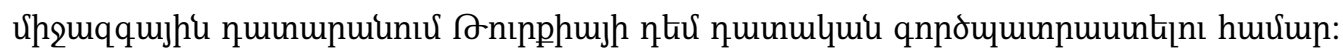

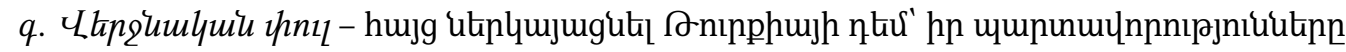

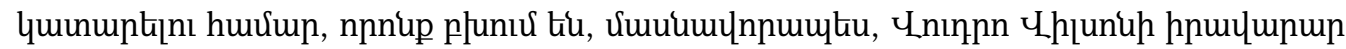
ufinh:

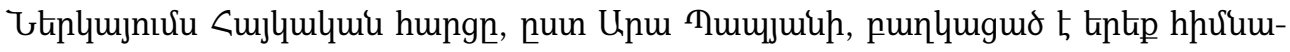

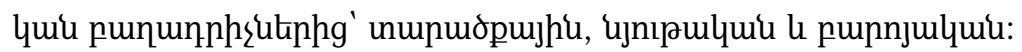

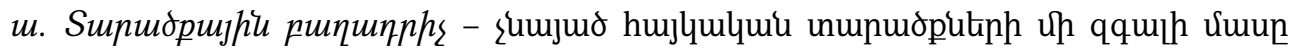

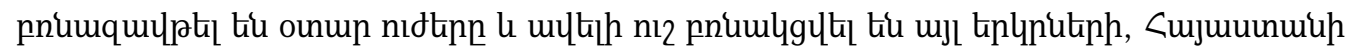

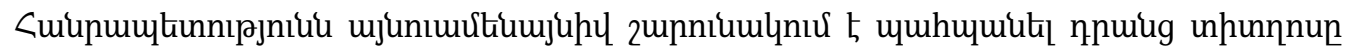

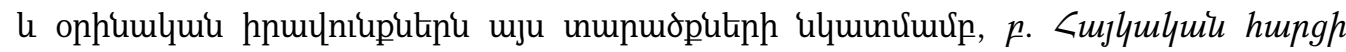

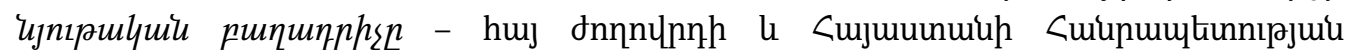

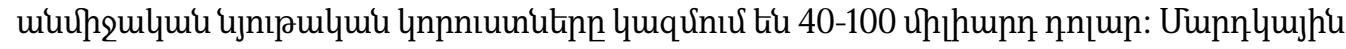

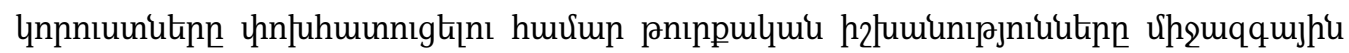

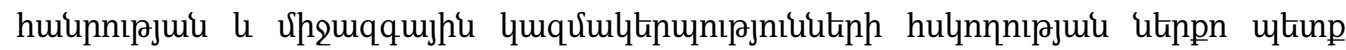

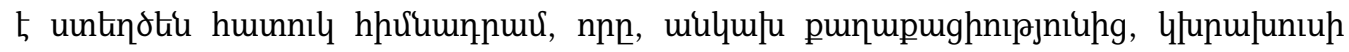

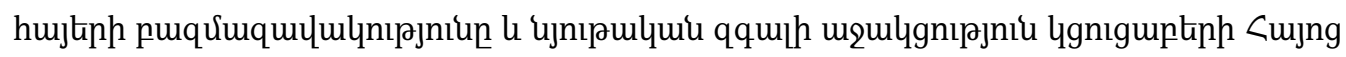

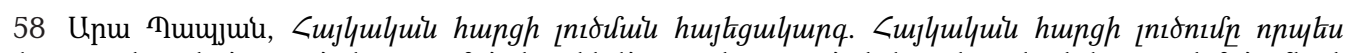

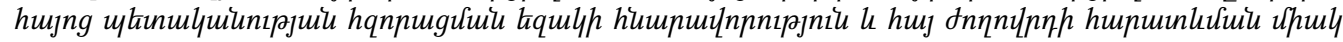
ninh, http://www.modusvivendicenter.org/hy/node/2574, nhunltıl 5 20.09.2021: 


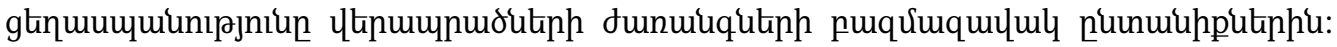

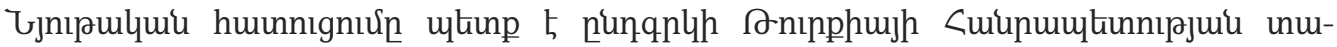

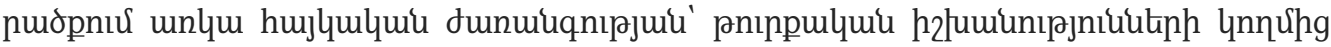

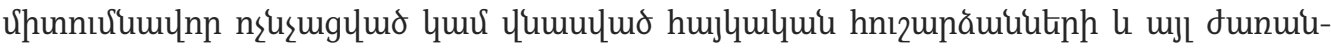

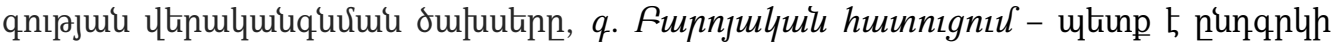

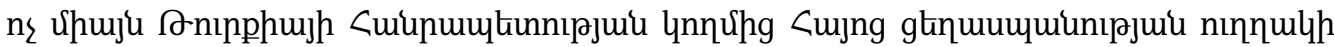

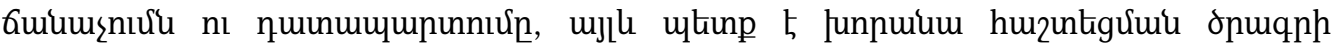

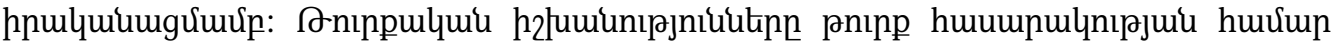

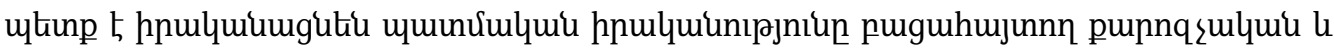

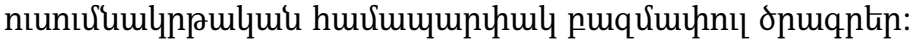

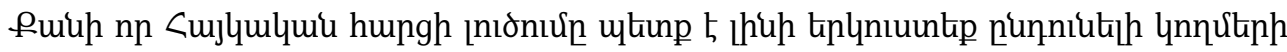

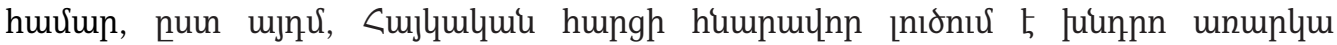

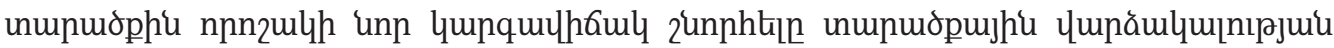

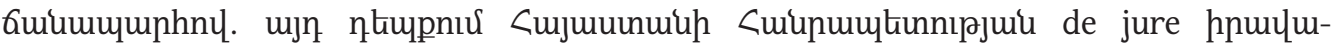

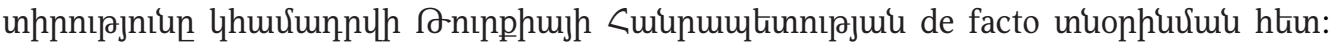

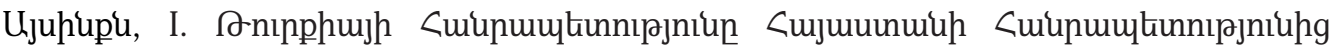

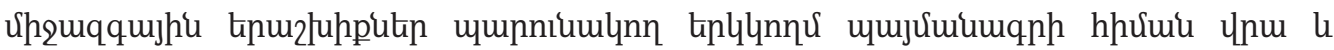

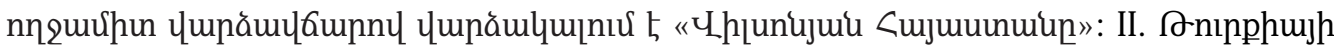

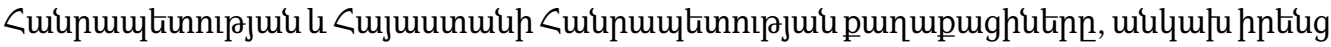

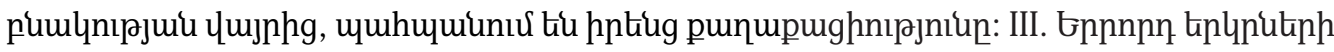

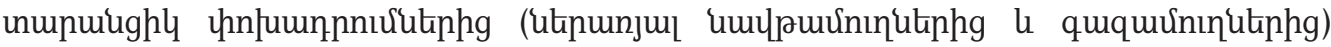

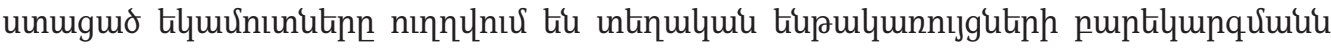

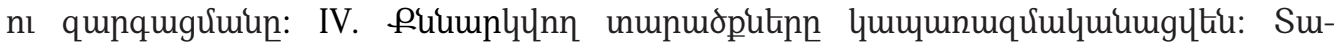

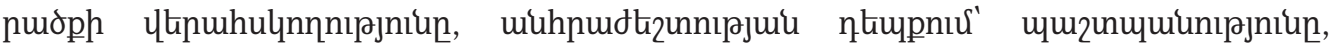

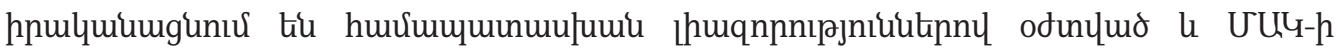

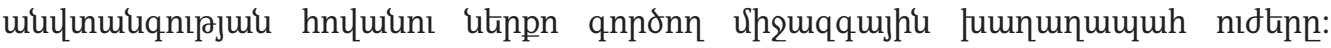

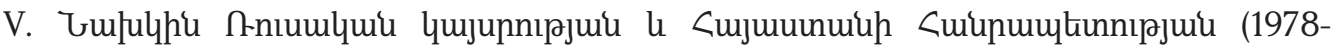

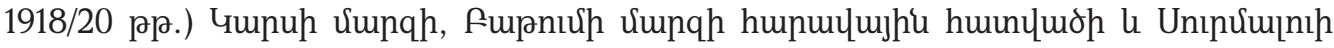

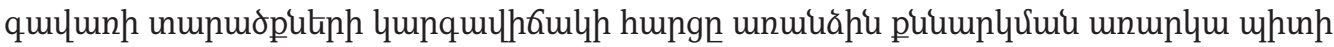

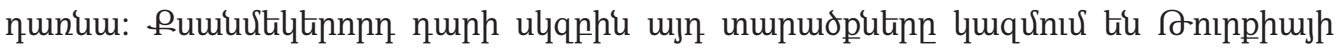

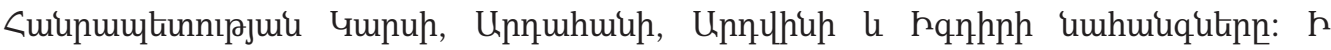

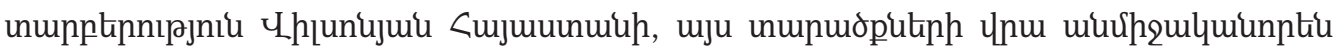

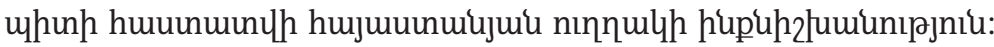

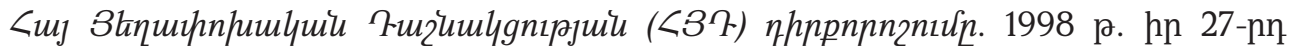

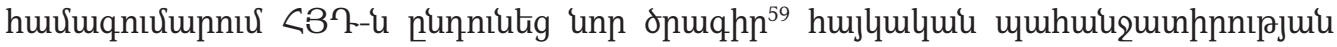

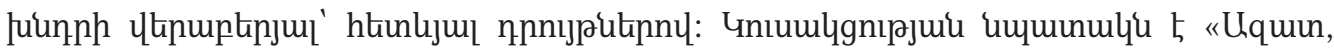

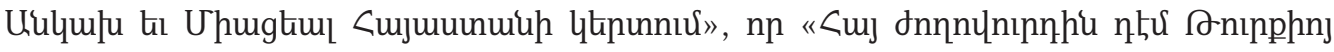

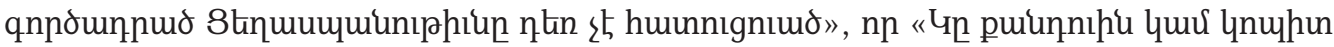

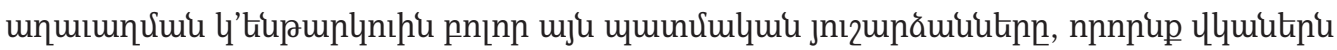




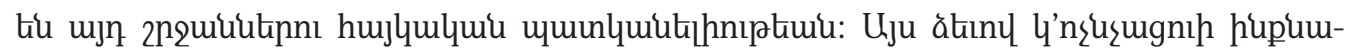

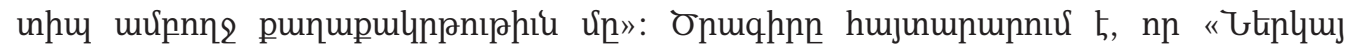

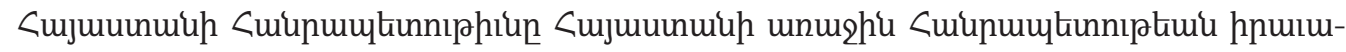

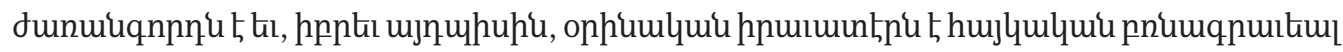

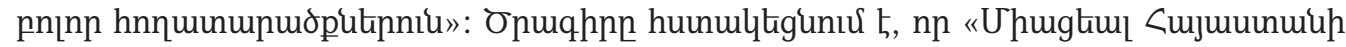

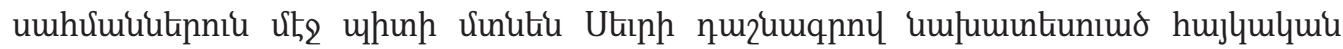

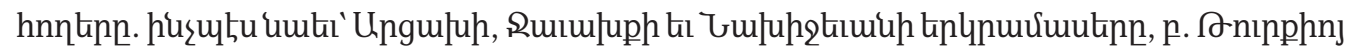

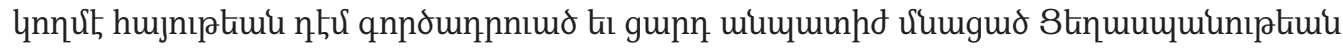

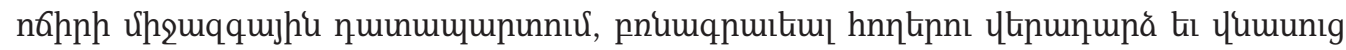

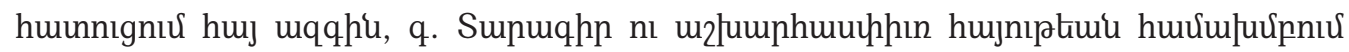

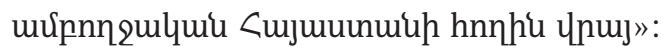

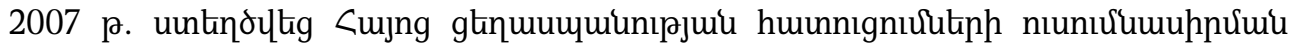

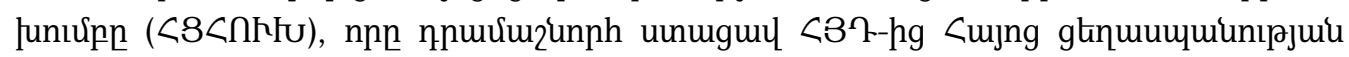

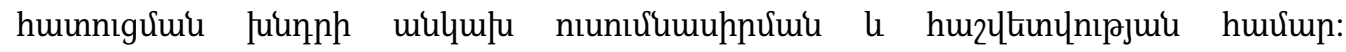

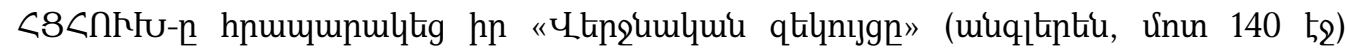

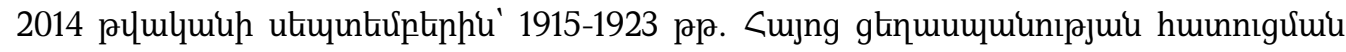

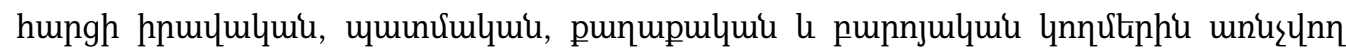

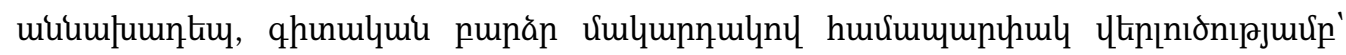

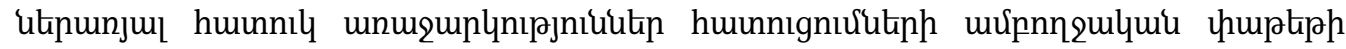
pununnhşutph hưump ${ }^{60}$ :

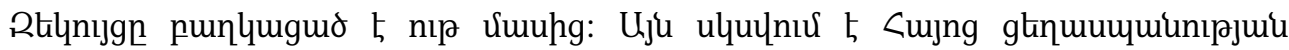

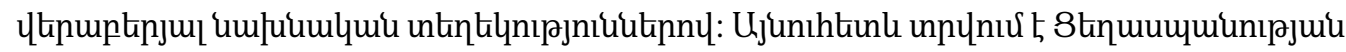

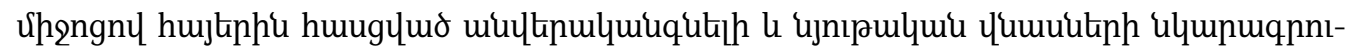

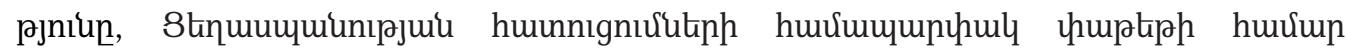

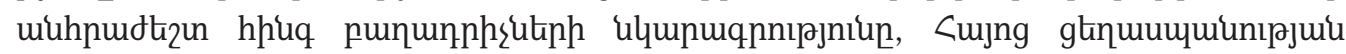

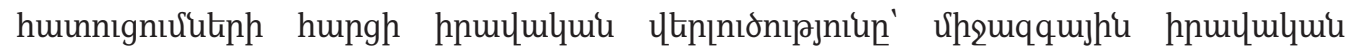

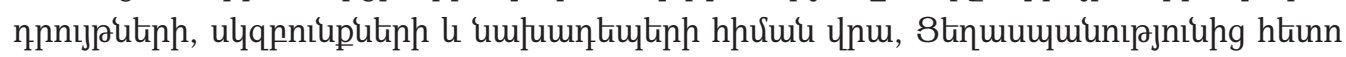

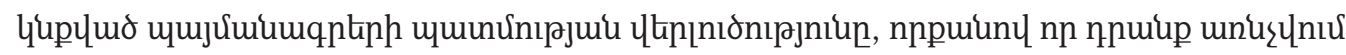

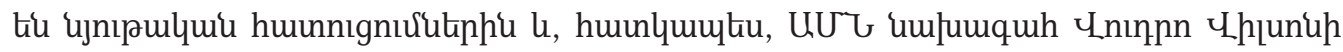

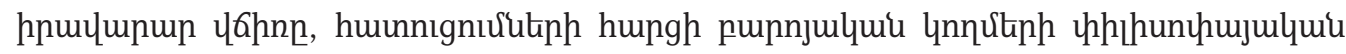

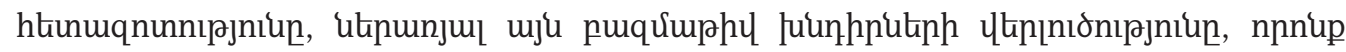

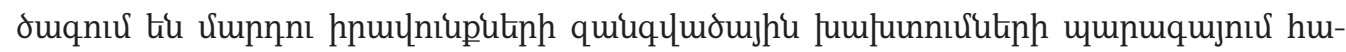

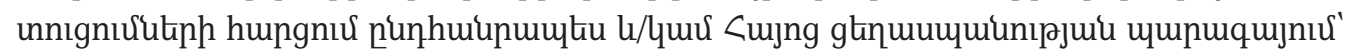

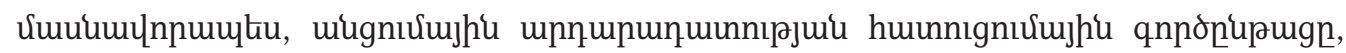

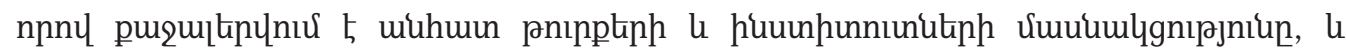

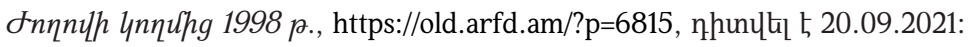

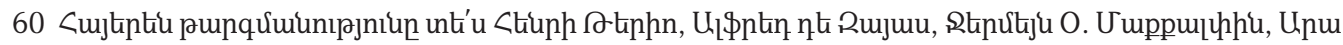

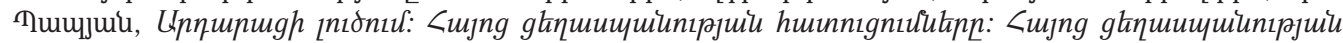

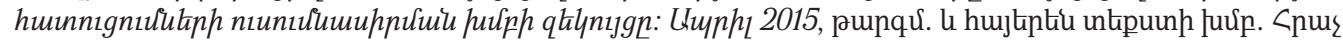
Ulnunıjuuh, http://www.armeniangenocidereparations.info/wp-content/uploads/2017/10/broshure_arm.pdf, nhunult 5 20.09.2021: 


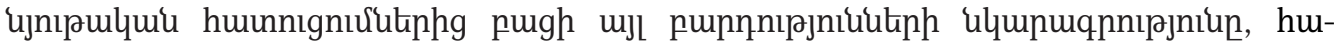

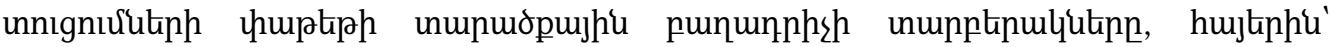

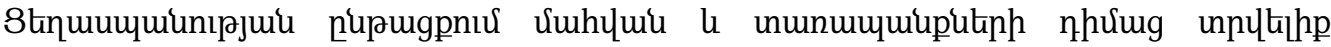

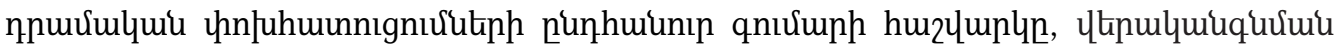

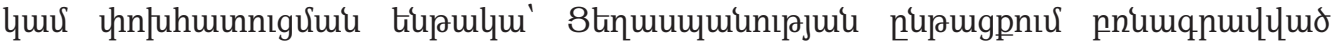

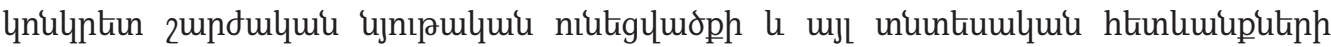

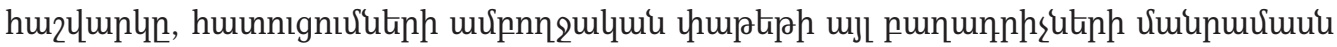
ulumuqnnıрjniun:

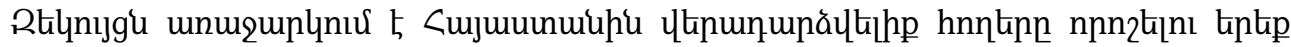

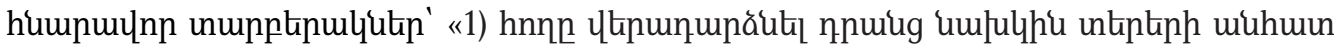

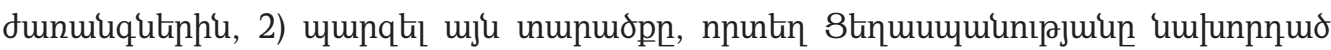

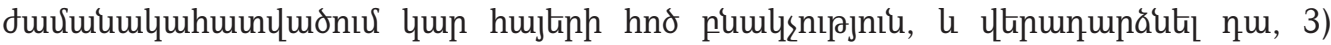

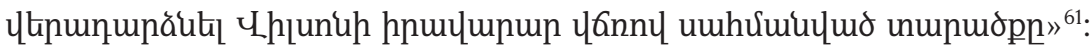

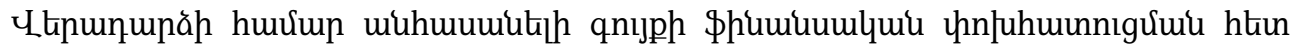

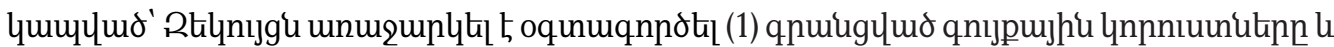

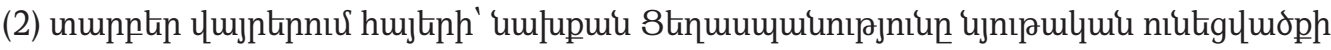

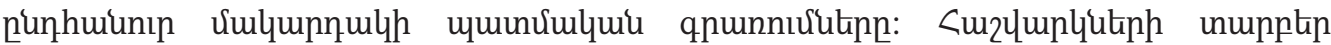

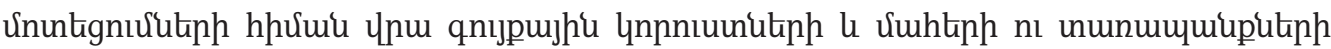

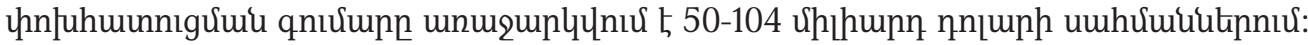

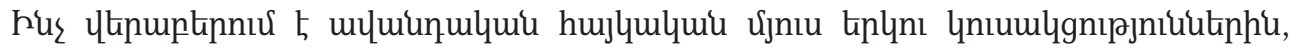

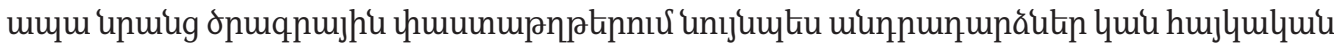

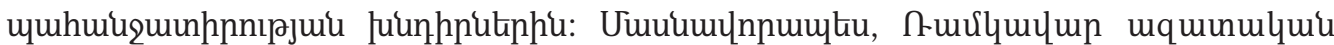

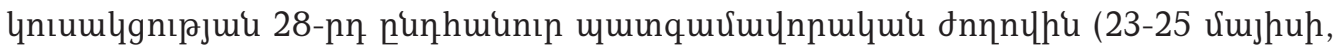

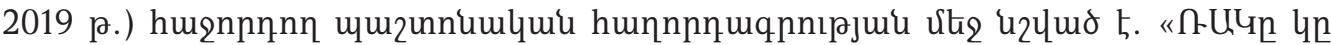

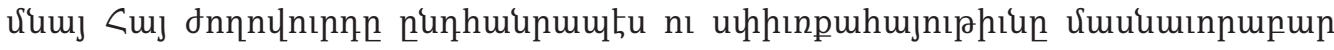

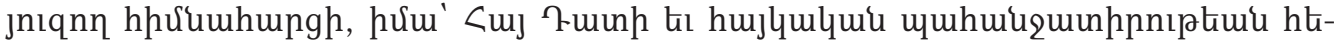

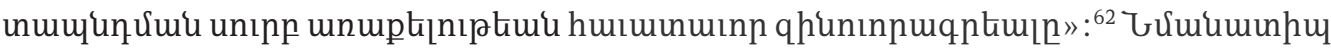

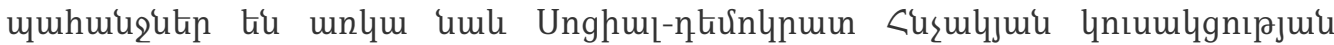
щum

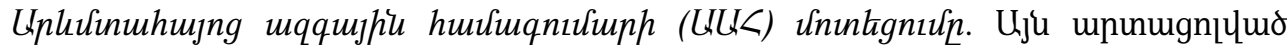

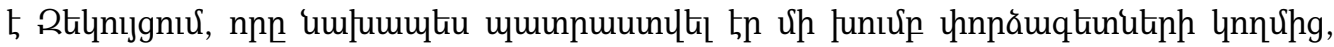

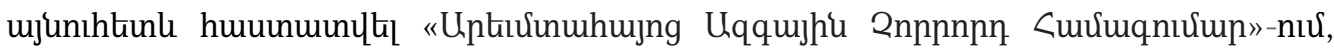

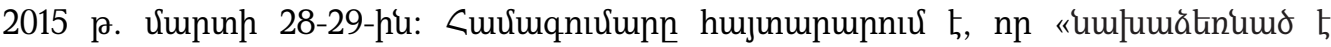

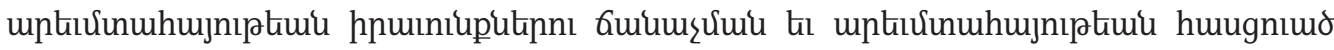

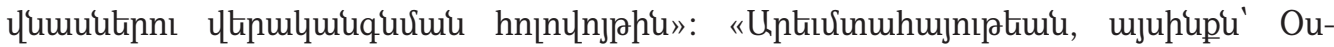

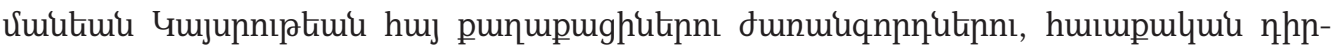

61 tnıju untinnư, 155-156:

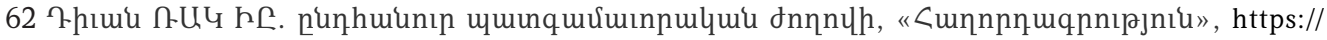
ramgavar.am/\%D5\%BC\%D5\%A1\%D5\%AF/\%D5\%B0\%D5\%A1\%D5\%B2\%D5\%B8\%D6\%80\%D5\%A4\%D5\%A1\%D5

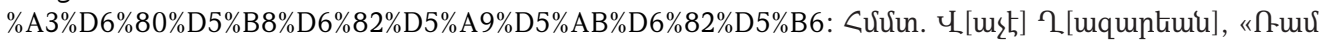

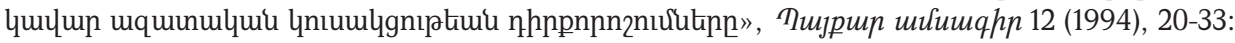




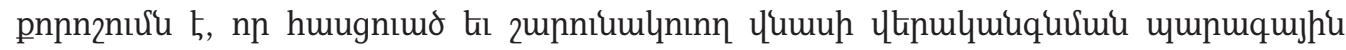

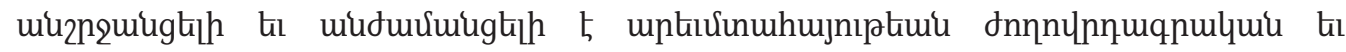

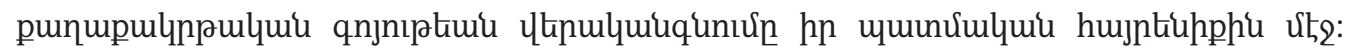

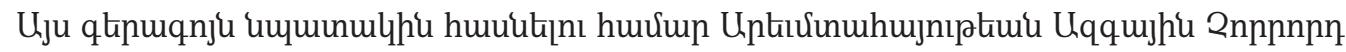

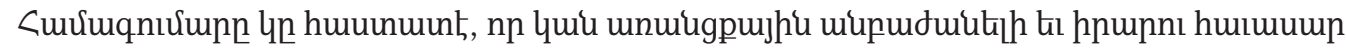

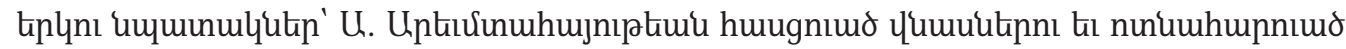

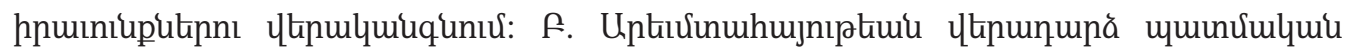

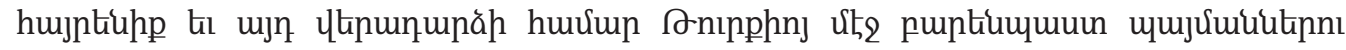

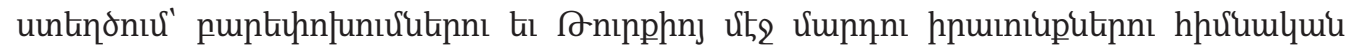

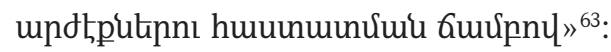

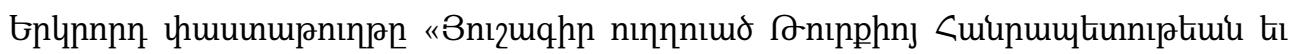

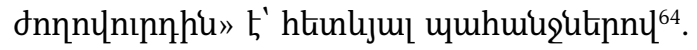

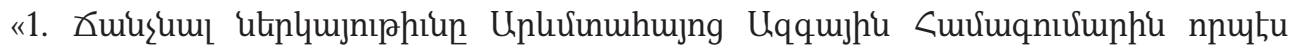

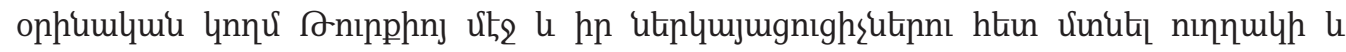

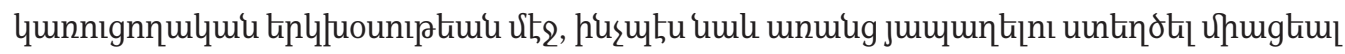

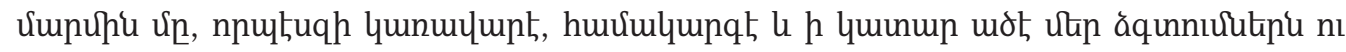
umnumuhnuithnutinn:

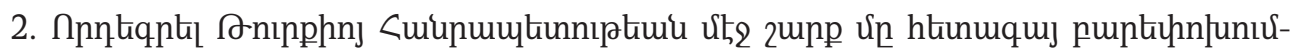

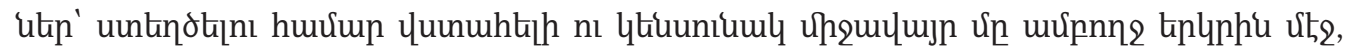

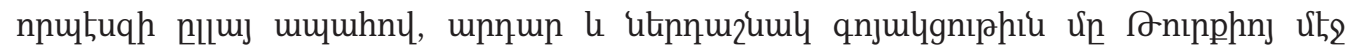

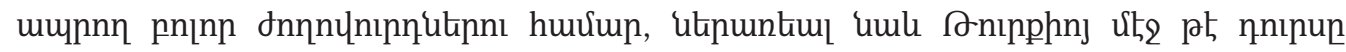

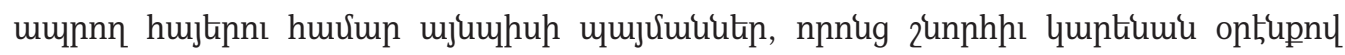

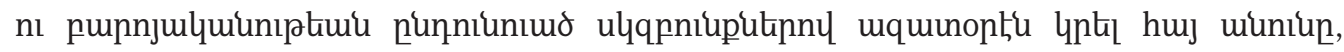

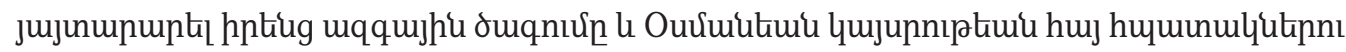

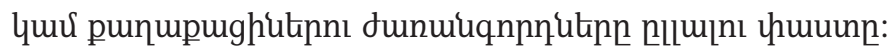

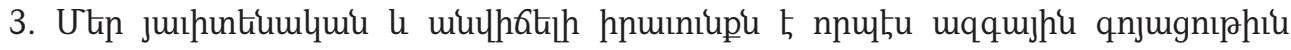

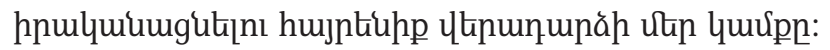

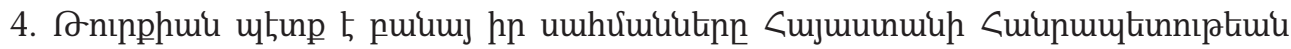

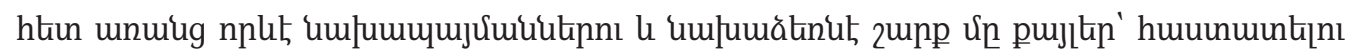

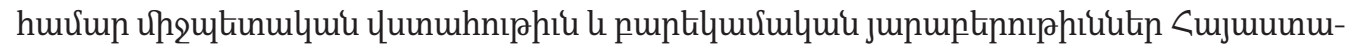

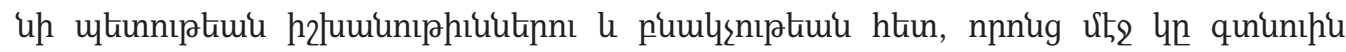

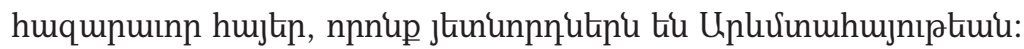

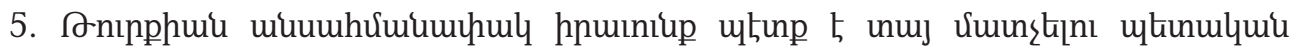

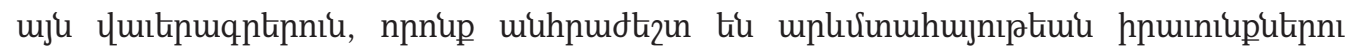

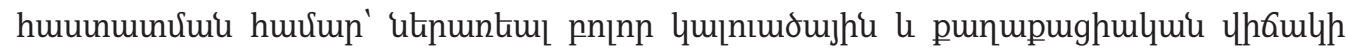

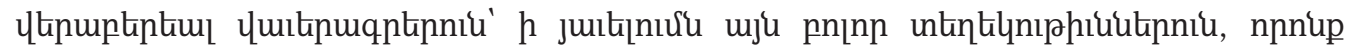

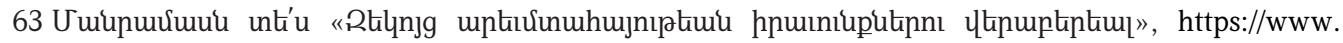
cnarmeniens.org/congress-document1, nhunlthl 5 20.09.2021:

64 "Memorandum Addressed to the Government and the People of the Republic of Turkey," Paris, 29 March 2015, http://cnarmeniens.org/4thCongress, nhunцlıl 5 20.09.2021: 


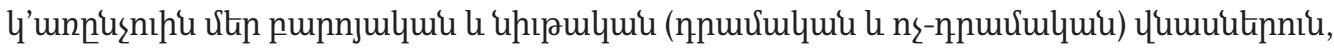

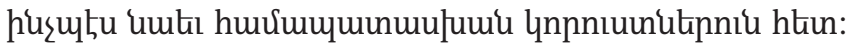

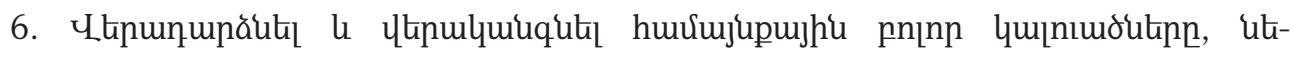

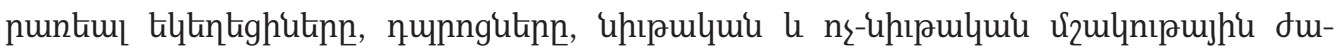
nuiqniphiuutinn:

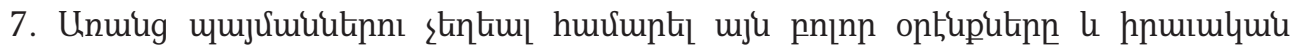

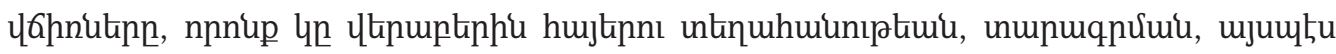

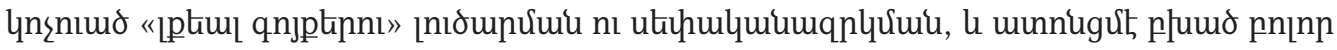

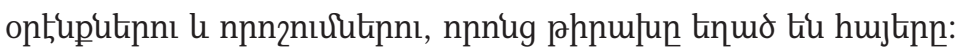

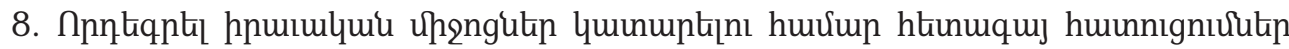

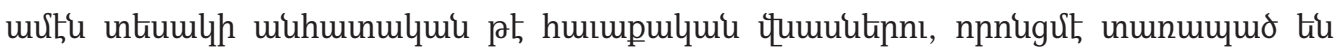
Uplưunuhwe utip umbuuhutinn»:

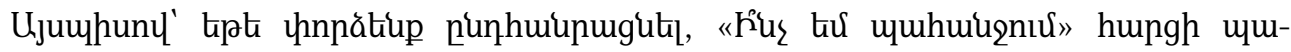

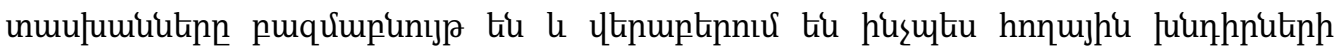

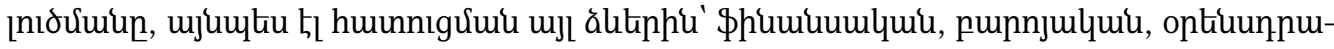

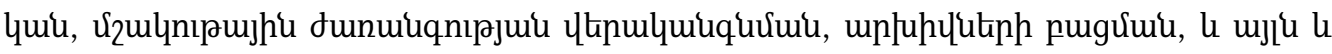

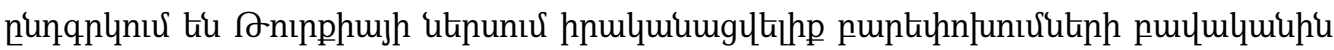

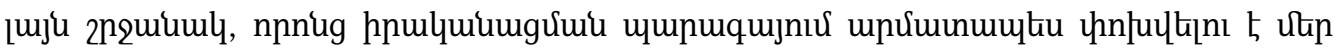
huplumu ukinnnpjui punıpn:

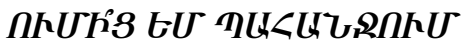

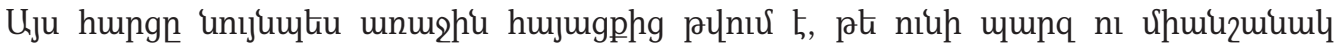

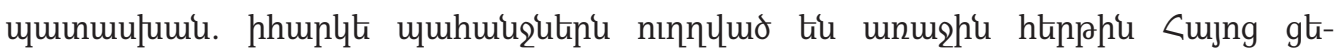

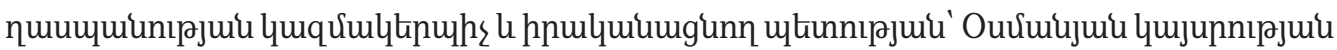

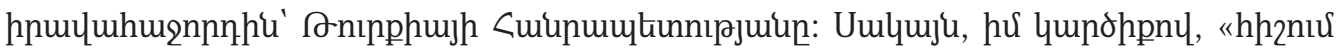

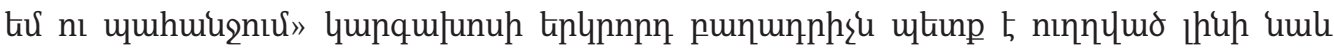

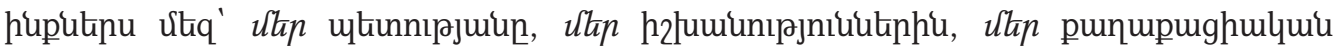

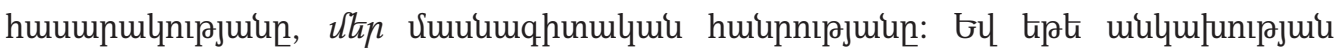

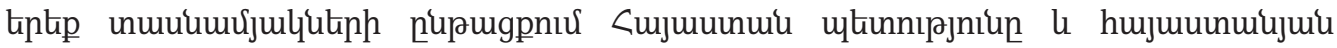

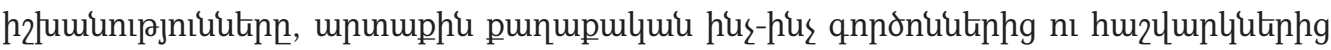

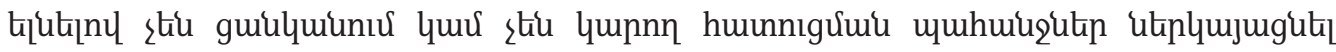

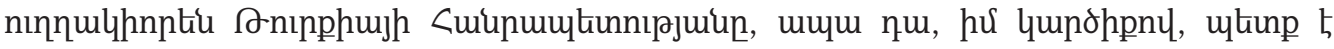

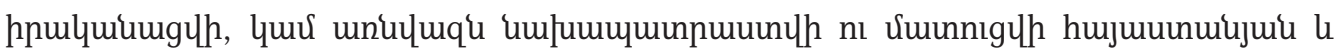

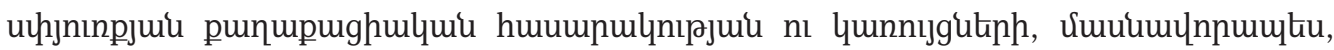

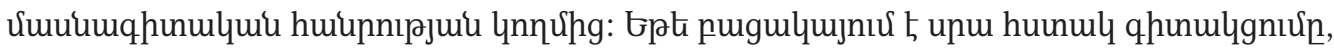

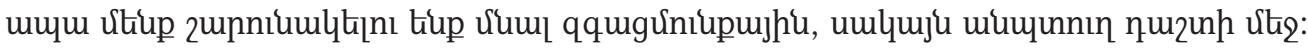

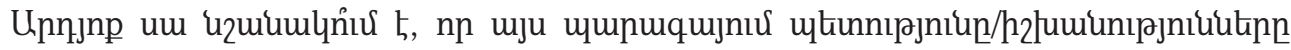

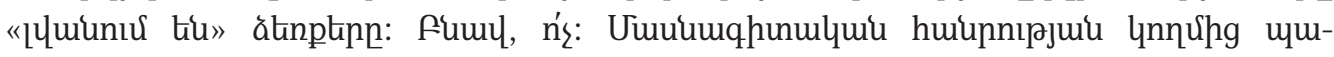

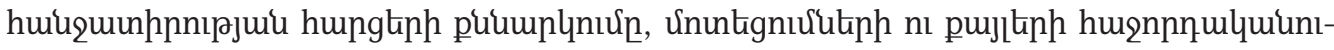




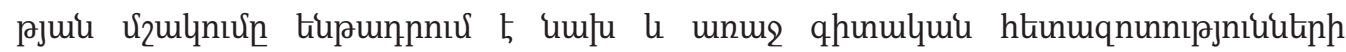

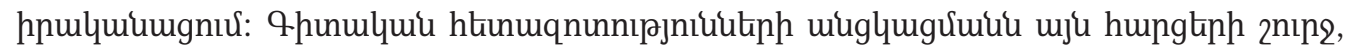

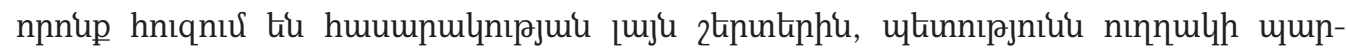

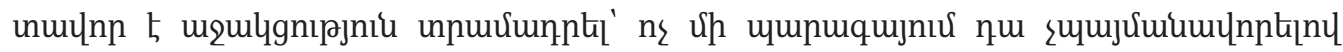

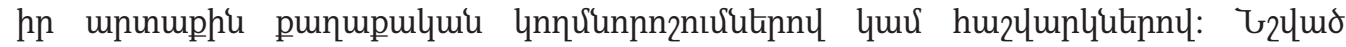

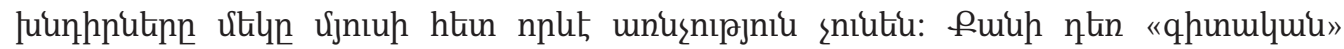

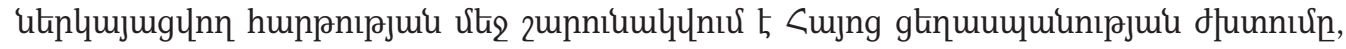

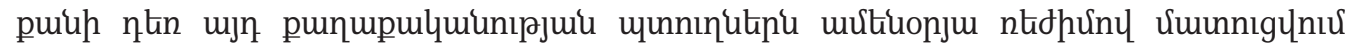

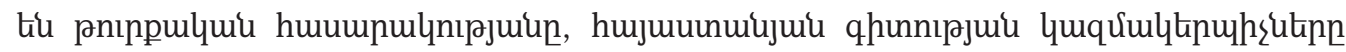

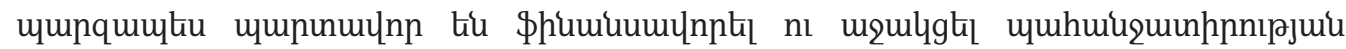

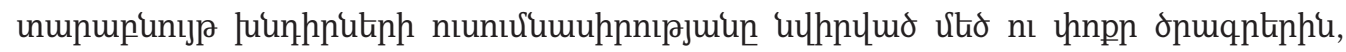

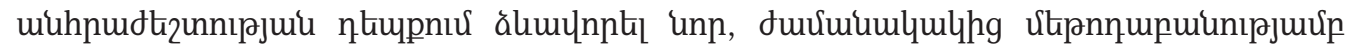

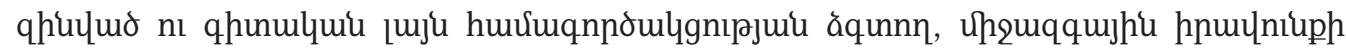

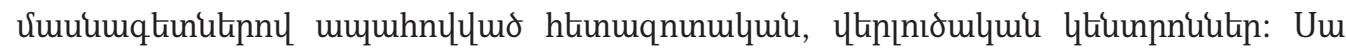

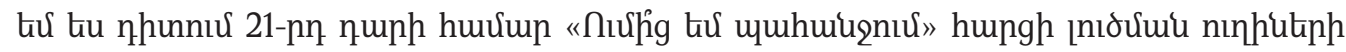

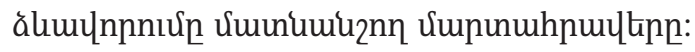

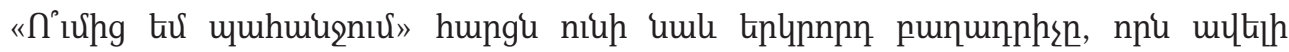

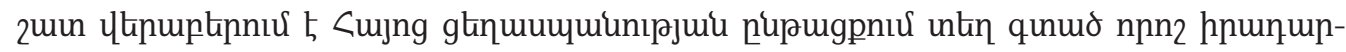

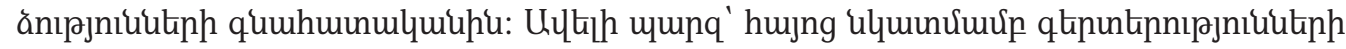

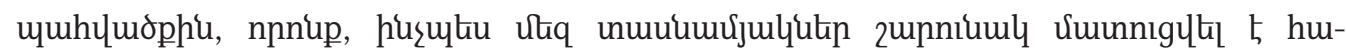

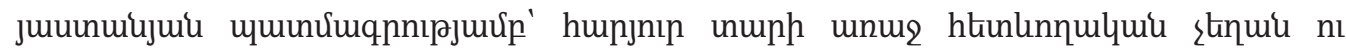

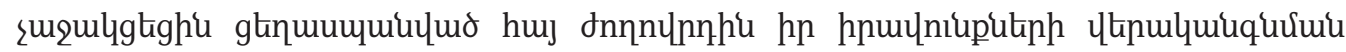

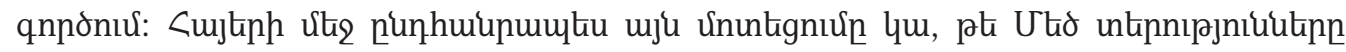

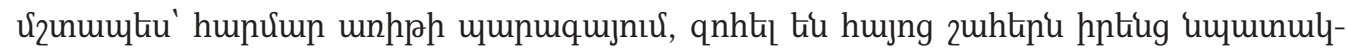

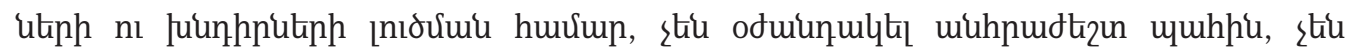

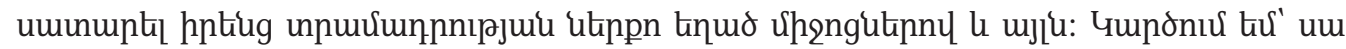

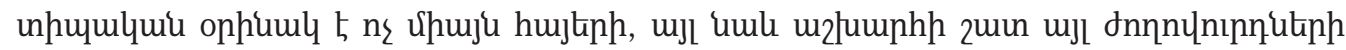

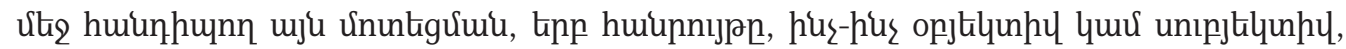

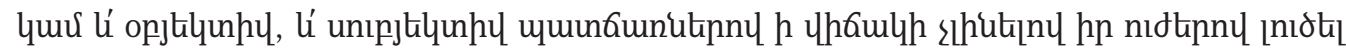

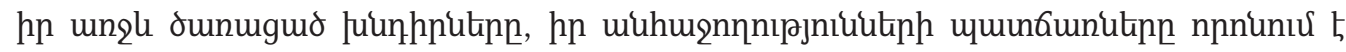

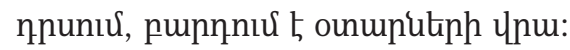

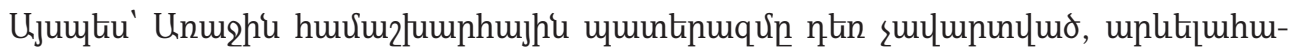

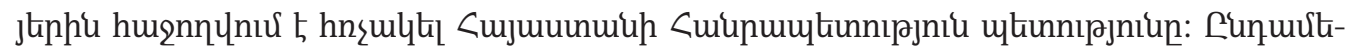

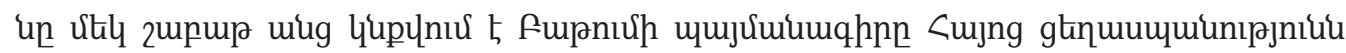

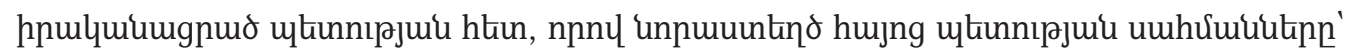

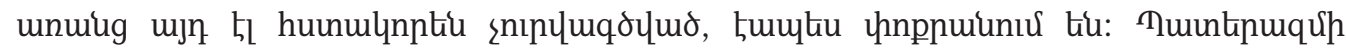

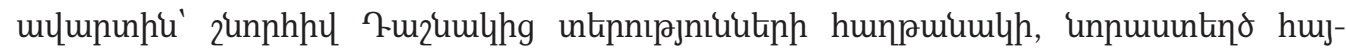

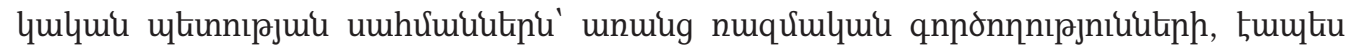

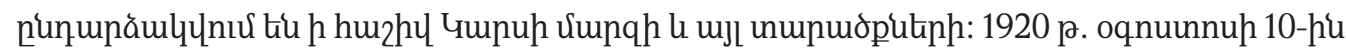

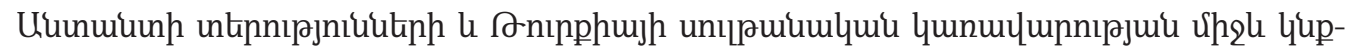




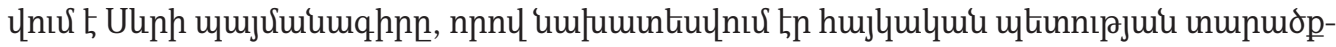

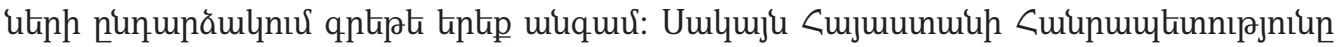

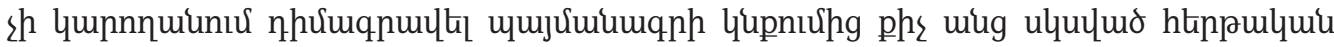

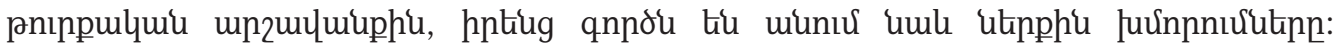

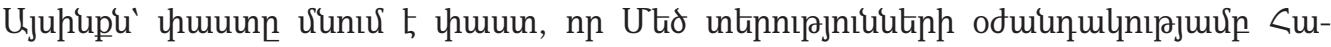

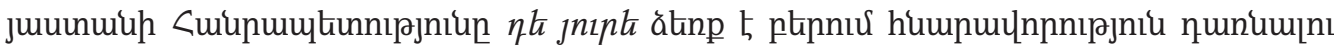

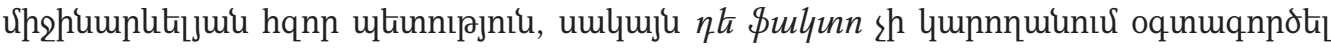

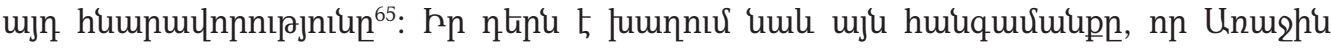

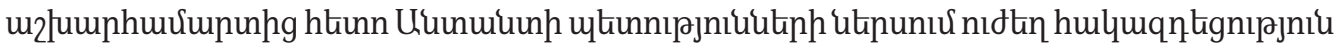

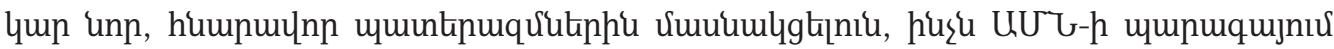

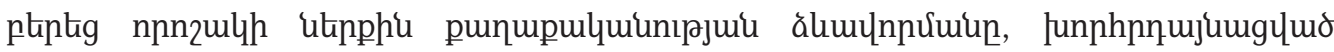

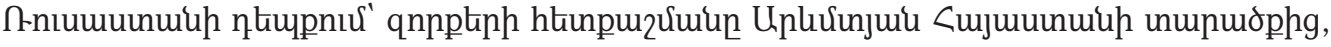

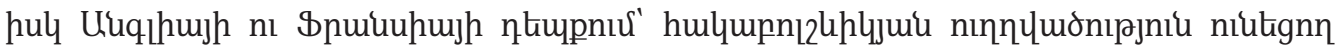

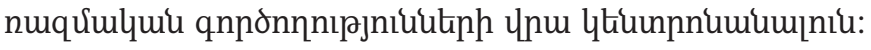

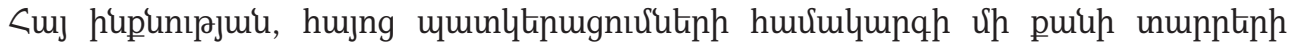

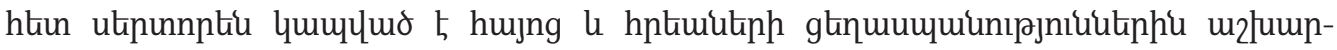

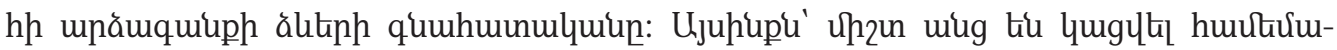

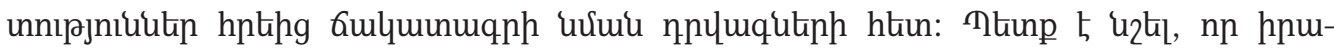

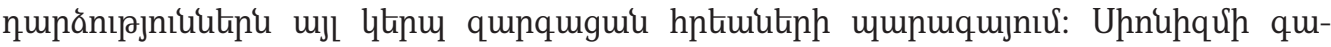

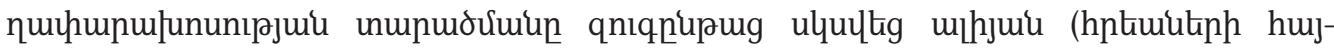

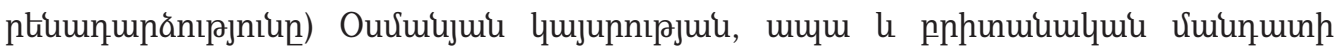

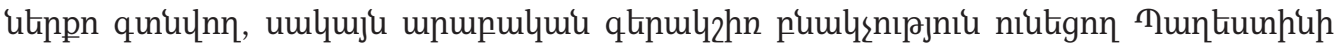

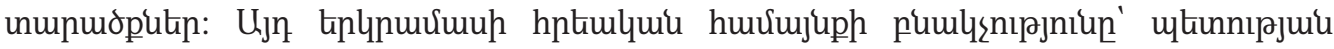

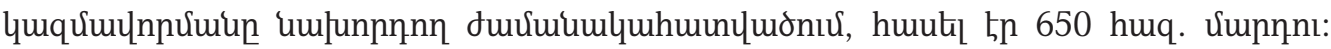

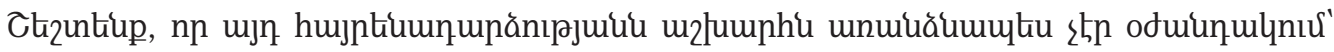

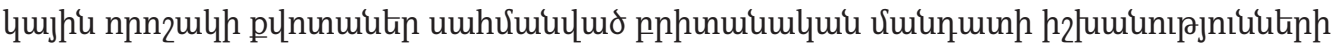

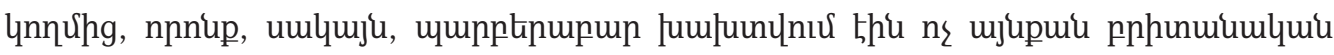

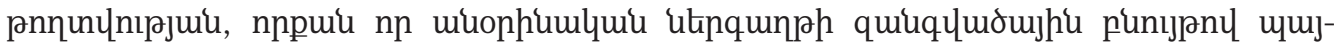

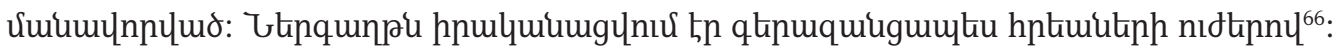

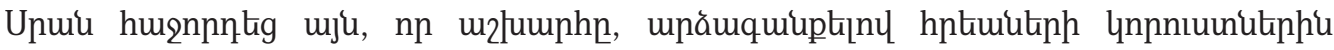

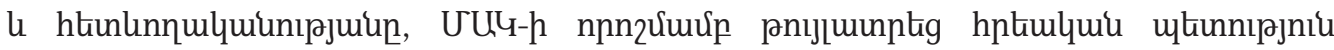

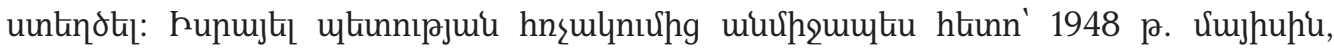

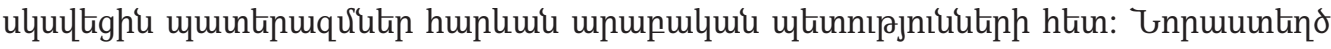

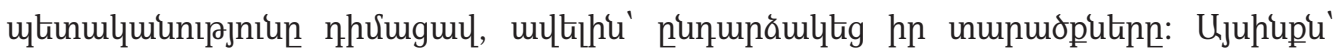

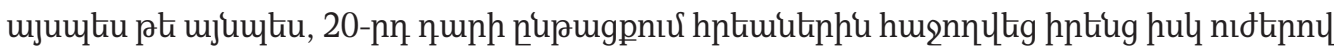

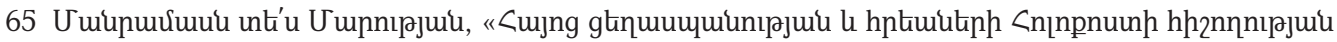

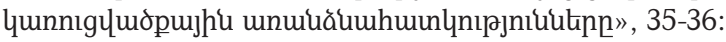

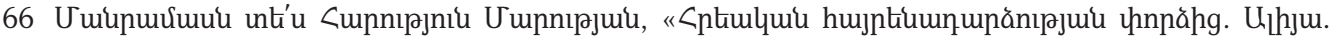

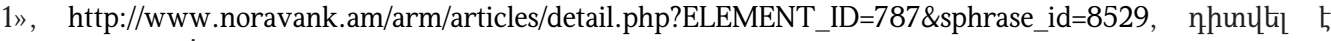

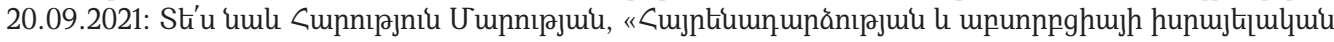

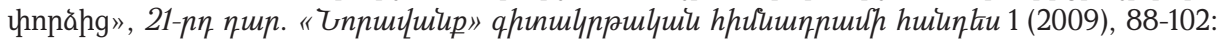




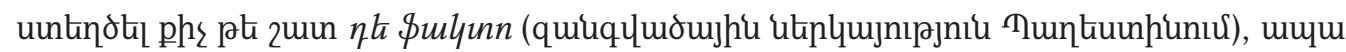

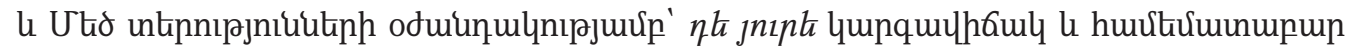

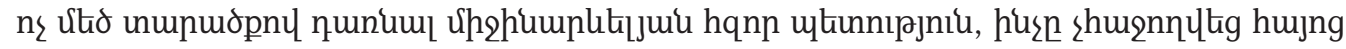
щщunuqujnuर:

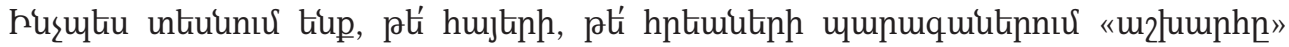

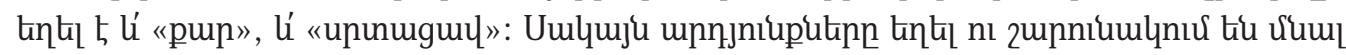
ununptip:

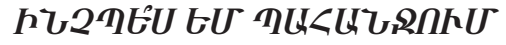

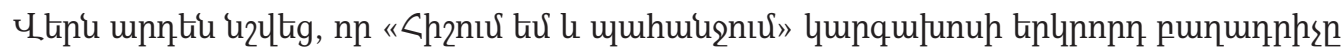

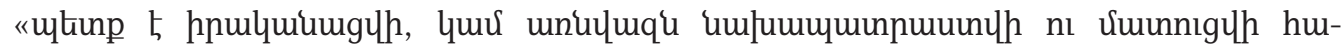

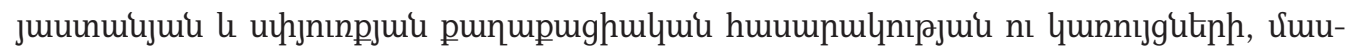

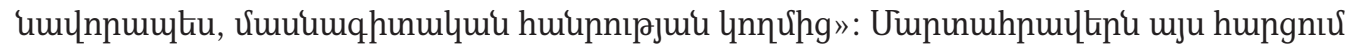

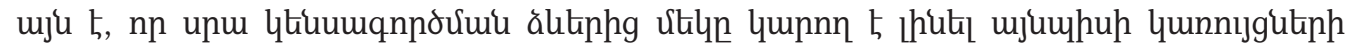

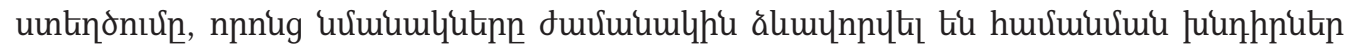

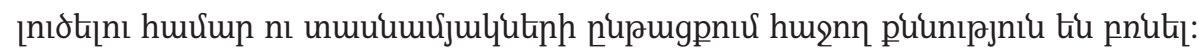

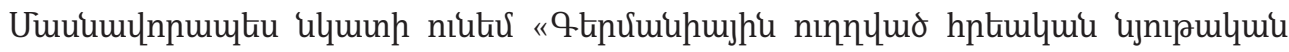

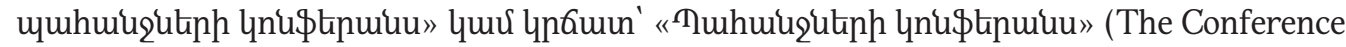
on Jewish Material Claims Against Germany - the Claims Conference) luquululnpunıрjuu

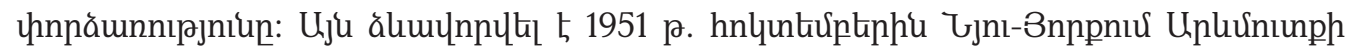

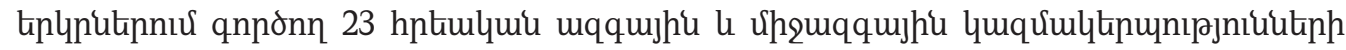

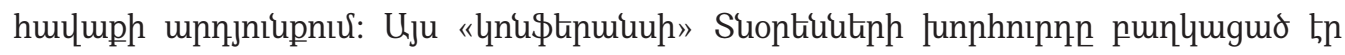

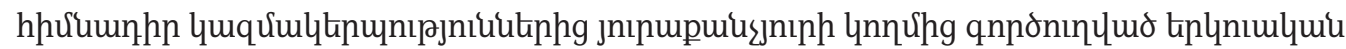

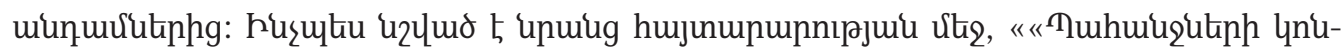

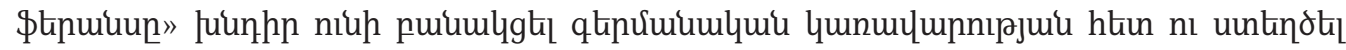

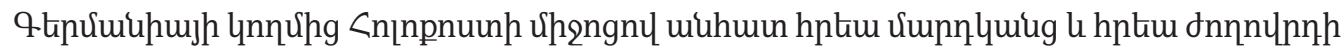

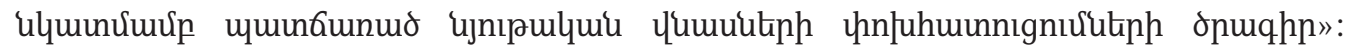

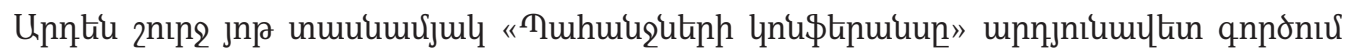

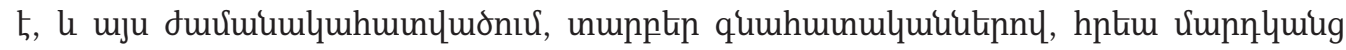

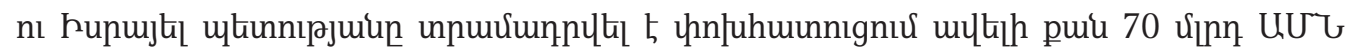
пnцunh цuиhnц:

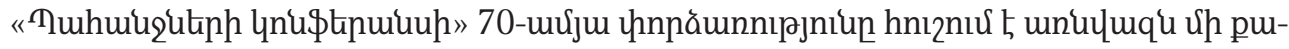

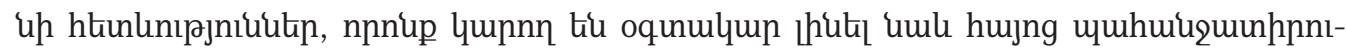
pjui unkumuljoniung.

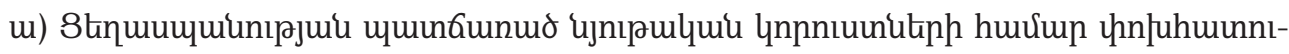

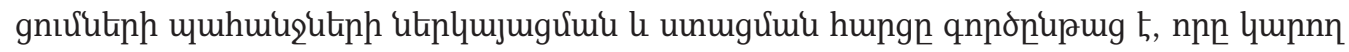

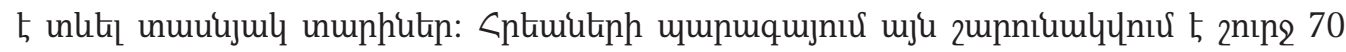
unuph:

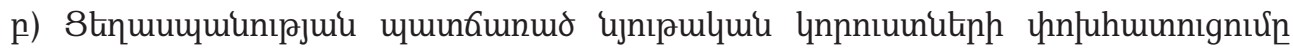




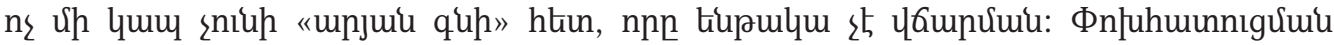

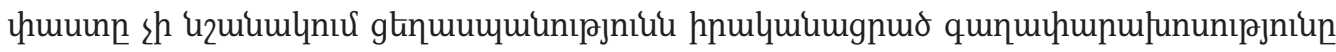

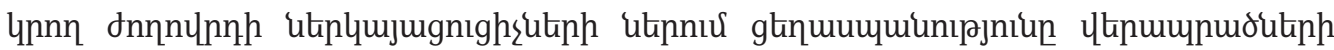

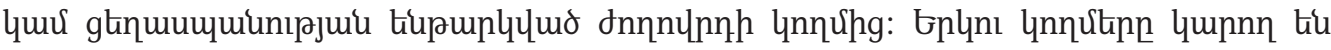

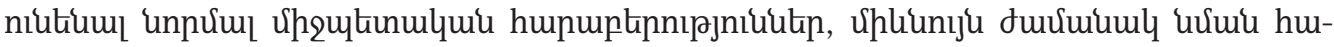

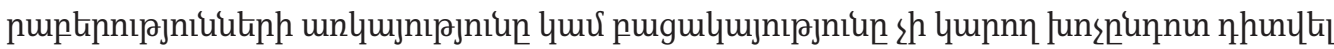

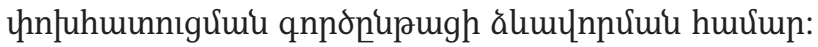

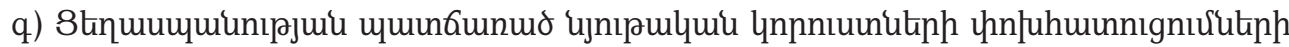

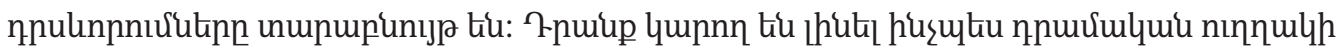

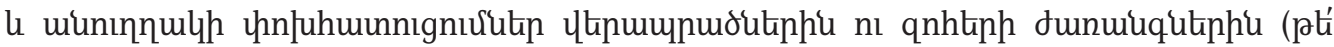

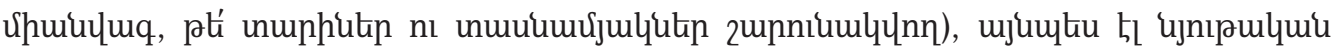

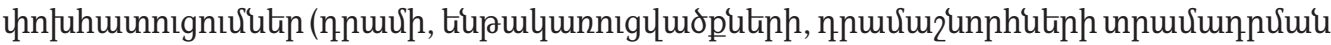

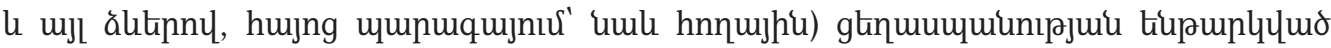

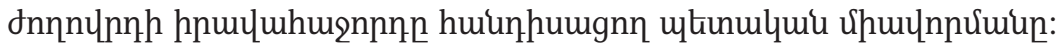

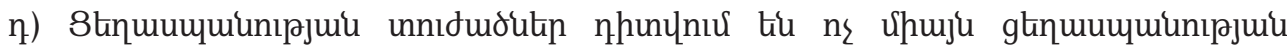

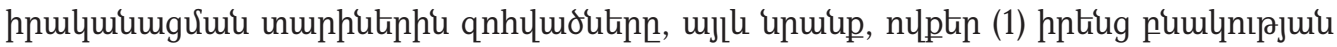

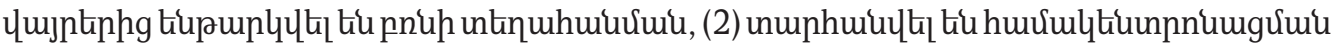

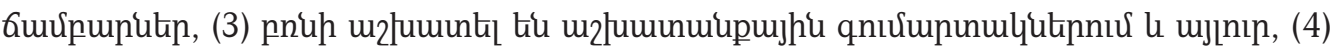

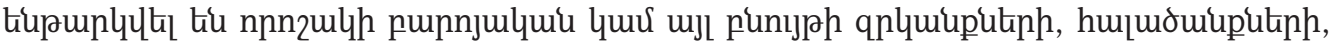
(5) humpuц

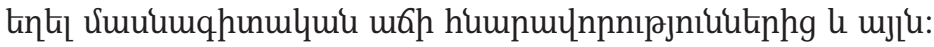

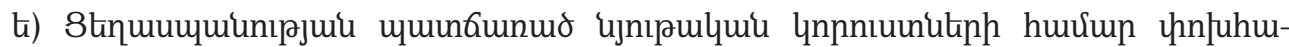

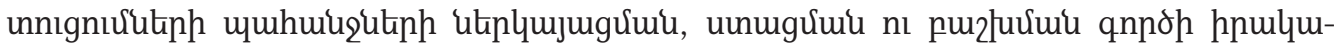

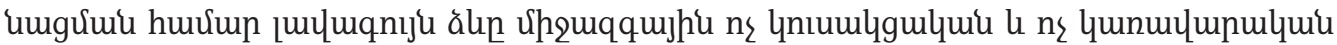

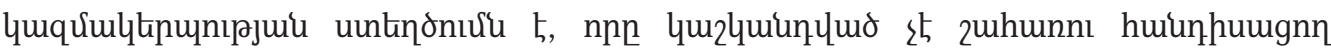

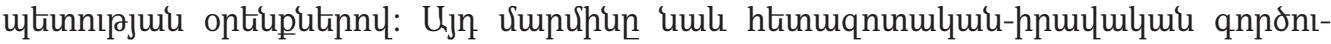

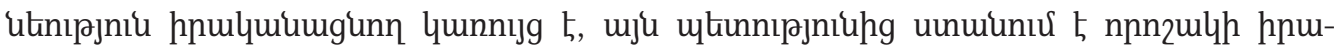

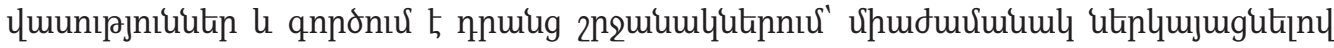

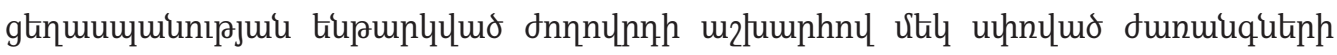
2whtipn:

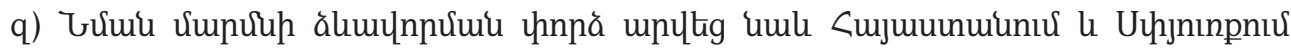

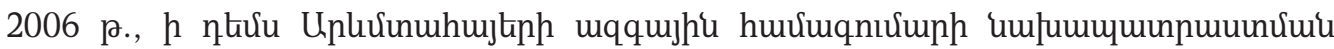

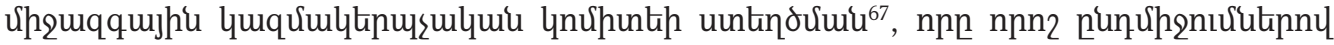

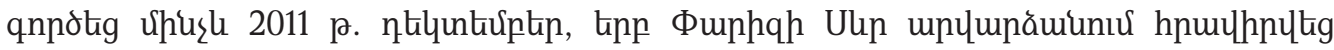

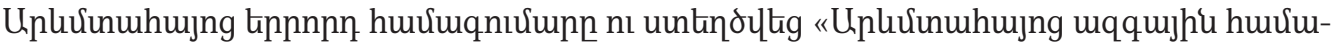

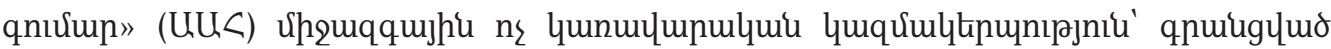

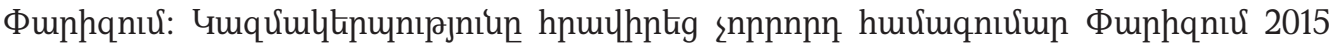

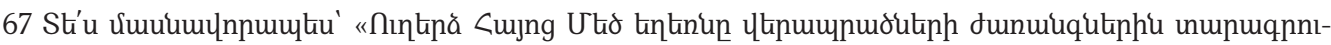

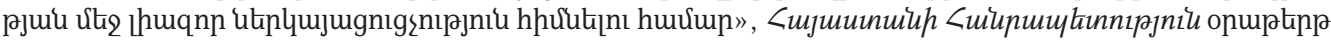
(Gplumu), 25 hnlunturptiph 2006: 


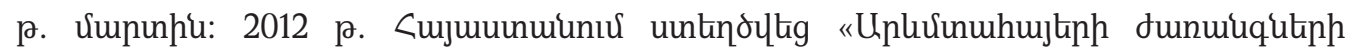

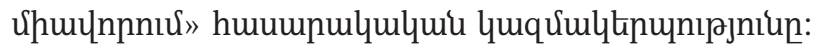

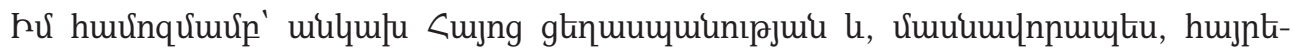

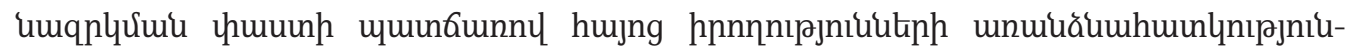

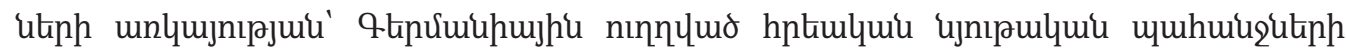

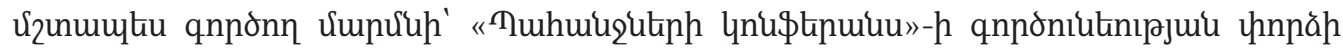

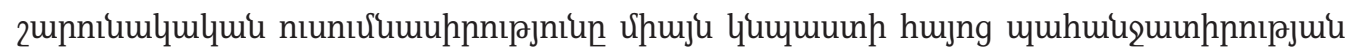

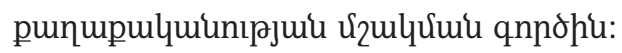

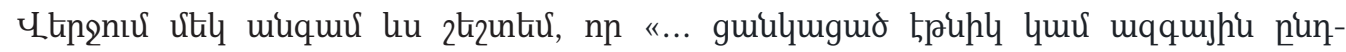

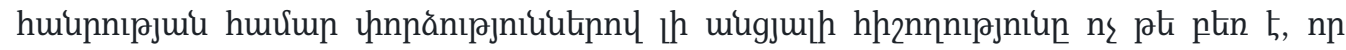

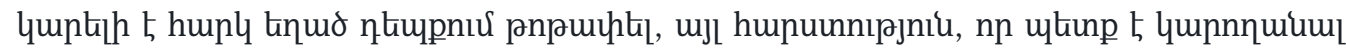

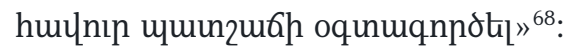

\title{
THE MOTTO “I REMEMBER AND DEMAND” AND THE CHALLENGES OF TRANSMITTING THE MEMORY OF THE ARMENIAN GENOCIDE IN THE $21^{\text {ST }}$ CENTURY
}

\author{
Harutyun T. Marutyan, \\ Armenian Genocide Museum-Institute, Armenia
}

\section{SUMMARY}

The Pan-Armenian Declaration, adopted on January 29, 2015 at the meeting of the State Commission on Coordination of the events for the commemoration of the $100^{\text {th }}$ anniversary of the Armenian Genocide, notes that it "considers the $100^{\text {th }}$ anniversary of the Armenian Genocide an important milestone on the ongoing struggle for historical justice under the motto "I remember and I demand."” Thus, it was proposed to consider this motto as a short formulation of the policy of memory of Armenians. This raises questions related to the components of this motto and requiring clarification in the context of conveying the memory of the Genocide in the $21^{\text {st }}$ century: Who do I remember? What do I remember? How do I remember? What do I demand? From whom do I demand? How do I demand?

The article proposes and justifies the answers to these questions. In particular, on the first issue, it is proposed to compile an electronic database of victims and survivors of the Genocide, their memories, video and audio recordings. The necessity of reformulating the name of the day of commemoration of the victims of the Genocide is substantiated. Answering the question "what do I remember?," it is proposed to remember also the self-defense battles during the Genocide; the humanitarian assistance of Armenian and foreign benefactors; humanitarian resistance to the perpetrators of the genocide; mutual assistance of family members, relatives, friends; moral victories; the struggle to stay alive. In

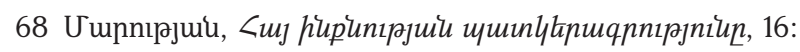


answer to the question "how do I remember?" talks about the problems of mourning and worthy memory; commemorative processions; the construction of monuments (khachkars); the introduction of the "Park of Memory" culture; forms of using the memory of the Genocide as a means of strengthening the Armenian Diaspora communities; the need to organize exhibitions; highlighting specific people and organizations from the collective image of the victims of the Genocide processions with their portraits; creation of methods of teaching genocide and other problems.

In connection with the question "what do I demand?" talks about various manifestations of Armenian demands (land, financial, moral), the question of the need to form a state approach to the problem is raised. Touching upon the question "from whom do I demand?," the views prevailing in the society (from the world, from Turkey, from the Armenians, etc.) are considered. When discussing the question "how do I demand?" we are talking about the creation of such structures, similar to which were formed in due time to solve analogous problems and successfully passed the exam for decades, and have an experience, knowledge of which will also be useful for Armenians (for example, the "Conference on Jewish material claims against Germany").

Key words: motto, memory of the Armenian Genocide, memory transmission, victims, survivors of the Genocide, those who resist, self-defense, Holocaust, database, rescue.

\title{
ДЕВИЗ “ПОМНЮ И ТРЕБУЮ” И ВЫЗОВЫ 21-ГО ВЕКА, СВЯЗАННЫЕ С ПЕРЕДАЧЕЙ ПАМЯТИ О ГЕНОЦИДЕ АРМЯН
}

\author{
Арутюн Т. Марутян \\ Фонд “Музей-институт Геночида армян,” Армения
}

\section{РЕЗЮМЕ}

Во Всеармянской декларации, принятой 29 января 2015 г. на заседании Государственной комиссии по координации мероприятий, посвященных 100-летию Геноцида армян, отмечается, что она “рассматривает 100-летие Геноцида армян как важную веху в процессе продолжения борьбы за историческую справедливость под девизом “Помню и требую.”” Таким образом предлагалось считать этот девиз краткой формулировкой политики памяти армян. В связи с этим возникают вопросы, относящиеся к компонентам данного девиза и требующие уточнения в контексте передачи памяти о Геноциде в 21-м веке: кого помню? что помню? как помню? что требую? от кого требую? как требую?

В статье предлагаются и обосновываются ответы на эти вопросы. В частности, по первому вопросу предлагается составить электронную базу данных о жертвах и переживших Геноцид, их воспоминаний, видео- и аудио-записей. Обосновывается необходимость переформулирования названия дня памяти жертв Геноцида армян. Отвечая на вопрос “что помню?”, предлагается помнить также самооборонительные бои в годы Геноцида, гуманистическую помощь армянских и зарубежных благотворителей, гуманитарное сопротивление исполнителям геноцида, взаимопомощь членов семьи, родственников, друзей, моральные победы, борьбу за то, чтобы 
остаться в живых. В ответе на вопрос “как помню?” говорится о проблемах скорби и достойной памяти, памятных шествий, строительстве памятников (хачкаров), внедрения культуры “Парка памяти," формах применения памяти о Геноциде как средства укрепления армянских общин диаспоры, необходимости организации выставок, выделения из собирательного образа жертв Геноцида конкретных людей и организации шествий с их портретами, создания методики преподавания геноцида и других проблемах.

В связи с вопросом “что требую?” говорится о различных проявлениях армянских требований (земельных, финансовых, моральных), выдвигается вопрос необходимости формирования государственного подхода к проблеме. Касаясь вопроса “от кого требую?”, рассматриваются бытующие в обществе представления (от мира, от Турции, от армянства и т.д.). При рассмотрении вопроса “как требую?” речь идет о создании таких структур, подобные которым в свое время были сформированы для решения схожих проблем и успешно выдержали экзамен на протяжении десятилетий, имеют опыт, знание которого будет полезно также для армян (например, действующая семьдесят лет “Комиссия по еврейским материальным искам к Германии”).

Ключевые слова: девиз, память о Геноциде армян, передача памяти, жертвы, пережившие Геноцид, сопротивляющиеся, самооборона, Холокост, база данных, спасение.

\section{RFERENCES}

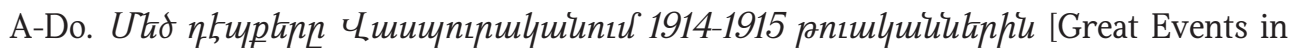
Vaspurakan]. Yerevan: Luys, 1917;

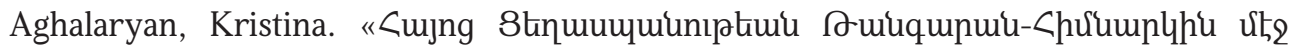

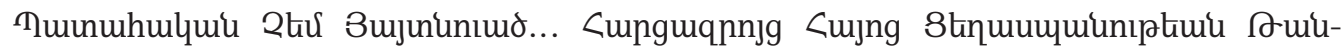

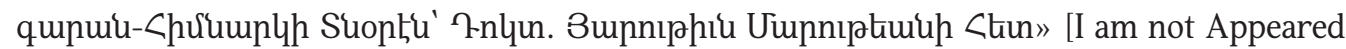
Accidently at the Armenian Genocide Museum-Institute... Interview with Armenian Genocide Museum-Institute Director Harutyun Marutyan]. Zart'onq (Beirut), 20 November 2018;

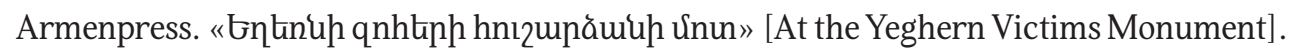
Patma-banasirakan handes 2 (1975): 79-80;

Arutyunyan, Ashot. Кавказский фронт: 1914-1917 г2. [The Caucasian Front: 19141917]. Yerevan: Hayastan, 1971;

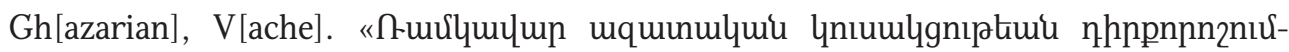
uknp» [The Stances of the Ramkavar Azatakan Party]. Baikar monthly (Watertown) 12 (1994);

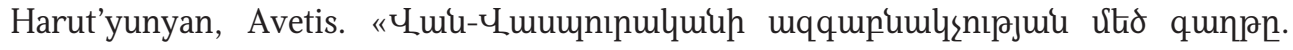

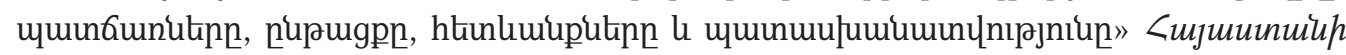

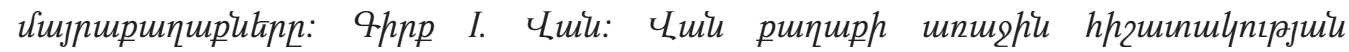

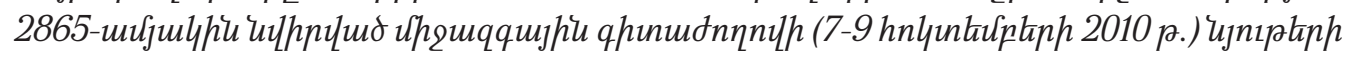

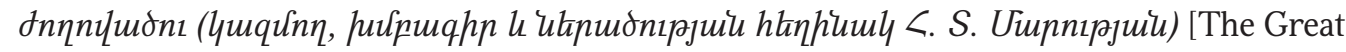
Migration of the Population of Van-Vaspurakan: Causes, Results and Responsibility in Capitals of Armenia. Book 1: Van. Proceedings of the International Conference, Dedicated 
to $2865^{\text {th }}$ Anniversary of the First Record about City of Van (October 7-9, 2010) (compiled and edited by Harutyun Marutyan)]. Yerevan: Gitut'yun, 2013, 170-196;

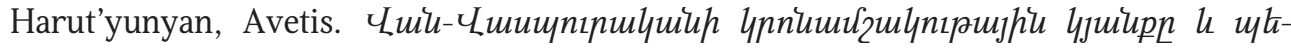

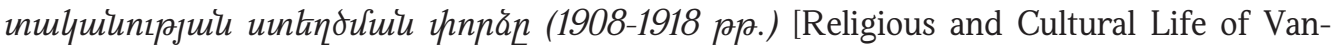
Vaspurakan and the Attempt of the Restoration of Statehood (1908-1918)]. Ejmiadzin: Publ. Of Holy See of Saint Ejmiadzin, 2018;

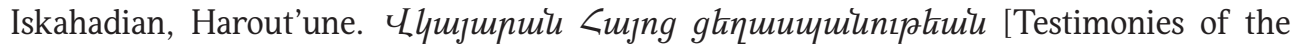
Armenian Genocide]. Beirut, vol. I-IX, 2010- ;

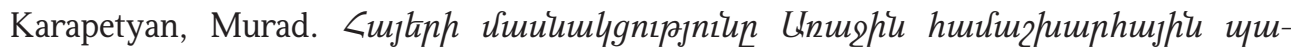
inknuqulfu (1914-1918 рр.) [Participation of Armenians in the First World War (1914-1918)]. Yerevan: Gitut'yun, 2014.

Kassouny, Yervant H. Lnıumpămuh muly miuhw6nj nllupn knuiunıphiun [The Felicity of Being Unpleasent Under the Spotlight]. Beirut: E.H.Q., 2017;

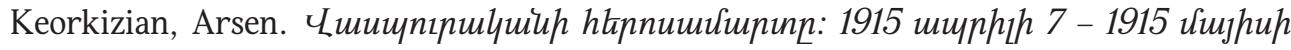
7: 3nju kı [nju [Heroic Battle of Vaspurakan. 1915 April 7 - 1915 May 7. Hope and Light]. Beirut: Publ. of Teqeyan Cultural Union, 1965;

Khudaverdyan, Konstantin (ed.). Армянский вопрос. Энциклопедия [The Armenian Question: Encyclopedia]. Yerevan: Haykakan hanragitarani glkhavor khmbagrut'yun, 1991;

Levon Mesrop (ed.). 1915. Un5ın lu Vlanuduniü [1915. Catastrophe and Rebirth]. Paris: Araks, 1952;

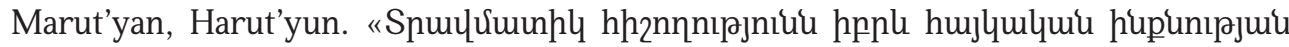

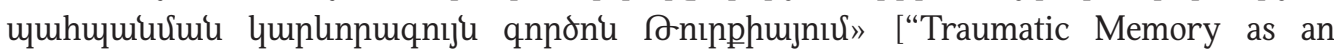
Important Factor for Preservation of Armenian Identity in Turkey]. Turqiayi hayut'yan khndirneri shurj. Teghekagir "Noravanq" himnadrami 22 (2008): 110-121;

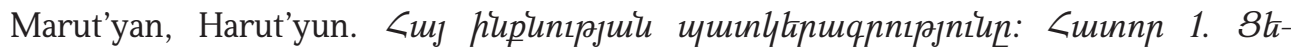

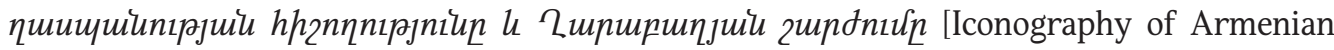
Identity. Volume 1: The Memory of Genocide and the Karabagh Movement]. Yerevan: Gitutyun, 2009. Anthropology of Memory 3;

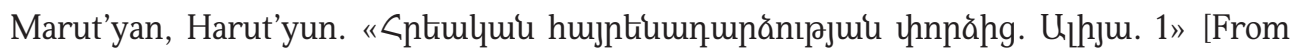
the Experience of Jewish Repatriation. Aliyah. 1.], http://www.noravank.am/arm/articles/ detail.php?ELEMENT_ID=787\&sphrase_id=8529;

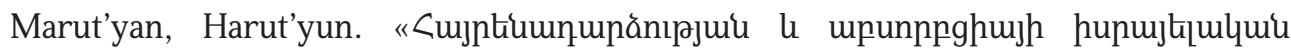
unnpăhg» [From the Israeli Experience of Repatriation and Absorption]. 21-rd dar: Teghekatvakan-verlutsakan handes 1 (2009): 88-102;

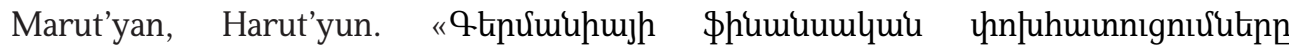

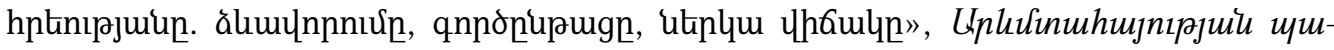

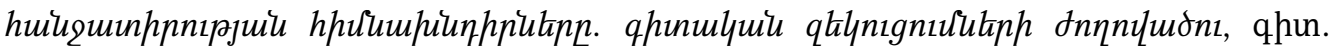

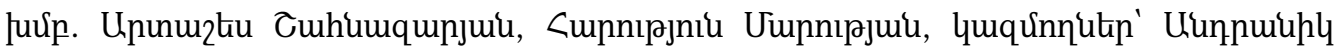
Unzuljuuu, ч cess and Recent Situation," in The Problems of Western Armenian's Claims: Collection of 
Conference Papers, edited by Artashes Shahnazaryan and Harutyun Marutyan, compliers Andranik Arshakyan and Vladimir Vardanyan]. Yerevan, 2009, 91-106;

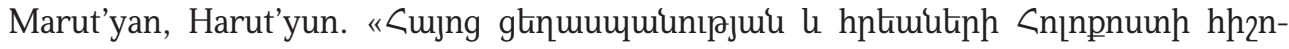

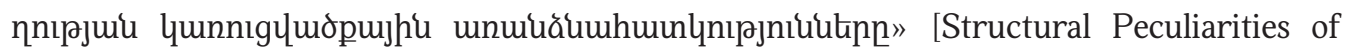
Armenian Genocide and Jewish Holocaust Memory]. Patmabanasirakan handes 2 (2011): 24-46;

Marut'yan, Harut'yun. "К вопросу об иконографическом восприятии памяти Первой мировой войны в армянской действительности” [On the Question of the Iconographic Perception of World War I Memory in the Armenian Reality]. Patmabanasirakan handes 1 (2013): 3-21;

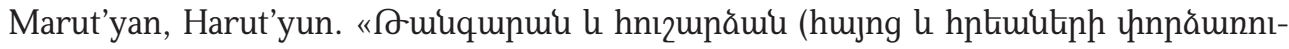

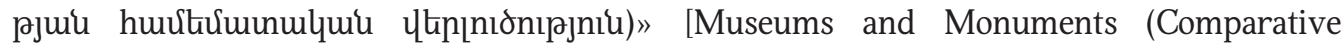
Analysis of Armenian and Jewish Experience)]. Études Arméniennes Contemporaines 3: Juifs, Arméniens: un siècle d'État (2014): 57-79;

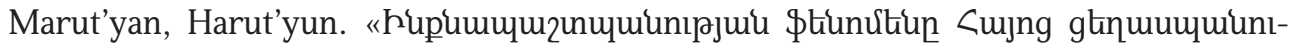

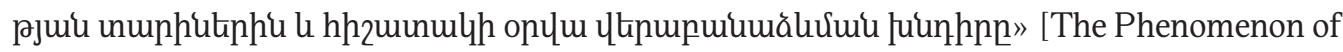
Self-defense during the Years of the Armenian Genocide and the Problem of Reformulation of the Memory Day]. T'éghaspanagitakan handes 3, no. 1-2 (2015): 76-80;

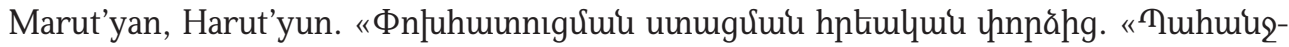

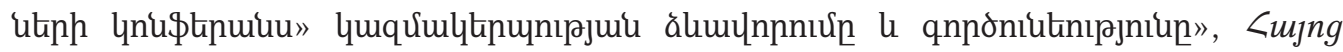

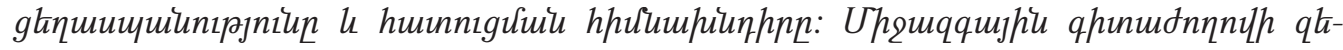

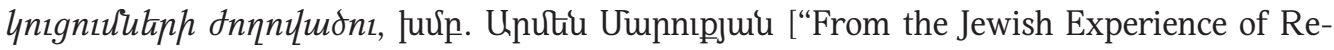
ceiving Compensations: Creation and Activities of the "Claims Conference" Organization," in The Armenian Genocide and the Problem of Reparation. Proceedings of the International Conference (ed. Armen Maruqyan)]. Yerevan: Institute of History of the National Academy of Sciences of Republic of Armenia, 2017, 156-173;

Marut'yan, Harut'yun. "Lujng gtпuuumunıрjuu qnhtph hp2uunulh opцu áluu-

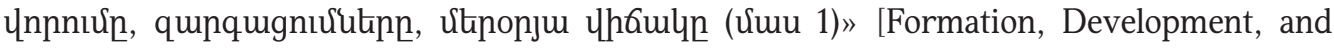
Current State of the Armenian Genocide Victims Remembrance Day (Part 1)]. Ts'eghaspanagitakan handes 6, no. 1 (2018): 105-129;

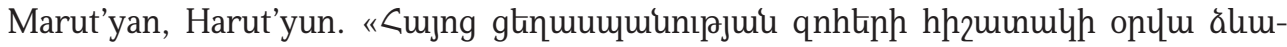

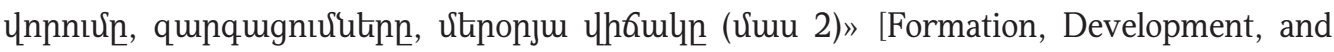
Current State of the Armenian Genocide Victims Remembrance Day (Part 2)]. Ts'eghaspanagitakan handes 6, no. 2 (2018): 103-142;

Marut'yan, Harut'yun. "husulku hunpuhumkl «qnhp punnnıjpn»» [How to Overcome the "Victime Stereotype"]. Hayastani Hanrapetut'yun (Yerevan), 12 March 2019;

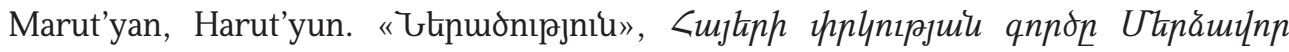

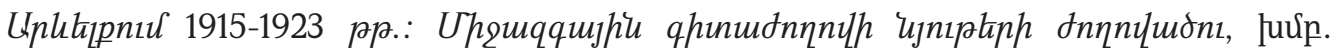

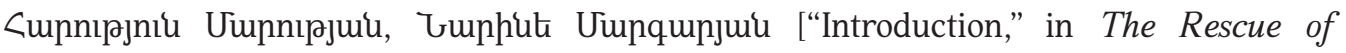
Armenians in the Middle East in 1915-1923: International Conference Proceedings, November 
9-11, 2020, eds.: Harutyun Marutyan, Narine Margaryan]. Yerevan: Armenian Genocide Museum-Institute Foundation, 2020, 11-26;

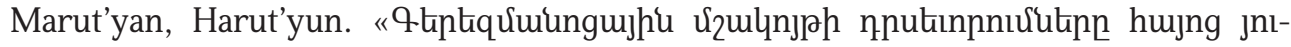

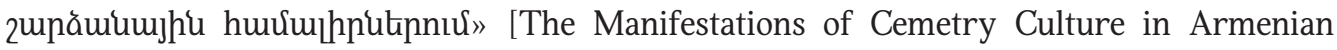
Monuments and Memorials]. Handes amsorya 1-12 (2020): 445-468;

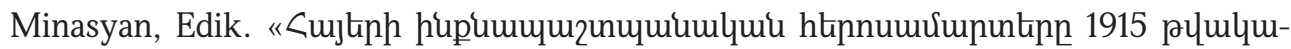
uhu» [Self-Defense Battles of Armenians in 1915]. Haykakan banak 1-2 (2015): 88-134;

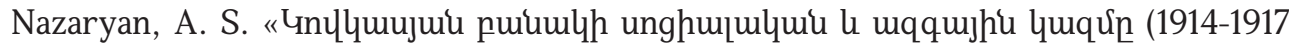
рр.)» [The Social and National Structure of Caucasian Army]. Banber Yerevani hamalsarani 3 (1989), 146-151;

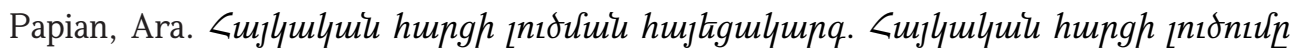

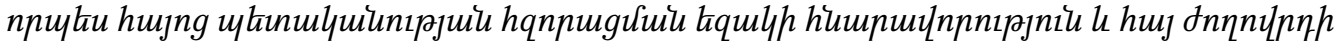
hupuinluuil Uhul nı१h [Strategy Paper on the Armenian Cause: The Resolution of the Armenian Question as a Singular Opportunity for the Consolidation of Armenian Statehood and the Only Path to the Endurance of the Armenian People], http://www.modusvivendicenter.org/hy/node/ 2574;

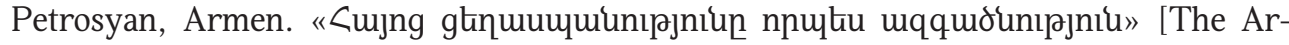
menian Genocide as a Birth of a Nation]. Hayats'q Yerevanits.' Hayagitakan 4 (1997): 50-51;

Ramkavar Azatakan Party's Representatives' 28 ${ }^{\text {th }}$ General Meeting's Record Office, «Lunnpnuqnnıphiu» [Information], https://ramgavar.am/\%D5\%BC\%D5\%A1\%D5 \%AF/\%D5\%B0\%D5\%A1\%D5\%B2\%D5\%B8\%D6\%80\%D5\%A4\%D5\%A1\%D5\%A3\%D6\%80\%D5\%B 8\%D6\%82\%D5\%A9\%D5\%AB\%D6\%82\%D5\%B6;

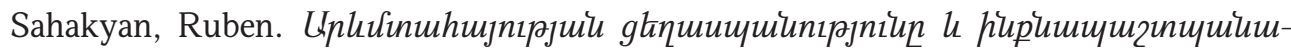

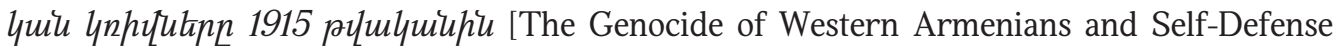
Battles in 1915]. Yerevan: Gitut'yun, 2005;

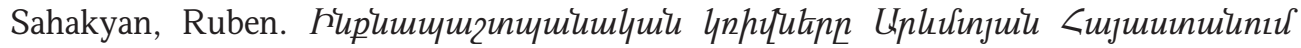

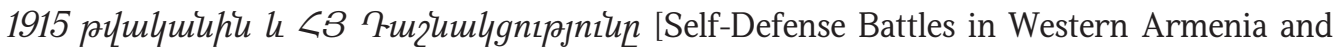
the Armenian Revolutionary Federation]. Yerevan: Self. publ., 2010;

Theriault, Henry C.; Zayas, Alfred de; McCalpin, Jermaine O.; Papian, Ara. Unqupugh

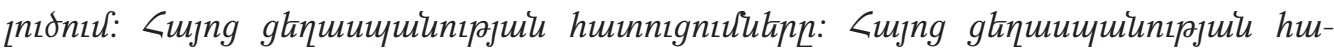

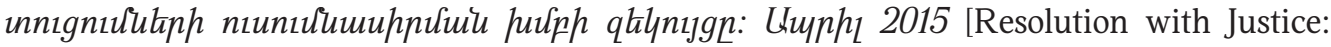
Reparations for the Armenian Genocide. The Report of the Armenian Genocide Reparations Study Group. April 2015], http://www.armeniangenocidereparations.info/wp-content/ uploads/2017/10/broshure_arm.pdf;

T’rvants', Anush. «Uthpuqunutiup Ukp unduumumunцnıpjniup» [Let us Retrieve Our Dignity. Interview with Harut'yun Marut'yan]. Zhamanak (Istanbul), 3 October 2018;

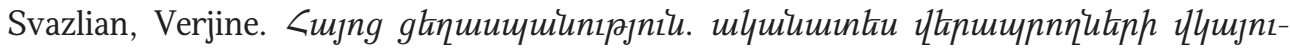

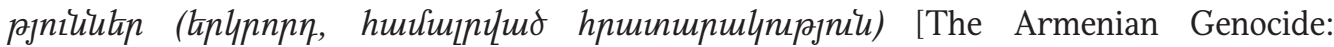
Testimonies of the Eyewitness Survivors (second revised edition)]. Yerevan: Gitut'yun, 2011;

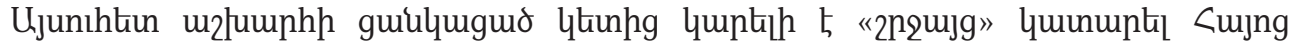


ghnuuumunıрjui puiqqunuinı [From now on it is Possible to make a "Tour" in the Armenian Genocide Museum], http://www.genocide-museum.am/arm/12.10.21.php;

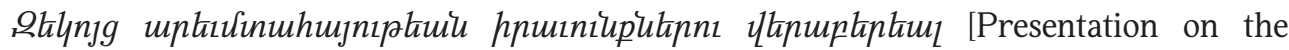
Rights of the Western Armenians], https://www.cnarmeniens.org/congress-document1;

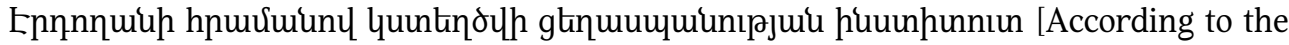
Decree of Erdoghan Genocide Institute will be Created], https://www.iammedia.am/en/post/ recognize-armenian-genocide-15-7;

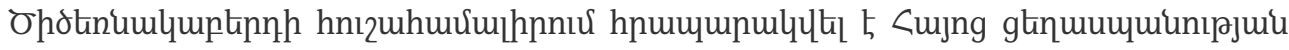

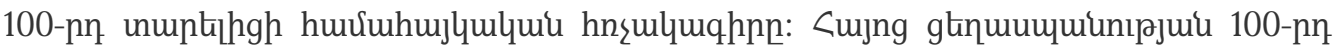

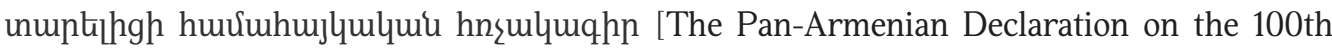
Anniversary of the Armenian Genocide was promulgated at the Tsitsernakaberd Memorial Complex], http://www.president.am/hy/press-release/item/2015/01/29/President-Serzh-Sargsyan-visit-Tsitsernakaberd-Genocide/;

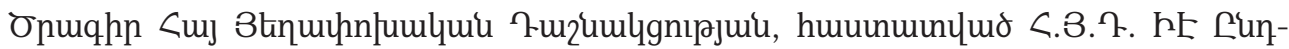

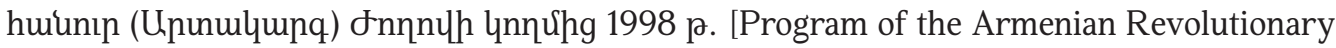
Federation, confirmed at the $38^{\text {th }}$ General (Extraordinary) Meeting in 1998], https://old.arfd. $\mathrm{am} / \mathrm{p}=6815$

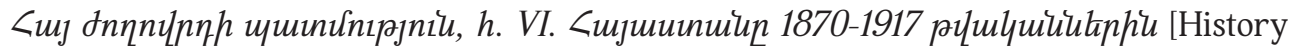
of Armenian People. Vol. VI. Armenia in 1870-1917]. Yerevan: Publishing House of Academy of Sciences of Armenian SSR, 1981;

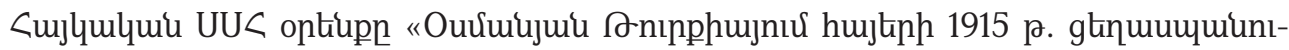
pjui nuunumununर्uiu Uuupu» [The Law of Armenian SSR "On the Condemnation of the 1915 Armenian Genocide in the Ottoman Turkey"], http://www.irtek.am/views/act. aspx?aid=8170;

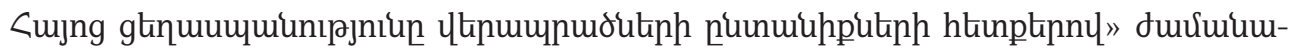
yuunn gnıgunnnıpjuu pugnıर् [Opening of the Temporary Exhibition "Tracing the Families of the Armenian Genocide Survivors"], http://www.genocide-museum.am/ arm/21.04.2021.php;

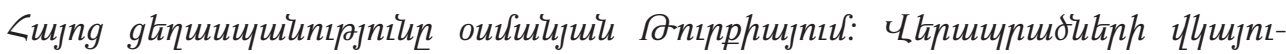

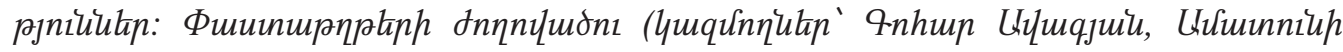

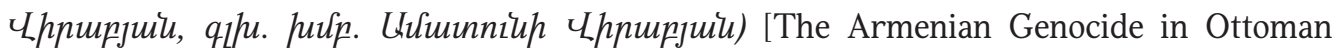
Turkey. Testimonies of Survivors. Collection of Documents (compilers Gohar Avagyan, Amatuni Virabyan, ed. Amatuni Virabyan]. Yerevan, National Archives of Armenia, vol. 1-3, 2012;

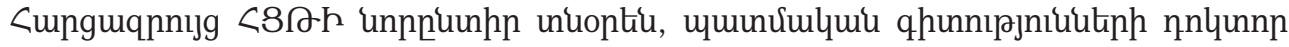
<upnıрjniu Uunnıpjuup htun [An Interview with Newly Elected Director of the Armenian Genocide Museum-Institute Dr. Harutyun Marutyan], http:/www.genocide-museum.am/ arm/news-27.09.2018-Marutyan-interview.php;

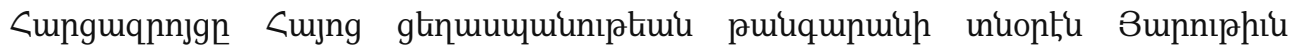
Uunniptumup htun [Interview with Armenian Genocide Museum Director Harutyun Marutyan]. Azat Or (Athens), 13 January 2020. 


\section{Ctinhiumh ưuuhi \\ About the Author \\ Об авторе}

<upnıpjnilu S. Uupnıpjuit, umunर्u. qhun. nnlunnn, uqquqnuqkin, "<ujng

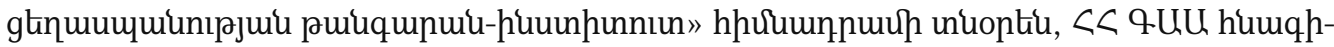

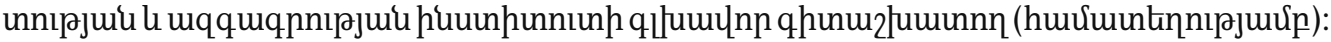

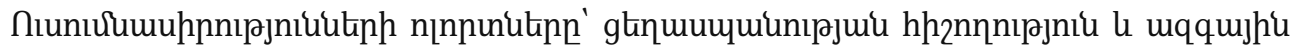

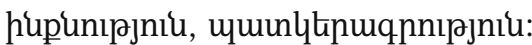

ㄴ. hnuunh huugt' agmidirector@genocide-museum.am

Harutyun T. Marutyan, PhD in History, social/cultural anthropologist, Director of Armenian Genocide Museum-Institute Foundation; Head Researcher, Institute of Archaeology and Ethnography, National Academy of Sciences, Armenia (part time).

Research fields - genocide memory and national identity, iconography.

E-mail: agmidirector@genocide-museum.am

Арутюн Т. Марутян, доктор ист. наук, этнограф, Директор Фонда "Музей-институт Геноцида армян"; Главный научный сотрудник Института археологии и этнографии Национальной академии наук Армении (по совместительству).

Область исследований - память о геноциде и национальная идентичность, иконография.

Эл. почта: agmidirector@genocide-museum.am 